1

\title{
1 The origins and significance of coastal resource use in Africa and Western Eurasia
}

3 Curtis W. Marean ${ }^{\mathrm{a}}$

4

5 anstitute of Human Origins, School of Human Evolution and Social Change, PO Box 872402,

6 Arizona State University, Tempe, AZ 85287-2402 USA, e-mail curtis.marean@asu.edu,Office

7 Phone: 480-965-7796

9 The systematic exploitation of marine foods by terrestrial mammals lacking aquatic

10 morphologies is rare. Widespread ethnographic and archaeological evidence from many areas of

11 the world shows that modern humans living on coastlines often ratchet up the use of marine

12 foods and develop social and technological characteristics unusual to hunter-gatherers and more

13 consistent with small scale food producing societies. Consistent use of marine resources often is

14 associated with reduced mobility, larger group size, population packing, smaller territories,

15 complex technologies, increased economic and social differentiation, and more intense and wide-

16 ranging gifting and exchange. The commitment to temporally and spatially predictable and

17 dense coastal foods stimulates investment in boundary defense resulting in inter-group conflict as

18 predicted by theory and documented by ethnography. Inter-group conflict provides an ideal

19 context for the proliferation of intra-group cooperative behaviors beneficial to the group but not

20 to the altruist (Bowles 2009). The origins of this coastal adaptation marks a transformative point

21 for the hominin lineage in Africa since all previous adaptive systems were likely characterized

22 by highly mobile, low-density, egalitarian populations with large territories and little boundary

23 defense. It is important to separate occasional uses of marine foods, present among several 
2

3

4 8

24 primate species, from systematic and committed coastal adaptations. This paper provides a

25 critical review of where and when systematic use of coastal resources and coastal adaptations

26 appeared in the Old World by a comparison of the records from Africa and Europe. It is found

27 that during the Middle Stone Age in South Africa there is evidence that true coastal adaptations

28 developed while there is, so far, a lack of evidence for even the lowest levels of systematic

29 coastal resource use by Neanderthals in Europe. Differences in preservation, sample size, and

30 productivity between these regions do not explain the pattern.

32 KEYWORDS: Middle Stone Age, Middle Paleolithic, modern human origins, coastal

33 adaptation, shell midden, marine foods 


\section{Introduction}

48 Considerations of the importance of aquatic foods (any foods coming from water) to

49 human diet has seen a jump in interest in recent years, cross-cutting a variety of disciplines

50 including nutrition, cognition, and paleoanthropology. This cross-disciplinary interest has

51 largely come from the recognition that aquatic foods have fatty acids that are important for

52 human health. This has led some researchers to probe the evolutionary context of the

53 introduction of aquatic foods to the hominin diet, and out of these investigations a debate has

54 arisen over whether these particular fatty acids must come from a diet rich in them, and whether

55 or not the terrestrial food chain can supply there fatty acids (Broadhurst et al., 2002; Langdon,

56 2006; Cunnane et al., 2007; Carlson and Kingston, 2007). While the richness or sparseness of

57 these fatty acids in the terrestrial food chain is debated, there is consensus that the aquatic food

58 chain is rich in them, and that their addition to the diet does have some measurable positive

59 impact on modern human health.

60 The earliest and best evidence for the exploitation of marine foods comes from a series of

61 sites in South Africa where dense archaeological mollusk remains are found with Middle Stone

62 Age (MSA) stone tools (Voigt, 1973b; Volman, 1978; Parkington, 2003). Until recently, the

63 earliest of these was dated to early marine isotope stage 5 (MIS5) at Klasies River (Deacon and

64 Geleijnse, 1988; Thackeray, 1988). Soon after, a series of excavations replicated the result so

65 that there is now consensus that archaeological deposits with dense mollusk remains exist in

66 South Africa beginning about 110 years ago (ka) and are inter-stratified with deposits that lack

67 mollusks at various sites that date between $\sim 110 \mathrm{ka}$ to the end of the Middle Stone Age $40 \mathrm{ka}$.

68 The appearance and disappearance of these shell-rich layers is influenced by changing sea level

69 heights that, due to the gradual slope of the Agulhas bank, result in rapid and substantial changes 
70 in the distance of the coast to the sites (Van Andel, 1989; Fisher et al., 2010). There is now a

71 high resolution computer model of this coastline movement in reaction to sea level change over

72 the last 420,000 years, and that model can be run for any location on the coast of South Africa

73 and provide accurate estimates of the distance to the coast at 1500 year time steps (Fisher et al., 74 2010).

75 In 2007 our team working at Pinnacle Point published on a MIS6 occupation (in a 76 stratigraphic aggregate named Lightly Consolidated-MSA Lower, or LC-MSA Lower) in a cave 77 called Pinnacle Point 13B (PP13B) dated to $164 \mathrm{ka} \pm 12 \mathrm{ka}$, using a combination of uranium78 thorium (U-Th) dating on directly overlying speleothems, optically stimulated luminescence 79 (OSL) ages on sediments, and correlation to the output of the coastline model mentioned above 80 (Marean et al., 2007). In 2010 we enriched this record with a full set of publications on the 81 context and finds from PP13B extending the record to $~ 90$ ka (Marean, 2010a). With increased 82 grain samples and added analysis and modeling, the OSL age estimate for the LC-MSA Lower 83 was revised to $162 \mathrm{ka} \pm 6 \mathrm{ka}$ (Jacobs, 2010). MSA occupations directly dated by numerical 84 techniques to MIS6 are rare along the southern African coast (there is only PP13B), and in 85 Africa overall, probably because populations were very small at this time (Foley and Lahr, 86 1997). Following qualitatively the quantitative principles of patch choice (McArthur and Pianka, 87 1966) and time allocation to patches (Charnov, 1976), I hypothesized that when these 88 populations were small and the landscape relatively sparsely occupied, people positioned 89 themselves adjacent to the highest ranked patch - the coast. Here they could exploit both the rich 90 mollusk beds as well as the diverse geophytes so common in the Cape Floral Region (CFR) 91 (Marean, 2010b; Marean, 2011). As an added bonus, it is possible that the exposed sections of 92 the Agulhas bank harbored an east-west moving large mammal migration ecosystem, creating a 
93 tri-pedal nutritional (shellfish, geophyte, large mammal) refuge for hominins during cold climate

94 cycles. As sea level changed over time, this long thin habitat moved back and forth across the

95 Agulhas bank and the centroid of people's annual foraging radius moved with it, so that

96 occupation intensities rose and fell at current "neo-coastal" sites such as PP as a function of

97 distance to coast. This coastline model applies only to when populations are very small, and

98 during the MSA I would argue that this is during MIS6 and early in MIS5. Populations seem to

99 recover in late MIS5 and pack the CFR landscape. However, the model seems to apply again

100 during MIS3 and 2, when the record has few numerically dated Later Stone Age (LSA) sites.

101 The record for South Africa, still our best record for use of coastal resources at this early

102 stage, forces us to ask the question "why did a diet focused on marine foods occur so late in

103 human evolution"? I have hypothesized that, at least in South Africa, regular and effective use

104 of coastal resources requires an understanding of the relation between the lunar calendar and 105 tidal cycles since return rates on mollusks collection should be driven by the tides. All things 106 being equal, the lowest and therefore most productive mollusk collection times are when the 107 moon is either full or new and the tides are in what is called a "spring" phase. This is when people should position themselves near the coast, and they should move away from the coast at 109 other times of the lunar month when the tides reveal less of the inter-tidal zone in what is called 110 the "neap" phase (Marean, 2010b; Marean, 2011). This required a complex cognition that could 111 make a novel connection between an astronomical observation, tidal character, and collection 112 return rates (Figure 1). Due to the specific (but not unique) inter-tidal topography and tidal 113 character in South Africa, it is only during spring low tides that the exposed inter-tidal zone is 114 large and mollusk collection is safe and produces high returns. During neap tides it is neither, 115 and those unfamiliar with coastlines of the South African type need to know that walking into 
inter-tidal zones to collect shellfish during neaps is highly risky and can be a death sentence.

The Mediterranean coast, where much of the contemporary Neanderthal record is reported, is a totally different system (I will discuss this further below). My hypothesis for South Africa may not apply in the Mediterranean.

It has been known for some time that there is evidence for the use of marine resources 121 outside of Africa and by Neanderthals (Garrod et al., 1928; Stiner, 1994). The presence of 122 mollusks in association with Middle Paleolithic artifacts attributable to Neanderthals is, in my 123 opinion, unquestioned. But more recently this observation has been elaborated to more 124 expansive claims that Neanderthals used coastal resources in a "systematic" manner (Stringer et 125 al., 2008; Finlayson, 2008; Cortés-Sánchez et al., 2011b) and even had a “coastal adaptation”, as 126 do modern humans in Africa and other locations worldwide (Cortés-Sánchez et al., 2011b). 127 Others have hypothesized that the coastal adaptation may have unlocked a coastal route for 128 movement of modern humans out of Africa (Oppenheimer, 2009), and even perhaps allowed 129 complex cognition to evolve (Parkington, 2001; Broadhurst et al., 2002). stimulate the development of social and technological features unusual to hunter-gatherers and Clearly, there is consensus that the use of marine resources and coastal adaptations are important topics in need of consideration but there is little consensus as to how such marine resources were significant, if at all, to human origins. Previous discussions of the significance of a coastal diet to human origins have focused on the importance of its high quality protein rich character, but I argue in this paper that it is other impacts that are more significant. As I will discuss below, ethnographic and archaeological evidence from many areas of the world shows that modern humans living on coastlines ratchet up the use of marine foods in ways that more consistent with small scale food producing societies. Focused use of marine resources 
139 drives reduced mobility, larger group size, population packing, smaller territories, increased economic and social differentiation, complex technologies, and more intense and wide-ranging

141 gifting and exchange. The commitment to temporally and spatially predictable and dense coastal

142 foods stimulates investment in boundary defense and inter-group conflict as predicted by theory

143 and documented by ethnography. Inter-group conflict provides an ideal context for the

144 proliferation of cooperative behaviors beneficial to the group but not to the altruist; the hyper-

145 prosocial proclivities of Homo sapiens (Bowles, 2009; Bowles and Gintis, 2011). The origins of

146 this coastal adaptation mark a transformative point in the diversity of adaptations in the hominin

147 lineage in Africa since the previous adaptive system probably was highly mobile, low-density, 148 and non-territorial. The implication is that hyper-prosociality may have been a late addition to 149 the human uniqueness suite (Hill et al., 2009), and probably was cultivated under very specific 150 ecological conditions where resources were predictable and dense. On the way to developing 151 that hypothesis I need to work through the definition of a coastal adaptation and define its 152 character of appearance in Africa and elsewhere.

154 How do we define a coastal adaptation?

155 The most comprehensive review of resource use of aquatic (both marine and 156 riverine/lacustrine) resources is that of Erlandson (2001) and I refer the reader to that important 157 paper for a full and detailed review. I will focus only on coastal resource use, being restricted to 158 those resources found at the contact of the sea and land. Littoral and coastal differ in definition 159 and character (Hallam, 1987) in that the latter is more inclusive and covers both coastal areas of 160 sea, land, and river, but my focus will be only the seashore. Here I am interested in getting 161 clarity as to what we mean by "systematic" use of coastal resources and "coastal adaptation" as a 
first step to understanding why it is significant to human origins research. We need concise and clear definitions. Early attempts at clarity appeared in early work on the Pacific North-west coast by Smith (1956) and King (1950) in the 1950s. Even at that time the importance of deep 165 sea fishing from boats was recognized as a distinct and specialized form of coastline use. King 166 uses the term "Maritime Adaptation" and clearly means an adaptation that includes sea-worthy 167 boats used to fish and whale. Since the word "maritime" is typically connected to seafaring and 168 its laws, it seems reasonable to reserve "Maritime Adaptation" for marine resource use that 169 includes boat technology capable of long distance transport and deep-sea fishing and whaling. 170 There is no evidence that MSA African hunter-gatherers ever had this technology, despite the 171 presence of rich near-shore fishing and whaling possibilities off the coast of the southern African 172 sub-region (Branch and Branch, 1992; Branch, 1994). Perhaps more surprising, there is no 173 evidence that South African Stone Age people ever had a maritime adaptation, even into the 174 Holocene (Deacon, 1984; Mitchell, 2002). This is surprising because by 162 ka whales were 175 scavenged, seals were exploited (Marean et al., 2007; Thompson, 2010), and certainly whales 176 and dolphins were regularly seen from shore (they are today). The lack of a maritime adaptation 177 I think likely explains why the South African Stone Age coastal adaptation never seems to reach 178 the level of social and technological complexity present in analogous coastal contexts such as 179 Peru, California, the US North-west coast, and the US South-east coast. I will not discuss 180 maritime adaptations further here, though I do wish to note that such an adaptation seems 181 required for the passage to Australia (Davidson and Noble, 1992; O'Connell et al., 2010), and 182 given the lack of evidence for it in Africa it likely evolved quickly in coastal Asia, or has gone 183 undetected in Africa. 
Discussions in the literature of "coastal adaptations" pick up dramatically in the 1970s . . .5 with two notable papers (Snow, 1972; Braun, 1974) both using the term "coastal adaptation" to clearly refer to coastline use that focused on spending a significant portion of the year at the coast and a diet that included substantial portions of mollusks and the production of shell middens. In 1980 two highly cited review papers (Perlman, 1980; Yesner et al., 1980) take on the issue of coastal resource use, signaling the arrival of this issue as having general importance and a substantive empirical base worth reviewing. Starting in the late 1980s and continuing to today a plethora of publications arose on coastal adaptations, their significance, and the nutritional, technological, and social implications of a life entwined with the sea. The archaeology of the Pacific coast has been a particularly fertile empirical base for these theoretical advances (Erlandson, 1988; Moss, 1993; Arnold, 1993; Arnold, 1996; Erlandson, 2001; Erlandson and Moss, 2001; Kennett, 2005; Erlandson et al., 2007; Rick and Erlandson, 2009; Arnold and Walsh, 2010; Moss, 2011), while discussions of coastal resource use and modern human origins have largely occurred disconnected to this literature. I attempted a beginning integration (Marean, 2010b; Marean, 2011) with the specific goal of trying to understand when the coastal adaptation took hold, under what conditions it happened, and what implications this could have for modern human origins. It is important to better contextualize the human origins research within the broader coastal archaeology literature (Erlandson and Moss, 2001;

Erlandson, 2001; Bailey and Milner, 2002) so as to position us to conduct more effective comparative studies. I continue that effort in this article and offer several explicit definitions, focused on foraging and the economy, to help us move that integration forward.

Researchers have used the term "systematic" coastal food use (Stringer et al., 2008; Finlayson, 2008) without defining what is implied. I take "systematic" to mean use that is 
methodical in practice, part of a plan (in keeping with the definition of the word "systematic"), and thus a regular and an important part of the diet. It is regularly embedded in the foraging system though does not necessarily imply a major component of the diet, and "systematic" use does not necessarily mean the same thing as a coastal adaptation. Beaton (1995) has an instructive discussion. He notes that the simple geographic position of a site in proximity to the 212 coast and/or negligible amounts of marine fauna in those sites does not imply a coastal 213 adaptation. Alternating between the term "coastal economy" and "coastal adaptation", Beaton 214 writes where "human life-ways are transformed by the marine factor, whilst in 'coastal use' the 215 marine element is visible but not transforming, and in chance 'coastal location' the material and 216 faunal components of sites are not significantly different from interior sites" (1995: 802).

217 Beaton's point deserves emphasis - systematic use of coastal resources is not demonstrated by 218 site proximity to the coast. Systematic use must be demonstrated.

219 So, systematic use of coastal resources is when coastal resources are part of a plan, occur 220 regularly and recurrently, but the use of these resources is not transforming. A "coastal 221 adaptation" is when the adaptation has been transformed to revolve around the sea. The hominin diet has a substantial portion of marine animals and these can include mollusks, crustaceans, fish, 223 sea mammals, and sea birds and these can be exploited unassisted or with spears, lines, nets, and 224 weirs but not sea-going boats. In a coastal adaptation the coastal foods are so important that the 225 mobility system is designed to intercept the coast as a planned part of the annual mobility 226 strategy, sometimes moving between the interior and the coast, or even staying there all year. 227 Coastal adaptations have a substantial portion of the diet derived from animals that live along the 228 coastline in and about the inter-tidal zone, where the coast is the zone where sea and land 
processes intermix. A maritime adaptation includes all the above, but is restricted to human societies that use open-ocean boats to assist in fishing, sealing, and/or whaling.

Very occasional sporadic use of coastal resources, where the coastal resources compose no more than a tiny part of the diet and are not exploited recurrently on a daily or monthly basis, is not systematic use or a coastal adaptation. The mobility system does not revolve around the coast and its resources, and there is no scheduling around coastal rhythms. Monkeys are known to exploit shellfish (Carpenter, 1887; Fernandes, 1991; Malaivijitnond et al., 2007; Gumert et al., 2009; Gumert et al., 2011) and chacma baboons do as well on the Cape Point of South Africa (Hall, 1962). There is no indication that they schedule their movements around the rhythms of the sea, nor is there evidence that they schedule their foraging to spring tides, so this is not a coastal adaptation. At this stage it is unclear how significant shellfish are to the overall diet of these primates. It is important to note that modern humans are the only terrestrial mammal known to have a maritime adaptation. It is debated as to whether other species of hominins, such as Neanderthals, had systematic coastal food use or a coastal adaptation, and evaluating the evidence for that is one of the goals of this paper.

\section{The impact of the coastal adaptation on technology, culture, and society}

The ethnographic and archaeological records show that when humans develop a coastal adaptation there is a dramatic impact on their diet, technology, mobility, and social behavior.

This is why it is important that we get the definition and identification of this adaptive system correct and consistent. As noted earlier, a coastal diet is rich in omega-3 fatty acids, which can have many direct nutritional benefits (Broadhurst et al., 2002; Cunnane et al., 2007). Much of the discussion and debate over the importance of aquatic foods has revolved around the 
importance of this shift in nutrition, but here I want to focus on some issues that I think may take larger prominence.

Comparative ethnographic analyses of hunter-gatherers consistently show that huntergatherers with significant amounts of aquatic resources are outliers, often extreme outliers, in a variety of ways (Kelly, 1983; Keeley, 1988; Binford, 1990; Kelly, 1995; Binford, 2001).

Hunter-gatherers focused on aquatic resources have larger population densities than non-aquatic hunter-gatherers, and coastal hunter-gatherers often have the densest populations (Kroeber, 1939; Birdsell, 1953; Fitzhugh, 1972; Yesner et al., 1980; Keeley, 1988). The largest populations and most densely settled populations of hunter-gatherers yet known, either ethnographically or archaeologically, were the coastal hunter-gatherers of southern California (Arnold and Walsh, 2010). In regions where we have good ethnographic information on coastal and non-coastal territory size, such as Australia, coastal hunter-gatherers have smaller territory size (Birdsell, 1953; Tindale, 1974). The coastal adaptation typically leads to larger local grouplband sizes (Yesner et al., 1980; Kelly, 1995), and residential mobility, defined as the frequency of moves by the band per annual round, is reduced in hunter-gatherers using aquatic resources (Kelly, 1983; Binford, 1990; Kelly, 1995; Binford, 2001). If we use a strict definition of "sedentary" where the hunter-gatherer group has at least a component of its band that stays in one location all year (Kelly, 1992), then aquatic and coastal hunter-gatherers have the highest levels of sedentary behavior of all hunter-gatherers (Yesner et al., 1980; Kelly, 1983; Binford, 1990; Kelly, 1995). 271 Hunter-gatherers using significant amounts of aquatic resources express the highest levels of 272 social complexity (political hierarchy) among all hunter-gatherers (Binford, 2004). It is common 273 for coastal hunter-gatherers to have high levels of conflict (Moss and Jon, 1992; Lambert, 1997; 274 Maschner and Reedy-Maschner, 1998; Lambert, 2002), and they likely have the highest rates of 
inter-group conflict of all hunter-gatherer adaptations. Coastal hunter-gatherers sometimes have relatively high levels of craft specialization (Arnold, 1992), and large network sizes with coastal goods such as shells sometimes being traded vast distances (Arnold and Walsh, 2010). Huntergatherer societies that reach the level of being "complex hunter-gatherers" (Arnold, 1996) are often heavily reliant on aquatic and/or coastal resources.

Hunter-gatherers using aquatic resources often have technologies of greater complexity than fully terrestrial hunter-gatherers (Oswalt, 1973; Oswalt, 1976). This is perhaps best expressed ethnographically by Pacific coast hunter-gatherers (Ames, 1994; Arnold and Walsh, 2010; Moss, 2011). This increased technological complexity could be a response to the complex tasks associated with coastal foraging (Oswalt, 1973; Oswalt, 1976), reduced residential mobility (Shott, 1986), and large populations and increased network size (Shennan, 2001; Henrich, 2004; Powell et al., 2009; Marquet et al., 2012). Hunter-gatherers utilizing aquatic resources often have many complex long-chain technologies designed for fishing with either line and tackle or harpoon. In maritime adaptations this reaches its greatest levels with deep-sea fishing boats and complex fishing gear, intensive storage strategies, permanent dwellings, money, slavery, and even monumental architecture (Ames, 1994; Arnold, 1996; Ames, 2001; Arnold and Walsh, 2010; Moss, 2011).

\section{How do we identify systematic coastal resource use and coastal adaptations?}

The discussion immediately preceding suggests that when hominins expanded their diet 295 to coastal resources, a social and technological tipping point may have been reached, or 296 minimally, a door to a more complex adaptation was opened. Given this, we need to ask the 297 question as to how to identify in the paleoanthropological record the various levels of 
commitment to the sea. As discussed above, the first discussions of coastal adaptations occurred in concert with the recognition of shell-rich archaeological sites. Such sites can be obvious landscape features in many localities worldwide, and in some cases are so dense and shell-rich that they appear to be solid deposits of shell with little else inter-stratified. In some cases there is little sediment or artifacts, and the few clues that these were collected and exploited by people are the ashes and burned shell resulting from cooking. These are commonly referred to as shell middens, though Claassen rightly points out that this assumes that dense shell beds are always food remains (Claassen, 1998). There is wide diversity in the density of shells in archaeological deposits, such that there is a continuum from nearly solid shell matrices to sediments with very few shells. Traditionally in archeology the definition of shell midden rests on the sediment being shell supported, such that shells inter-finger with other shells and the matrix fills in between. This is a "clast-supported" matrix and its recognition is based on the presence of clasts (shells) that dominate the sediment and matrix filling the voids. With shell middens the deposition of shell was so fast that it exceeded the deposition of sediment, provided the finer sediments were 312 not washed out. Micromorphology can be used to determine if sediments were washed out and the matrix is shell-supported because it is a lag (Goldberg, 2000; Goldberg and Sherwood, 2006). The recognition of shell middens has traditionally been used as an indicator in 315 archaeology of a diet rich in mollusks (Snow, 1972; Braun, 1974). I will use the presence of 316 shell middens as a core archaeological proxy indicator of a coastal adaptation. I will use a 317 density of shell that is less than "clast-supported", but occurring with regularity and recurrently 318 through the sediments, as a core archaeological proxy indicator of systematic use of coastal 319 resources. A singular occurrence of a small number of shells is not evidence for systematic use of coastal resources. 
There are potential problems with using the presence of shell-supported matrix as an indicator of the amount of exploited mollusks. Taphonomic factors can affect shell preservation, and it is certainly possible that sediment was shell-supported during the time of deposition but that shell was subsequently removed by decalcification (Karkanas, 2010). There is evidence that this occurred at PP13B in the LC-MSA Lower (Karkanas and Goldberg, 2010) and at Die Kelders Cave 1 (Goldberg, 2000) in South Africa. Perhaps the best way to identify the impact of decalcification, and to identify very small eroded shells as an indicator of once more abundant shells, is through micromorphology (Goldberg, 2000; Goldberg and Sherwood, 2006). However, even if one successfully identifies a decalcified deposit and small shells invisible to the naked eye, this still does not indicate that shell remains were once present or abundant. There are other ways to discover the presence of mollusk exploitation. For example, mussels typically congregate in rocky zones and connect themselves to the rocks through a strong thread (byssus). 333 The process of wave action often throws small water-worn pebbles into the clusters of mussels and these get entrained in the byssus mass. When humans collect mussels they often knock or grab clusters of mussels and toss them into their collection bag, and these water worn stones get carried back to the consumption area and deposited there. These remain a nearly indestructible 337 proxy indicator of mussel exploitation, and only mussels, as they are not connected to limpets. 338 However, finding them requires sorting procedures designed to discover and analyze them. The remains of marine mammals, fish, and birds in the form of skeletal remains is an important proxy for coastline use, but faunal remains suffer the same potential taphonomic problems associated with decalcification of sediments, though it is thought that faunal remains 342 preserve at higher rates than shell in decalcifying conditions (Karkanas, 2010). It is also well 343 documented that carnivores such as hyenas scavenge dead sea birds and sea mammals and 
concentrate their remains (Avery, 1986), so the presence of these sea birds and mammals does not by itself signal a coastal adaptation: taphonomic analysis of sufficient sample size is required to document that people accumulated the remains. Modern humans scavenge sea mammals such as seals and whales. Foragers on the Namibian coast in 1906 were observed to systematically search for stranded whales (Jacobson and Noli, 1987) as did Australian Aborigines (Tindale, 1974). Schapera and Farrington relate an observation from van Riebeeck's travels in the Cape in 1654: "It has happened that they scooped out by handfuls, and gulped down like that, the sundried blubber of a whale stranded in the Salt River, also cutting out pieces which they buried under the sand to eat later" (Schapera and Farrington, 1933: 57). The presence of sea mammals does not in and of itself indicate hunting, but neither does a scavenged pattern of sea mammals indicate the lack of a coastal adaptation. Large numbers of seals are present in many South African LSA sites and the pattern of age at death suggests that most of these were scavenged (Parkington, 1976; Klein and Cruz-Uribe, 1996), but their presence in dense shell middens clearly is further evidence of a coastal adaptation. Without boats to get to island seal haul-outs, coastal hunter-gatherers are left to scavenge wash-ups. The presence of significant quantities of fish bones is a good indicator of coastal adaptations. Productive and regular coastal fishing requires reasonably specialized and complex technologies, normally involving fishing tackle and/or the construction of traps. The ecological knowledge for successful fishing is equally complex. Probably for these reasons, systematic fishing tends to be a rather late addition to the coastal adaptation worldwide, so I will not deal with it further here as it tends to postdate the focus of this paper.

As discussed above, coastal adaptations have a foraging system that is structured around movement to the sea in a strategic manner or permanent occupation near the sea. There are 
several temporal changes in resource abundance and climatic conditions that could drive huntergatherers to strategically schedule movements around rhythms of the sea. These include but are not restricted to 1) solar seasonal phases that, through changes in terrestrial food returns, draw foragers away from the coast; 2) lunar monthly phases that lower the returns of shellfish collecting such that they are no longer productive, 3) external forces such as red and brown tides that poison the coastal foods, and 4) harsh climate conditions during, for example, winter months. Mollusks have breeding cycles that change their nutritional character and attractiveness to people as food, and there is ethnographic evidence that people know these changes and react accordingly (Van Erkom Schurink and Griffiths, 1991; Lasiak, 1992; Lasiak, 1993; Kyle et al., 1997a; Kyle et al., 1997b; Tomalin and Kyle, 1998), so it is likely people did so in the past.

377 Parkington has summarized the importance of red tides and their potential to drive the scheduling 378 of visits to the west coast in South Africa (Parkington, 1972; Parkington, 1976), and such 379 poisonous tides occur frequently in many differing marine ecosystems.

The primary driver of the collection productively of mollusks for human foragers in coasts with significant tidal flux is the spring versus neap tide, which operates on a lunar monthly schedule. When the sun and moon align, their gravitational forces are additive and spring tides occur where the low tide is very low and the high tide is very high (tides "spring" 384 back and forth). Spring tides correspond to full and new moons. When the sun and moon are not 385 aligned, their gravitational force is either unsupportive or subtractive, resulting in neap tides that 386 hover more tightly around the mid-tidal (mean sea level) mark. Observations of human foragers 387 in these contexts consistently show that people favor spring low tides for collection and they 388 avoid collection during neaps (Meehan, 1982; Lasiak, 1992; Lasiak, 1993; Kyle et al., 1997a; 389 Kyle et al., 1997b; Tomalin and Kyle, 1998). There are also some rare lunar annual patterns that 
create particularly low spring tides, such as a day or two after the full or new moon if it is near to an equinox. I have hypothesized that a movement strategy designed to minimize costs and maximize returns would involve being at the coast for the peak high return collecting days around spring tide, and then moving at least $10 \mathrm{~km}$ inland during neap tide (Marean, 2011), and I summarize that model schematically in Figure 2. If we could detect these lunar-month movement patterns, then we would have a powerful tool for detecting a coastal adaptation.

These seasonal and lunar patterns of movement are detectable using certain archaeological proxies. For example, there are a variety of growth indicators of season at death among animals that have been used to infer seasonal mobility, and these include both mammals and mollusks. These approaches excel at indicating season of death, but the lack of prey dying in a season does not necessarily indicate a lack of occupation. In areas with expansive intertidal zones, there can be significant taxonomic zonation to the presence of mollusks, such that some species occur high in the inter-tidal zone (and thus are easier to collect) while others occur low and are only exposed at low spring tides, or not at all. This is the case along the South African coast (Branch and Menge, 2001). The presence and absence of species from differing zones can suggest tidally focused mobility. For example, along the south coast Patella cochlear dominates the lower balanoid zone, and is unavailable for collection (without extreme risk) 407 except during low spring tides (Branch and Branch, 1992). Its consistent presence in 408 archaeological sites would suggest that people were either moving to the coast for exploitation 409 during spring tides, or they live at the coast constantly throughout at least one tidal cycle per 410 year.

Robust evidence for a coastal adaptation is direct isotopic proxy for a diet rich in foods from the marine food chain (Sealy and Van der Merwe, 1987; Sealy and Sillen, 1988). This 
413 approach has been applied with great success from throughout the world but requires the 414 preservation of collagen from bone, and thus has limited applicability to very old sites. People

415 with coastal adaptations often embed in cultural institutions their reliance on the sea through the 416 use of sea shells (shells collected for symbolic purposes), beads made of shells, and sea-based 417 iconography (Beaton, 1995). The presence of consistent finds of this type provides further proxy 418 evidence for a coastal adaptation, and expands that evidence out of a strictly foraging mode to its 419 social impacts.

When does the coastal adaptation occur in Southern Africa, the Mediterranean Basin, and the Atlantic coast of Europe?

As noted above, mollusk-bearing MSA and Middle Paleolithic sediments are known from Neanderthal sites in Europe and early modern human sites in South Africa. More recently an argument has been advanced that Neanderthals used coastal resources in a manner comparable to that during the MSA in South Africa, and that this use was "systematic" and even displayed a "coastal adaptation". For example, "Vanguard Cave shows that Neanderthals were not only systematically exploiting terrestrial mammals but also marine mollusks, pinnipeds, and cetaceans" (Stringer et al. 2010), and "Coastal areas are prime ecotones that often combine marine with terrestrial and wetland resources (Finlayson, 2004, 2006). As such they would have always been premium sites for hominins and the Neanderthals were no exception. The richness and diversity of available resources would have enabled Neanderthals in such coastal areas to maintain relatively small home ranges that would be known intimately and exploited systematically during the course of the annual cycle. During the greater part of OIS 3, with lowered sea levels, the coastal shelf would have also permitted connectivity between 
Neanderthal coastal populations, thus reducing extinction risks associated with isolation"

(Finlayson, 2008: 2251. The recent report from Bajondillo Cave claims a coastal adaptation for

Neanderthals comparable to that practiced by early modern humans in South Africa:

"The coincidence of dates at Bajondillo Cave with those from Pinnacle Point in South Africa, suggest that shellfish gathering reveals yet another case where Neanderthals and Modern Humans might have been following parallel behavioural trajectories, with different evolutionary outcomes. For that reason, and also because shellfish gathering appears to be totally disconnected from the symbolic sphere, those data reinforce our suspicion that the coastal adaptation, however important it might have been at the local level of specific populations, may be yet another overrated phenomenon in the list of behaviors long considered to represent modernity" (Cortés-Sánchez et al., 2011b: e24026).

As noted there are several sites that show that Neanderthals used coastal resources, but so do chacma baboons (Hall, 1962). The important question concerns the importance of coastal resources in the diet and overall adaptive system of Neanderthals - did they use them systematically and/or did they have a coastal adaptation? It is important to carefully consider 453 the evidence for Neanderthal systematic use of coastal resources and a coastal adaptation given 454 the significance for diet and social behavior (as reviewed above).

Erlandson (2001) provides a comprehensive review of the evidence for the use of aquatic foods in the archaeological record, and his review begins with the record in Africa and Eurasia. He does not attempt a detailed and critical review of the evidence from each site (that was not his goal), so I will look more closely at the specifics of these reports in the crucial time slice (Middle 


\section{Southern Africa}

Paleolithic and MSA and older) and update this review with more recently published information.

There are sites along the South African coast that are either dated with numerical techniques to MIS5 and MIS4, or argued through other reasoning to be of this age, and have substantial numbers of mollusks in the deposits. These include, from west to east, Boegoeberg, Sea Harvest, Hoedjiespunt, Ysterfontein, Die Kelders 1, Blombos Cave, PP13B, PP5-6, Herolds Bay Cave, and Klasies River. Some of these have numerical age estimates combined with wellpublished contextual details, while others have very little in publication. It is also difficult in many cases to evaluate the density of shell because many do not have published descriptions of sufficient clarity. I would recommend that such publications in the future standardize this presentation by providing a combination of the following for mollusks remains: numeric presentations of both counts and weights, amount of sediment excavated, photographic documentation either through high resolution close-up photography or micromorphology, and piece-plots of the shell (if available). My review will proceed from northwest to east along the coastline.

Boegoeberg 2 is a rockshelter formed in schist on the Atlantic Ocean north-west coast of South Africa about $860 \mathrm{~km}$ north of Cape Town. The site was discovered during mining operations and, along with the hyena den Boegoeberg 1, was excavated as a rescue operation. It is described as an MSA shell midden (Klein and Cruz-Uribe, 1996; Avery et al., 2008), and in Parkington (2006) there is a section photograph presented that suggests that the shell, with well- 
preserved limpets, is reasonably dense and interstratified at the top of a cobble beach. There is no other published description of the sediments and materials, and the age is unknown.

Sea Harvest is an open-air locality on the Atlantic Ocean south-west coast of South Africa about $120 \mathrm{~km}$ north-west of Cape Town. Archaeological field observations are only available in Volman (1978) and geological section descriptions and interpretations in Butzer (2004). Two ostrich eggshell fragments submitted for radiocarbon dating provided ages greater than $40 \mathrm{ka}$, and geological observations are interpreted to suggest an age within MIS5b (Butzer, 2004). The site is stratified above a wave-cut platform that is roughly at the height of MIS5e ( 5-6 masl), leading these authors to think the site post-dates $125 \mathrm{ka}$. The site is described by Volman (1978) as a shell midden and as occurring in discrete lenses separated by sterile sands, and he reports on faunal remains that includes one Cape fur seal bone fragment and one fish bone fragment. It is important to note that the large faunal sample reported as being from the Sea Harvest site (Klein, 1983) does not refer to the archaeological layers but rather from paleontological layers at the same locality that are thought to be hyena accumulations. None of the finds reported are from excavated contexts but rather are surface collections. Given the lack of excavation and documentary evidence, it is difficult to assess in more detail the character of this site.

Hoedjiespunt is an open-air locality on the Atlantic Ocean south-west coast of South Africa just north-west of Cape Town in close proximity to Sea Harvest, and there are three localities reported (1-3). Locality 1 is a carnivore den (below) and archaeological site (above)(Will et al., 2013). There are hominin specimens from the den (Berger and Parkington, 1995; Stynder et al., 2001), and the Hoedjiespunt Locality 3 is described as an MSA "shell midden" (Parkington, 2003; Parkington, 2006). Parkington (2003) cites a James Feathers 
personal communication of OSL ages ranging between 120-110 ka for Hoedjiespunt 1 and a personal communication from R. Grun that Hoedjiespunt 3 is roughly the same age as Hoedjiespunt 1. The shell weights presented in Parkington (2003) for Hoedjiespunt 3 show there are substantial amounts of limpets and brown mussel, but since sediment amounts are not presented there is no way to determine the density of shell. The photograph presented (Parkington, 2006: 99) is not an intact deposit but rather eroded shell that is out of context, so it is difficult to determine if this is a shell midden. A recent publication of excavations at Hoedjiespunt 1 (Will et al., 2013) provides a section photograph, and excavation director Nick Conard was kind enough to share a high resolution section photograph with me. Neither shows a shell midden despite high quality shell preservation, and Conard concurs that this site does not meet the definition of a shell-supported matrix (personal communication, 2013). Nonetheless, this is an interesting site for being the only known open-air locality where MSA mollusk processing occurred.

Ysterfontein is a rockshelter cut into calcrete above a diorite platform on the Atlantic Ocean west coast of South Africa with a 3.8 m sequence of MSA deposits (Halkett et al., 2003; Klein et al., 2004; Avery et al., 2008). An accelerator mass spectrometry age is reported to be $>46$ ka (Avery et al., 2008). Four optically stimulated luminescence ages of $128.6 \pm 6.3,120.6 \pm$ 6.6, and $132.1 \pm 8.0$ and $127.5 \pm 8.8$ are reported in this paper by way of personal correspondence from Zenobia Jacobs (Avery et al., 2008). The authors discount the ages asserting that OSL relies on "site-specific assumptions" (as do all trapped charge techniques such as ESR and TL), and they note that the MIS5e high sea stand (+5-6 m (Hearty et al., 2007)) would have flushed out the deposits (the cave is estimated to be $+7 \mathrm{~m}$ asl). The authors favor an age between MIS 5c and 5a, or in the latter part of MIS3, largely based on estimates of where 
they think the coast would have been and its significance for the likelihood that hunter-gatherers would have transported mollusks back to the site. It is important to note that all the presented OSL ages are within error, and the spread of ages could place the age of occupation within a regressive phase of 5e (Hearty et al., 2007). Section photographs (Figure 5 in Avery et al. 2008, see also Parkington, 2006) shows there are multiple layers of shell supported matrix. Cape fur seal is abundant throughout the deposits. Ysterfontein, based on the numeric age estimates, is perhaps one of the earliest shell middens in South Africa.

Die Kelders 1 is a cave on the shore of Walker Bay near the juncture of the Atlantic and Indian Oceans on the south-west coast of South Africa. It is formed at the contact of the overlying Bredarsdorp limestone and the underlying quartzitic Table Mountain Sandstone (Tankard and Schweitzer, 1974). The site preserves a series of MSA occupations in levels numbered 14 through 4 which have alternating densities of MSA occupation (Avery et al., 1997; Marean et al., 2000b). OSL (Feathers and Bush, 2000) and ESR (Schwarcz and Rink, 2000) dating was done when these techniques were in their formative stages in application to archaeological and cave deposits and the OSL ages are not single grain ages. The age estimates from the full span of MSA layers from both techniques all fall within error of each other and it is 543 not possible to detect stratigraphic patterning to the estimates, which range from 50 to $160 \mathrm{ka}$, 544 depending on the technique and model assumptions. In my opinion Die Kelders 1 is essentially 545 undated beyond accepting that it is post MIS5e since the cave is so low-lying that it would have 546 been washed out by the MIS5e high sea stand. Cape fur seal is present in relatively small numbers in all the layers (Klein and Cruz-Uribe, 2000; Marean et al., 2000a), and macroscopic 548 mollusk remains were mostly unobservable. In thin section micromorphology the upper MSA 
Layers of 8 and 6 preserve mollusk shells in a state of dissolution, prompting Goldberg to note

that shell may have once been much more abundant (Goldberg, 2000).

Blombos is a cave on the shore of the Indian Ocean south coast of South Africa formed in

limestone of the Bredarsdorp Group above quartzite of the Table Mountain Group. The dating and special finds are well-published and widely known. The stratigraphy is grouped into 3 main

Layers (BBC 3, BBC 2, and BBC 1; bottom to top) and the occupation layers date between 110 and 70 ka (Jacobs et al., 2003a; Jacobs et al., 2003b; Jacobs et al., 2006; Tribolo et al., 2006; Jacobs et al., 2008; Jacobs and Roberts, 2008; Henshilwood et al., 2011). The reported shell weight densities reported in Henshilwood et al (2001) are: BBC $1\left(17 \cdot 5 \mathrm{~kg} \mathrm{per} \mathrm{m}^{3}\right)$, BBC $2(31 \cdot 8$ $\mathrm{kg}$ per $\left.\mathrm{m}^{3}\right)$, BBC $3\left(68.4 \mathrm{~kg} \mathrm{per}^{3}\right)$, and the LSA (13.2 $\mathrm{kg}$ per $\left.\mathrm{m}^{3}\right)$. The high densities reported in some sub-layers within BBC 3 (for example sub-layer CI at $163 \cdot 8 \mathrm{~kg} \mathrm{per} \mathrm{m}^{3}$ ) almost certainly meet the definition of being shell-supported and thus represent reasonable confirmation of shell midden status from Blombos by MIS5-4 times. Updates of those counts confirm the high densities of mollusk remains (Langejans et al., 2012). Cape fur seal are present in all three layers, and it is one of the more abundant taxa in BBC 1. Blombos preserves shell beads (Henshilwood et al., 2004) and ochre grinding containers (Henshilwood et al., 2011) made from marine shells, a find-type that that was also reported in the MSA at Klasies River (Voigt, 1982).

The Pinnacle Point locality preserves a large sample of caves and rockshelters on the shore of the Indian Ocean south coast. The caves are all formed in quartzites of the Table Mountain Sandstone which in this area is overlain by calcrete formations. The sediments at PP13B are dated by a combination of OSL and U-Th, and I calculated very conservative age spreads for each layer based on a combination of the dating techniques and the reported errors for each age (Marean et al., 2010). The LC-MSA Lower occupation is the earliest well described 
and securely dated occurrence of mollusks that were clearly used for consumption by people (Marean et al., 2007; Jerardino and Marean, 2010). The mollusks remains in these layers at PP13B (the LC-MSA Lower) are reasonably dense but do not meet the definition of a shell midden. It is notable that dissolution is evident (Karkanas and Goldberg, 2010) and it is possible that substantial amounts of mollusks were removed by dissolution, but this does not make the case for a shell midden. Small numbers of marine mammals are present (Thompson, 2010), and there are barnacles that are only found on the skin of whales, mostly southern right and/or humpback (Marean et al., 2007; Jerardino and Marean, 2010). These whale barnacles are most parsimoniously interpreted as having their origin in human scavenging of whales since there is no evidence for stone age people in South Africa having boats, and there are ethnographic accounts of coastal South African foragers scavenging whales (see discussion above). This layer dates to MIS6, when for most of this time the coast is distant (Fisher et al., 2010) and outside the daily foraging radius of hunter-gatherers $((\sim 10-12 \mathrm{~km}$, (Marlowe, 2005). The mean weighted age from OSL is $\sim 162 \pm 6 \mathrm{ka}$, while the coastline model (based on a global tuning age scale) centers this transgression at $\sim 167 \mathrm{ka}$, which is within error for the numerical age estimate. Marean et al. (2007) interpreted the shell occupation as dating to this short transgression. PP13B has two stratigraphic aggregates that cluster near MIS5e and these are the LCMSA Middle and the LC-MSA Upper Lower Dune. The minimum and maximum ages for these two layers based on the total age spread with error are 130 to $120 \mathrm{ka}$ and 133 to $115 \mathrm{ka}$, and it is likely that both date to a regressive phase of MIS5e (Marean et al., 2010). The densities of mollusks are high and approach the character of a shell-supported matrix. Clear shell middens are present in the Upper Roof Spall and Shelly Brown Sand with maximum and minimum age ranges of 114 to $110 \mathrm{ka}$ and 98 to $95 \mathrm{ka}$, respectively (Figure 3), and there is no evidence that 
sediment was removed and left the shells as the clasts in a lag deposit (Karkanas and Goldberg, 2010). Shells interpreted to have been brought in as sea shells are present in these layers (Jerardino and Marean, 2010).

PP5-6 is currently still under excavation and analysis, but portions of an intensive OSL dating study was reported for the middle through upper sediments of the Long Section; a 14 vertical m sediment stack of MSA sediment (Brown et al., 2009; Brown et al., 2012). In Brown et al. 2009 we reported OSL ages from sediments in the lower portion of the Long Section from the stratigraphic aggregate Light Brown Sand and Roofspall (LBSR) of $86 \pm 3$ ka to $79 \pm 3$ ka. In the near future we will present the results of a much wider dating program, and the dates are consistent with these prior age estimates. The Long Section commences formation on top of the 90 ka dune that sealed PP13B, so this site continues the sequence that is abruptly halted at 606 PP13B when it was closed to access by this dune. The LBSR and underlying YBSR 607 stratigraphic aggregates preserve recurrent phases of occupation and non-occupation and some of 608 these occupation horizons are shell middens. The Shelly Ashy Brown Sand (SADBS) has a 609 dense distribution of shell throughout (Figures 4-6). PP5-6 provides another case of shell610 midden deposits in MIS5-4 times, and there is no evidence that sediments were removed and left 611 the shell as a lag deposit (Karkanas et al., 2013).

612 Herolds Bay Cave is a small cave on the Indian Ocean south coast just east of Pinnacle 613 Point, excavated in 1979 (Brink and Deacon, 1982). It is cut into the metamorphic pre-Cambrian 614 Kaaimans Group rocks. More recently, Brink and the Pinnacle Point team completed a section 615 cleaning, description, and dating analysis. A detritus-free speleothem layer caps the entire 616 sequence, and in Brink and Deacon (1982) they report that, using alpha spectrometry, Vogel 617 dated the speleothems to c. $80 \mathrm{ka}$ (citing Vogel personal communication to Brink), providing a 
minimum age for all the deposits below. We will report on a series of U-Th age estimates using improved techniques as well as OSL age estimates in the near future, and so far our results are consistent with those of Brink and Deacon but further refined. At the base of the sequence there is a beach at approximately +5 masl which is interpreted to be the MIS5e beach, and there is a "shell midden" stratified on top of the beach, though the shell remains have not been described. At this stage we do not have sufficient information to determine if this is a true shell-supported matrix.

Klasies River is a locality on the Indian Ocean south coast of South Africa that preserves a series of caves and rockshelters with substantial and well-known MSA deposits. The caves are all formed in quartzites of the Table Mountain Sandstone which in this area is overlain by calcrete formations. These sediments have regularly been pointed to as preserving some of the world's earliest and best documented evidence for early coastal foraging. The site was excavated twice (Singer and Wymer, 1982; Deacon and Geleijnse, 1988), and the samples from both excavations have been studied and published. Voigt (1973a, b; 1982) presented on the 632 Singer and Wymer excavations; material that was retained in a highly selective manner. 633 Thackeray (1988; se also Langejans et al., 2012) reported on the more controlled and unbiased 634 sample from the Deacon excavations. Voigt's study, despite the biased sample, is a landmark 635 analysis that provides a detailed discussion of the species present, their positions within the inter636 tidal zone, and the implications of this for foraging preferences. Thackeray's study focused on 637 quantitative analyses of density and shell size. Shell concentrations are very high from the beginning of the Klasies River sequence in the MSA I layers in Cave 1A and 1B, and remain steadily high through the MSA II layers in Cave 1A. Shell densities begin to decline in the Howiesons Poort (HP) layers when the sea was further away, drop precipitously near the end of 
the HP, and then recover to moderate levels in the MSA III. The MSA deposits at Klasies River have regularly been referred to as having shell middens, though there is no published photography that I can find that documents their shell midden status. I have visited the site on several occasions and inspected all the exposed sections. Shell is abundant and sometimes dense, and this is clear from Thackeray's analysis, but most of the exposed MSA deposits that I observed do not meet the criteria of "shell-supported". However, I have documented by photograph two MSA sections that reveal a shell-supported matrix (Figure 7). Voigt identified two shell specimens that had beach wear and she interpreted as having been brought in as seashells, and she also identified a large Patella that had been collected dead and had ochre staining inside it, which she interpreted as a "paint-pot", as was more recently described from Blombos (Henshilwood et al., 2011).

\section{North Africa}

North Africa is currently undergoing a burst of research on its MSA sites and it is likely that in the near future there will be substantially improved descriptions of well-excavated material. The North African record stretches across a major coastal ecosystem change from the 657 Mediterranean to the Atlantic coasts (Fa, 2008; Colonese et al., 2011). Unfortunately the 658 mollusk remains from those excavations that pre-date the 1970 s received at best very brief 659 descriptions that make it impossible to determine the abundance and density of the mollusk 660 remains. That record has recently been reviewed (Steele and Álvarez-Fernádez, 2011; Steele, 661 2013), and these authors show that the paucity of factual detail makes it impossible to determine 662 the details of the mollusk remains from many of these sites, so there is no value in a site by site 663 review here. Several observations not in those reviews do merit presentation and discussion. 
The Témara region on the Atlantic coast of Morocco has a number of important coastal

665

8

sites. El Mnasra and El Harhoura 2 are caves cut by the MIS5e high sea level in calcarenites.

Mollusk remains are reported though densities are not provided (Stoetzel et al., 2013), and descriptions of the stratigraphy do not document shell supported matrix (El Hajraoui and Debénath, 2013; Nespoulet and El Hajraoui, 2013; Boudad et al., 2013; Aldeias, 2013). Dar esSoltan I is a cave site in calcarenite about $260 \mathrm{~m}$ from the coast (Ruhlmann, 1951; Barton et al., 2009). The excavations by Ruhlmann in the 1930's were written up posthumously, and mollusk remains are reported but not in a way where the abundance and densities can be determined. Barton et al. (2009) includes detailed descriptions of the sediments, and while the base of the deposit preserves a geogenic shell midden in the form of a raised beach, and the Neolithic deposits also appear to preserve shell middens, the MSA Aterian and Mousterian layers do not. Contrebandiers Cave is formed in calcarenites in the Témara region. Earlier excavations at the site reported limpet remains (Roche and Texier, 1976) without detailing the densities and amounts. The most recent excavations report on $\sim 10,000$ shell fragments from $\sim 3000$ individuals (Steele and Álvarez-Fernádez, 2011; Dibble et al., 2012), with the marine taxa representing mostly limpets, topshells, and mussels from the rocky inter-tidal zone. Dibble et al. (2012) provides data on 15 layers of Mousterian and Aterian remains, and substantial numbers of marine mollusks are present in all but three of these, showing a constant pattern of 682 representation. A species list is available from earlier excavations (Bouzouggar et al., 2002). 683 The excavation and stratigraphy reports provide high quality section photography (Dibble et al., 684 2012; Aldeias, 2013) and none of these documents a shell-supported matrix, despite the abundant 685 mollusks. 


\section{Europe}

The oldest reported use of mollusks from Europe are from late Acheulian contexts at Terra Amata but reported only anecdotally in a Scientific American article (de Lumley, 1969). The depositional security of the site has been challenged (Villa, 1983). There is a report of marine mollusks from the Middle Paleolithic site of Ramandils, but beyond a one sentence note I cannot find any other description of these data (Cleyet-Merle and Madelaine, 1995). Finlayson (2008: 2249-2251) points to evidence from Israel, Italy, southern Iberia, and Portugal as supporting a systematic pattern of shellfish collection by Neanderthals citing the following (Stiner, 1994; Stiner et al., 1999; Stiner et al., 2000; Stringer et al., 2008; Bailey and Flemming, 2008). In Israel there is no evidence in these cited papers for use of marine mollusks for food during the Middle Paleolithic and I have been unable to find evidence published elsewhere. There is a one page report on 20 marine shells from a large excavation of Middle Paleolithic deposits at Ras El Kelb in Lebanon (Reese, 1998), but it is unclear how these extremely rare shells were accumulated.

In Italy the most commonly cited Middle Paleolithic site for primary evidence for coastal resource use is the limestone cave site of Grotto dei Moscerini on the east Tyrrhenian coast of Italy. Stiner (1994) has provided the faunal data as well as a clear reconstruction of the mostly 704 unpublished excavations conducted in 1949 of the $\sim 8$ m sediment stack that dates back to $\sim 120$ 705 ka. Stiner provides details of stratigraphic drawings and descriptions from the notes of the 706 excavator (Serge), and there is no shell midden reported, or even a concentration of shell. Stiner notes that "Although the site was revisited over many thousands of years, Mousterian hominids 708 collected little more than an armload or two of mollusks over many thousands of years (1990: 
194). She goes on to note that "Moscerini does not contain the sort of dense shell middens that

710

are classical for some later cultural periods" (1990: 194).

Cueva de los Aviones is a cave in carbonate rocks on the Mediterranean on the Murcia coast (Montes, 1991; Zilhão et al., 2010). The current position is just above mean sea level. The Middle Paleolithic is preserved as a calcified remnant clinging to the western side of the cave.

714 The materials reported in Zilhão et al. (2010) are from prior excavations in 1985. The original excavators recognized six archaeological layers with mollusks remains reported from $\mathrm{V}$ through I, and radiocarbon ages are interpreted to suggest an age of $\sim 48-45 \mathrm{ka}$ cal BP. The original excavation report provides a schematic drawing of the stratigraphy indicating the presence of mollusk remains in layer $\mathrm{V}$ but there is no indication of their abundance and density. The report in Zilhão et al. (2010) shows that the mollusks are sparsely distributed through the sediments, and combined with the one section photograph that has been presented, these remains do not meet the definition of a shell midden. Zilhão et al. (2010) argue that this site preserves shells that were intentionally transported to the site and used in conjunction with colorants.

Bajondillo Cave is a rock shelter cut in travertine near the city of Torremolinos and is currently $\sim 250 \mathrm{~m}$ from the present-day coastline (Cortés-Sánchez et al., 2011b). It is at $\sim+15 \mathrm{~m}$ asl and thus escaped the high sea levels of MIS5e. The sedimentary sequence of $\sim 5.4 \mathrm{~m}$ has 20 recognized archaeological layers. The layers from $\mathrm{Bj} 0$ to $\mathrm{Bj} 16$ are dated by a series of 727 thermoluminesence (TL) and AMS ages, with Bj13 and 14 being Aurignacian and Mousterian, 728 respectively. The TL ages show good stratigraphic progression with age. The lowermost TL age 729 is from Bj17 and is $64500 \pm 6360$, and all lower layers are dated by U-Th applied to bone (the 730 archaeological layers) and to a stalagmite crust and travertine (underlying the entire section). Bj19 has two uranium thorium ages on bone (149400 \pm 9600 and $151200 \pm 14600)$, with Bj18 
being undated, and Bj17 having two U-Th ages of $73100 \pm 3800$ and $65800 \pm 4200)$. This requires a substantial unconformity in the area of $\mathrm{Bj} 18$. The lowermost layer, $\mathrm{Bj} 19$, is claimed to have the oldest evidence for systematic marine resource exploitation by Neanderthals. There are no marine mammals reported, and mollusk remains are present throughout the Middle Paleolithic sediments but are sparsely distributed. A section photo displays no concentrated layer of shell in this deposit (Cortés-Sánchez et al., 2011a), and the excavator Miguel Cortés Sánchez states (personal communication, 2012) that there is no shell midden deposit in the cave.

The caves at Gibraltar have figured prominently in discussions of coastal resource exploitation by Neanderthals. Garrod's excavations at Devil's Tower, a long narrow cave cut in limestone with a floor $~ 9$ masl, was described as seven layers of deposit with Layer 5-1 being Mousterian. All the Mousterian layers contained mollusk remains (Garrod et al., 1928). There are no counts or weights of mollusk remains presented, but in the narrative descriptions the mollusk remains are described as being dense in some locations, sometimes in association with hearths.

Vanguard Cave and Gorham's Cave at Gibraltor are large caves formed in limestone. Vanguard Cave includes several major stratigraphic units of Mousterian deposit and the upper Mousterian layer, Unit B, includes a single layer of marine shells with ashy sediments (Barton, 2000; Macphail and Goldberg, 2000). Originally reported in the monograph, this layer was also reported in Stringer et al. (2008) and forms one of the key pieces of evidence for claimed 751 systematic use of marine resources by Neanderthals. No other marine fauna are reported from Unit B. Units C and D are lower in the cave sequence and are described as having well defined occupation horizons that contain hearths and Mousterian stone tools. Fossil faunal remains are well preserved and the assemblage is dominated by terrestrial mammals such as ibex (Capra 
ibex), red deer (Cervus elaphus), as well as small quantities of marine mammals (seals and dolphins, with a total marine mammal specimen count of 9 bone fragments). Some of the marine mammal fragments are reported to have stone tool cutmarks. There are 149 fragments of mollusk shell also reported from a large excavated area.

At Gorham's Cave a small sample ( 9 pieces) of marine mammal bones (seals and dolphins) are reported from level IV, a Mousterian layer (Stringer et al., 2008), dated to between >32-30 ka 14C BP (Finlayson et al., 2006). Fa (Fa, 2008) reports percentages of mollusk taxa, but there is no information reported on the densities and abundance. An unpublished manuscript on the molluscan assemblage was kindly shared with me by $\mathrm{Fa}(\mathrm{Fa}, 2013)$. The sample of mollusk remains from the Mousterian level is small (39) from a large excavated area (12 $\left.\mathrm{m}^{2}\right)$, and thus Gorham's resembles Vanguard in having very low densities and small overall counts relative to excavated area.

Neanderthals were probably responsible for the transport and consumption of these marine fauna at the Gibraltar Caves, but we need to put the remains and their density into context. Do these caves preserve shell middens, do they document systematic use of marine resources, and how does this pattern compare to sites in South Africa of comparable age? The most detailed published data is from Vanguard, and there is nothing in the descriptions that 772 suggest these deposits are shell-supported and thus a shell midden. The micromorphology stratigraphy paper (Macphail and Goldberg, 2000) does not mention a dense shell deposit. This same paper notes that this is a calcium carbonate-rich deposit where it is unlikely that shell was removed by diagenesis - "most of the Vanguard sediments are calcareous with little diagenesis, except for phosphatisation at the very top of the cave" (Macphail and Goldberg, 2000: 189). I sought further clarification on this, and Goldberg (personal communication, 2012) describes it 
thus: "I had a look at Vanguard field and thin section photos, and only a few of them [perhaps 3 or 4 samples] had remains of shells in them. In any case, I don't see any evidence for what one would want to call a midden. It looks like they brought in a few shells there but that's it." Gorham's Cave seems very similar in character to Vanguard, but a confident assessment must await the publication of a more detailed description. Devil's Tower, with its narrative 783 784 descriptions of dense mollusks remains, is intriguing but requires further documentation.

Around the Iberian peninsula on the coast of Portugal the record is beginning to fill in but there is only a small sample of Middle Paleolithic sites with mollusk remains, while the Upper Paleolithic displays a convincing sample of shell middens (Bicho and Haws, 2008; Hawes et al., 2011). Gruta da Ibn Amar is a cave in limestone on the south coast of Portugal. Mollusk remains are reported in association with Middle Paleolithic lithics but the density is light (Bicho, 2004). Gruta da Figueira Brava is a cave in limestone on the Setubal peninsula just south-east of Lisbon (Antunes, 2000). The Middle Paleolithic layers are stratified below Holocene sediments and are thought to date to late in MIS3 (Hawes et al., 2011). There are 900 mollusk fragments reported and a small sample of marine mammals (Antunes, 2000) but it is unclear what the density of these remains are relative to the excavated deposit. I have been unable to find any reported associations of molluscan fauna with the Middle Paleolithic along the north-western Iberian coast and it appears that it is only in the Upper Paleolithic that this association begins, and when it does, it has all the features of a coastal adaptation (Straus, 1992).

\section{Comparative Summary of the Evidence}

Several patterns should emerge when hominins begin to use coastal resources in a systematic manner or have developed a coastal adaptation. Mollusks should be common, occur 
recurrently through a stratigraphic record and among multiple sites, or form shell middens in the archaeological sediments. The presence of marine mammals can be informative, but the presence of trace amounts is not indicative of systematic use of marine resources or a coastal adaptation, since these animals can be easily scavenged from the beach. Collecting sea shells, and the use of shells for other symbolic purposes, when found with shell middens is another signal of a coastal adaptation, but their absence is not a clear indicator that hominins were not foraging off the sea, and their presence alone does not indicate systematic coastal foraging or a coastal adaptation.

The evidence summarized above documents several sites along the Southern African coast dating to MIS5, to as early as $\sim 110 \mathrm{ka}$, that have features consistent with a coastal 811 adaptation as it is widely defined in the coastal hunter-gatherer literature. This includes true 812 shell middens with high densities of mollusk remains, regular and recurrent representation of 813 large quantities of mollusk remains throughout the stratigraphy of most coastal sites, the 814 presence of mollusk-rich sites both in cave/rockshelter and open-air contexts, and some 815 indicators of the embedding of the coastline in symbolic behavior (collection of sea shells). 816 There is some evidence for fish remains in South African MSA sites (Henshilwood et al., 2001), 817 but fish are rare in MSA contexts and only become abundant in the LSA. Marine mammals, 818 primarily Cape fur seal, are present in virtually all the coastal MSA sites reviewed here and in 819 some of the sites (Ysterfontein, Die Kelders Cave 1, Blombos, PP13B, and Klasies River) are 820 consistently present throughout the sequences. Some sites have indicators of whale scavenging. The record of Middle Paleolithic sites in Europe displays a different pattern. 822 None of the Neanderthal sites reported in the literature preserve shell middens, and when mollusks are present in the assemblages, they are present in small amounts and sparsely 
824 distributed, often restricted to one thin lens even when the sediment stacks are substantial. In many of the publications the data presented are of insufficient detail to evaluate the abundance and density of the mollusk remains. For comparison, Figure 8 shows the plotted shell from Vanguard Cave in a way that allows a direct comparison to PP13B as they are scaled the same. The Vanguard Cave shells are rare and dispersed, scattered across a single layer, and easily could 829 represent a single instance of transport of a connected cluster of mussels. The PP13B mollusks 830 are dense and occur repeatedly through the section, showing consistent use with every detectable 831 occupation. This pattern at PP13B, dated to between $\sim 110-90 \mathrm{ka}$, is repeated at other MSA sites 832 in South Africa, for example at PP5-6. Marine mammals in Neanderthal sites are occasionally 833 present but always extremely rare. A striking pattern with the European record is the abundance 834 of coastal and near-coastal Middle Paleolithic sites with no mollusk remains, or very small 835 amounts restricted to individual layers. These patterns, of roughly coeval sites, along the coasts 836 of South Africa and Europe are striking and clearly differences in kind. The North African 837 MSA record is in the formative stages of being published, but at this stage the record is 838 ambiguous. Some sites show large quantities of mollusks throughout the sequences, but it is unclear if they form a shell midden.

This review shows conclusively that, with the current available evidence, there is no 841 evidence for a coastal adaptation or even a systematic use of coastal resources by Neanderthals 842 in Europe, while the North African record perhaps meets the definition of "systematic" use of 843 coastal resources, but we need further samples to reach a firm conclusion. 


\section{Why don't Neanderthals display systematic use of coastal resources or coastal adaptations?}

Since there is no evidence for a systematic use of coastal resources or a coastal adaptation by Neanderthals, we need to ask why this is. There are several possible explanations, none of which are mutually exclusive. Perhaps the sites have not yet been discovered? This is always a possibility I guess, but seems particularly unlikely given the intense study of Paleolithic archaeology in Europe. Certainly, the number of studied and excavated Middle Paleolithic sites in Europe exceeds that in South Africa by at least an order of magnitude, and perhaps more.

One could argue that the pattern is due to differences in preservation - the mollusk remains in Europe have been leached away while those in South Africa are better preserved. The Mediterranean sites are nearly all in highly calcareous rocks (see review above), while many of the sites in South Africa are in acidic quartzite (PP and Klasies), though both have calcretes stratified above the quartzite that provide some buffering action. These South African sites are in more acid conditions than the Mediterranean ones and thus would be expected to be poorer environments for shell preservation. In the specific case of Gorham's Cave, a diagenesis interpretation is directly contradicted by the micromorphology study (Macphail and Goldberg, 2000), as discussed above.

One could argue that Mediterranean Middle Paleolithic shell middens are all submerged 864 by higher sea levels, and during regressions the current coastal caves were too far from the coast 865 for Neanderthals to have transported shell to them regularly. It is important to note that, even 866 during maximum sea level regressions, most Mediterranean sites were still within $\sim 10-12 \mathrm{~km}$ of 867 the reconstructed position of the coast (Colonese et al., 2011), this being the average daily 868 foraging radius of hunter-gatherers (Marlowe, 2005). In contrast, along the south coast of South Africa during maximum glacial regressions the coast was as much as $\sim 120 \mathrm{~km}$ distant (Van 
Andel, 1989; Fisher et al., 2010). This is because the Agulhas bank is for most of its extent wider and more gently sloping than the continental shelf in the Mediterranean, so this affect would pose a greater challenge to the formation and preservation of shell middens in South African than in the Mediterranean.

Another potential explanation is that the coastal areas used by Neanderthals were too unproductive to warrant systematic use of the intertidal zone. Both Fa (2008) and Colonese et al. (2011) provide excellent reviews of the inter-tidal productivity of the Mediterranean coastal zone, and $\mathrm{Fa}$ extends this around the Iberian coast into the Atlantic. Both note that the Mediterranean coastal zone is relatively nutrient poor with low productivity resulting from little terrestrial runoff, reduced upwelling, and very moderate inter-tidal flux. There is a west to east gradient with the western zones, closer to the opening to the Atlantic, having higher productivity. Colonese et al. (2011) cite a figure of about $30 \mathrm{~cm}$ of maximum tidal amplitude (the difference between high and low spring tide). This is important because the height differential defines the extent of the inter-tidal community - greater amplitude results in more areas for inter-tidal communities to develop, and greater variation for varying communities. In contrast, while there is also an east-west gradient in South African coastal productively, the South African west and south coasts are extremely productive and support rich inter-tidal ecosystems (Branch and Branch, 1992; Branch and Menge, 2001). The South African coast also has substantial tidal amplitude running at about $1 \mathrm{~m}$ above and below mean sea level (Mather et al., 2009).

The "unproductive coastline" explanation is insufficient as an explanation for the lack of Neanderthal systematic exploitation of coastal resources and coastal adaptations for several 891 reasons. First, the explanation should apply across all time periods including the Upper 892 Paleolithic. This is not the case - dense mollusks remains are found in the Upper Paleolithic 
throughout the region (Stiner, 1994; Colonese et al., 2011). Neanderthal occupations are not restricted to the Mediterranean but rather carry on around the Iberian Peninsula to the coast of Portugal, where the inter-tidal ecosystem is nutrient rich due to substantial terrestrial runoff and marine upwelling and stronger tidal amplitude (Fa, 2008). Fa notes that the primary driver of inter-tidal resource abundance in these regions is the difference between the exposed inter-tidal zones during low and high spring tide. Figure 9 shows the tidal amplitude across several locations relevant here. The Italian tide gauge site is consistent with the generalization of Mediterranean tidal flux by Colonese et al. (2010), but note that Gibraltar is close to South Africa in tidal amplitude, and Portugal is comparable to South Africa. Furthermore, upwelling intensity along the Portuguese coast was greater during the colder phases of the Pleistocene, so the coastal productivity was probably higher during Neanderthal occupation (Bicho and Haws, 2008). If Neanderthals failed to systematically exploit coastal resources due to unproductive coasts and low tidal flux, then we should see that constraint released in Portugal and there should be shell middens there in the Middle Paleolithic. There are not, but the Upper Paleolithic documents clear systematic use of coastal resources and coastal adaptations (Bicho and Haws, 2008).

Another potential explanation is that Neanderthals did not exploit coastal resources 910 because those resources ranked low in the diet breadth and were not taken regularly for this 911 reason, following the diet breadth model (Stephens and Krebs, 1986). In this argument, 912 Neanderthal populations were relatively small, other higher-ranked food resources were present and abundant (such as large mammals), and thus Neanderthals eschewed coastal resources due to 914 their relatively low net return rate. This explanation might argue that modern humans during the 915 Upper Paleolithic expanded their diet to lower ranked food resources for a variety of reasons 
such as resource depletion and population increases (Stiner et al., 2000; Stiner, 2001), and this is why we observe systematic coastal resource use among modern humans during the Upper Paleolithic in Europe but not during the Middle Paleolithic. This is a reasonable explanation that warrants careful consideration and further study. I see two possible problems with it, neither fatal.

First, as far as I know, we do not have net return rate data for human collection of Mediterranean and Atlantic coast mollusks that shows definitively that these resources rank below that of other food resources exploited by Neanderthals. Rocky shore shellfish collection in the Merriam Islands nets 455 and $1106 \mathrm{kcal} / \mathrm{hour}$ for two species (Bird et al., 2004), and this return is high enough to merit collection among those modern foragers. But return rates can be expected to vary widely by region due to the significant differences in mollusks size, density, and diversity, so we need regional studies to develop proper rankings based on return rates. One would anticipate that the return rates for Portugal would be higher than those in the Mediterranean, and perhaps comparable to South Africa due to the similarities of the coastal environments.

A second problem is that Neanderthals failed to exploit coastal resources whether or not 932 they were in nutrient rich (Portugal) or poor (Mediterranean) areas, while modern humans in 933 those selfsame areas, whether nutrient rich or poor, systematically exploited coastal resources 934 and even developed true coastal adaptations. In South Africa the coasts were systematically 935 exploited from the MSA right through to the late Holocene, and modern humans in Europe did as well. Neanderthals are an outlier in this pattern. (1) 3 5 


\section{Hypothesis}

I offer an alternative hypothesis for the lack of systematic collection of shellfish by

Neanderthals. In Marean (2011) I discussed the challenge to a coastal inter-tidal forager, and

this is summarized in Figure 2. The basic problem for a forager is the returns from inter-tidal shellfish collection during times other than low spring tides are likely to be low, and the collection is dangerous, because little of the inter-tidal zone is exposed. Modern humans understand this and typically only forage during low spring tides, and rarely collect shellfish during neap tides because it is simply too costly and dangerous. Tidal patterns are driven primarily by lunar position such that spring tides are centered on full and new moons. The difficulty for scheduling visits to the coast is that tides follow the lunar schedule, and a lunar month is about 27.3 solar days. One cannot schedule coastal visits around the solar calendar as this will shift off schedule over time. Modern foragers schedule visits to the coast around lunar phases to maximize their collection rates. Added to this scheduling difficulty is the fact that tides change their time of occurrence in the day on a lunar schedule, not a solar schedule. While most regions receive two high and two low tides per day, the peak of each changes its time of occurrence each day, advancing roughly 50 minutes per day. This is why tide tables are so complicated. Spring low in South Africa is short, sometimes lasting only 90 minutes, so it is easy to miss the productive and safe collection time. Meehan, working with coastal foragers in Australia, notes that she observed this happen to these skilled foragers (Meehan, 1982).

So to be a systemic coastal forager, and develop a coastal adaptation, the terrestrial forager must first have an understanding of the relations of the lunar phases to the tides and their return rates. The optimal strategy is to position the residential site next to the coast during full and new moons, and then move the residential site back away from the coast when the tides shift 
to neap and return rates are very low. I think this is why the evidence for systematic coastal foraging in South Africa occurs so late - people had not developed this complex knowledge of the relation between lunar phases, tidal states, and return rates. My hypothesis is that Neanderthals failed to develop this understanding. When modern humans entered Europe, they quickly developed this strategy, and the coastal adaptation appears soon after their arrival.

This hypothesis has a number of predictions. A "coastal adapted forager" tracking the tides, foraging consistently during spring lows, and avoiding high tides and neaps will create a specific type of shell assemblage that differs from the more "opportunistic forager" who occasionally exploits the inter-tidal zone in a non-strategic manner. First, mollusk taxa that are found deep down in the inter-tidal in areas where one cannot forage except during spring lows will be abundant in the shell-middens of the coastal adapted forager, while these will be relatively rare to absent in the assemblages of the "opportunistic forager". Second, it is known 974 that, at least for bivalves, shell micro-growth patterns differ between spring and neap tide. Using 975 high resolution schlerochonology methods it is possible to identify whether mollusks were 976 collected during the spring or neap (Hallmann et al., 2009). I would expect that the coastal adapted forager would have a tidal pattern of mollusk collection more structured than an opportunistic forager. A coastal adapted forager should show focused low spring tide collection, particularly in species low in the inter-tidal zone, while an opportunistic forager should not. If my hypothesis is correct, then Neanderthal shellfish collections should have relatively few taxa 981 that require low spring tides for collection, and their kill patterns of mollusks should not be spring tide focused.

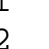
. 年 


\section{Coastal Resources and the Origin of Prosocial Behavior}

As noted above, coastal adaptations have received increasing attention in human origins studies, and I have reviewed some of the reasons for this interest. At this point I will expand beyond these previously discussed considerations, and develop a hypothesis that identifies another possible implication of the development of coastal adaptations. The hypothesis, in summary, is that when early modern humans in Africa expanded their diet to coastal foods it provided a uniquely spatially and temporally predictable, dense, and high ranked food resource. This triggered high levels of territoriality, and that territoriality resulted in inter-group conflict. This regular inter-group conflict provided conditions for group-level selection for prosocial behaviors, which subsequently expanded through the population. An implication of this hypothesis is that the incubating environments for prosocial behaviors are not universal and are in fact restricted to ones where high ranked resources are dense and predictable. The coast of the southern African sub-region is one such region. Another implication of this hypothesis is that the strongly prosocial behaviors that characterize modern humans occurred relatively late in human evolution, and thus was one of the final additions to the human uniqueness suite (Hill et al., 2009), and not shared by Neanderthals.

The literature on hunter-gatherer inter-group conflict has a long history of changing ideas, but after a significant amount of ethnographic, archaeological, empirical and theoretical research, a consensus has been reached on a number of aspects. Men do most of the fighting, and they fight over resources, land, women, and honor, and they do so as individuals but also as groups (Keeley, 1996; Gat, 1999; Kelly, 2000; Gat, 2000a; Gat, 2000b; Otterbein, 2004). There have been two trajectories to the literature on hunter-gatherer inter-group conflict and these have never been well integrated. There is a warfare, or primitive warfare, anthropological literature 
(Keeley, 1996; Gat, 1999; Kelly, 2000; Gat, 2000a, 2000b; Otterbein, 2004) and a territoriality

anthropological literature (Speck and Eiseley, 1939; Heinz, 1972; Petersen, 1975; Dyson-Hudson and Smith, 1978; Petersen, 1979; Cashdan, 1983). The former has focused on organized fighting between groups of people and the origins of war by examining hunter-gatherer and mid-level societies. This literature typically does not attempt to develop formal theory for why warfare exists. The term "warfare" can be somewhat problematic because it conjures images of large forces arrayed on the battlefield. This may have contributed to the debate over whether or not hunter-gatherers had warfare, and may also have triggered the use of the qualifier "primitive warfare" when describing hunter-gatherer conflicts. Here I will stick to the less-loaded term "inter-group conflict" to refer to situations when one group fights another either as organized groups or in more occasional and opportunistic raiding and ambush by small groups or individuals.

Anthropology, and particularly cultural anthropology, has a long tradition of consideration of territoriality in hunter-gatherers (Speck and Eiseley, 1939; Heinz, 1972;

Petersen, 1975; Dyson-Hudson and Smith, 1978; Petersen, 1979; Cashdan, 1983). DysonHudson and Smith (1978) use this definition for territoriality and I will as well: a territory is "an area occupied more or less exclusively by an animal or group of animals by means of repulsion through overt defense or advertisement" (Wilson, 1975: 256) where I would replace "animal or group of animals" with "local group or tribe". A consistent feature of the anthropological literature has been the attempt to develop theory to explain the conditions under which huntergatherers will establish territories and defend them. This literature was vigorous for quite some time and had several key insights that accumulated to produce some insightful theory. Originally researchers defined territoriality in terms restricted to active or perimeter boundary defense, but 
Petersen (Petersen, 1975; Petersen, 1979) described a second type of territoriality that he termed "social boundary defense", and this involved situations where boundaries were defined but they were not actively defended. Groups could thus still claim exclusive rights to a territory without the constant costs of perimeter patrol. Individuals from other groups could gain access to a territory by passing through a specific ritual, after which they might be granted passage.

Dyson-Hudson and Smith (1978) provided a powerful model grounded in evolutionary ecology that explained territoriality as a function of resource predictability and density, a result that aligned hunter-gatherer territoriality with its study among non-human animals. This model predicts that hunter-gatherers will be territorial only when resources are predictable and dense, and thus can be effectively delineated with a protective boundary that can be patrolled.

Boundaries will be defined and defended when the cost associated with patrol and defense is outweighed by the gains incurred through such patrol and defense. Storage immediately transforms a resource into being dense and predictable, and hunter-gatherers typically defend significant caches of stored resources. Food production of course creates the most dense and predictable of food resources, and this is where we see the highest levels of territoriality (and warfare). Cashdan (1983) expanded on this model by building in Petersen's social boundary defense and the importance of competition. My discussion draws primarily on the DysonHudson and Smith formulation - that highly predictable and dense food resources trigger intergroup conflict. I am also primarily concerned with active boundary defense since these are the territorial conditions that typically result in inter-group conflict. I will add one caveat - the resources in question must be high-ranked before they stimulate active boundary defense since low ranked resources that are rarely used, even if predictable and dense, are unlikely to be defended. Fallback foods such as dense and predictable tubers among the Hadza (Marlowe and 
Berbesque, 2009) are an example of dense, predictable, low ranked resources that are unlikely to

be defended, except during times when fallback foods are important. Levels of territoriality can be contextual.

Richerson and Boyd (2005) argued that inter-group competition and conflict could result in group selection and the spread of cultural variants. They postulated that for a group-beneficial cultural variant to spread it must first begin in a subpopulation, and that it will spread faster in smaller populations. This line of argument was expanded (Bowles, 2009; Bowles and Gintis, 2011) to the spread of prosocial behaviors with mathematical and simulation support for the following propositions. The prosocial behaviors so evident in modern humans are difficult to arrive at with standard models of individual-based selection. Reciprocal altruism and kin selection don't provide conditions where individually costly behaviors spread. Their conclusion is that selection for such prosocial behaviors can only occur when groups are in conflict. Groups that have higher numbers of prosocial people will out-compete others, thus resulting in the spread of proclivities for prosocial behavior. While there is likely to be debate about this conclusion, there is no doubt that it is a novel and important conclusion. I assume for my purposes that it is correct. That leads us to another question - under what conditions will there be regular inter-group conflict between hunter-gatherers?

If we assume that all modern humans share this prosocial proclivity, then it is most parsimonious to argue that the shared common ancestor of modern humans had it as well. The modern human lineage evolved in Africa (Ingman et al., 2000; Gonder et al., 2007), so if we are interested in identifying environments within which territoriality would arise, trigger inter-group conflict, and then create a species-wide proclivity for prosocial behavior, Africa must have been the location for its appearance and fixation in the genome. Currently documented African 
hunter-gatherers, such as the various Khoi-San groups and the Hadza, practice low levels of

territoriality typically of the social boundary defense type, likely due to the large size of their

territories that results from the relatively low productivity of these regions (Cashdan, 1983).

Active boundary defense typically is only practiced when boundaries can be patrolled, and this is only possible when the territory is small, or the hunter-gatherers are equestrian and can cover larger distances. Small territories typically result from situations where resource productivity is high, and in Australia where we have the best documentation of territory sizes for coastal and inland hunter-gatherers in similar environments (Tindale, 1974), coastal hunter-gatherers had the smallest territories (Birdsell, 1953). Coastal and lacustrine hunter-gatherers have the highest levels of territoriality and inter-group conflict recorded for hunter-gatherers (Moss and Jon, 1992; Lambert, 1997; Maschner and Reedy-Maschner, 1998; Lambert, 2002). Bowles’s (2009) review of the evidence for "warfare" in the Pleistocene reflects this - the African examples he cites are all lacustrine or coastal.

Prior to hunter-gatherers expanding their diet to aquatic resources, the predominant adaptation in Africa for millions of years of hominin evolution was likely to have been characterized by low population density, large territory size, high residential mobility, light technologies, and low levels of active boundary defense. This is consistent with the character of the archeological record in that from the earliest archeological sites through most of the MSA there are none of the tell-tale signs of sedentary, complex, territorial hunter-gatherers as signaled by cemeteries, high levels of violence, regionally defined stylistic markers, and densely occupied sites. During MIS6 from $~ 195-125 \mathrm{ka}$, when the modern human lineage arose, most of Africa was cooler and more arid than it is today, and hunter-gatherer populations were likely small and regionally isolated (Lahr and Foley, 1998; Lahr and Foley, 2001). 
Conditions were different in the Cape through much of the Pleistocene. The unique floral ecosystem provided a high diversity of geophytes, the coastline a highly predictable and dense set of protein resources, both immune to the cooler conditions of the glacial phases. The exposed Agulhas Plain supported large populations of gregarious grazing ungulates (Marean, 2010b; Marean, 2011). Given the size of the typical hunter-gatherer band annual round (Marlowe, 2005), any hunter-gatherer group in the Cape Floral Region would either have had direct access to the coast, or have been just one band territory removed from that coast. Cape foragers expanded into the coastal niche at least by $\sim 162 \mathrm{ka}$ and by $\sim 110 \mathrm{ka}$ were fully committed to this adaptation along the shores of the Cape of South Africa, as discussed above. This dietary expansion, given everything we know from the ethnographic and archaeological records of hunter-gatherers worldwide, would have been accompanied by heightened levels of territoriality and active boundary defense with consequent inter-group conflict. These conditions would have created, perhaps for the first time in human evolution, and perhaps uniquely for this time in Africa, the conditions modeled to be ideal for the proliferation of prosocial behaviors (Bowles, 2009; Bowles and Gintis, 2011). It has been argued that true projectile weapons such as atlatls are indicated by the presence of microlithic tools dated at PP to $71 \mathrm{ka}$ (Brown et al., 2012). A highly cooperative prosocial species equipped with projectile weapons presents the world with a new formidable predator where neither prey nor competitor is safe. With this lethal combination of within-group cooperation, strong ethnically defined hostility to others, and long range weaponry, modern humans rapidly replaced other sister taxa when they left the African continent. 


\section{Conclusions}

The origins of the systematic use of coastal resources, and the eventual transition of this systematic use to a true coastal adaptation, have gained increasing interest in paleoanthropology. To effectively evaluate when hominins began systematically using coastal resources and ratchet up to a coastal adaptation, we need to define what we mean by systematic use of coastal resources and coastal adaptations, and develop proxy indicators for both. Having sites on the coast, even in rich marine contexts, does not make the case for either, even though the use of those seemingly rich and nearby resources makes intuitive sense. In this paper I developed definitions of "systematic use of coastal resources" and "coastal adaptations", partially through review of the rich and diverse literature from other regions and time periods where coastal archaeology has a long tradition. I also developed proxy indicators for both, and a review of the published Middle Paleolithic and MSA records from the Mediterranean, the Atlantic coast of Iberia and North Africa, and South Africa showed that those regions where Neanderthals are thought to have lived show no evidence for systematic coastal resource use or coastal adaptations, despite claims for both. The North African record is rather ambiguous at this point, but does show some indicators of systematic coastal food use. South Africa shows clear evidence for coastal adaptations by $\sim 110$ ka during the MSA. Explanations that rely on preservation, sample size, and ecology for this lack of systematic coastline use by Neanderthals were considered, and all were found insufficient.

I have argued here that a neglected aspect in the discussions of the expansion of the hominin diet to coastal foods has been the implications of this dietary shift for social and technological aspects of hominin adaptations. The ethnographic and archaeological records show that when hunter-gatherers break into the marine food niche, there is a recurrent and 
transformative impact across their entire adaptive system. When hunter-gatherers ratchet up

their use of coastal resources to the point that we can recognize a coastal adaptation, the common result is reduced mobility, larger group size and population packing, smaller territories, complex technologies, increased economic and social differentiation, and more intense and wide-ranging gifting and exchange. Ethnographic and archaeological evidence, as well as theory, shows that a commitment to temporally and spatially predictable and dense foods, such as coastal foods, stimulates territoriality, investment in boundary defense, and inter-group conflict. Inter-group conflict provides an ideal context for the proliferation of intra-group cooperative behaviors beneficial to the group but not to the altruist (Bowles, 2009; Bowles and Gintis, 2011), and I have hypothesized that this could be the first time in the evolutionary record of hominins in Africa that the conditions were optimal for the selection for the hyper-prosocial proclivities that characterize our species. The origins of this coastal adaptation marks a transformative point in the primary hunter-gatherer adaptation of the hominin lineage in Africa since the previous adaptive system was likely characterized by high residential mobility, low population levels, light technology, and low territoriality.

At this stage in research the earliest evidence for coastaline use is at $\sim 162 \mathrm{ka}$ at PP13B (Marean et al., 2007), and I have argued above that the earliest evidence for a coastal adaptation is $\sim 110 \mathrm{ka}$. Why did hominins fail to make this shift earlier? It is possible that the coastlines of the Cape remained outside their reach largely because they failed to recognize the lunar-driven schedule of the shellfish return rates, and thus were unable to develop a tactically designed mobility strategy that could move them to the coast during low spring tides and thus make the returns of shellfish gathering exceed the costs of being at the coast. At some point near the origin point of our lineage, perhaps in or shortly before MIS6, the ability to map onto a lunar 
${ }_{5}^{4} 1169$ schedule arose and the first coastline use occurred. Sometime after the first forays into the inter-

71170 tidal zone a coastline adaptation making use of significant amounts of inter-tidal shellfish arises 8

91171 in the Cape and this almost certainly triggered territoriality. That territoriality provided the 


\section{Acknowledgments}

I thank the MAPCRM staff for their assistance, the Dias Museum for field facilities, and SAHRA and HWC for permits. This research was funded by the National Science Foundation (\# BCS-9912465, BCS-0130713, BCS-0524087, and BCS-1138073 to Marean), the Hyde Family Foundation, and the Institute of Human Origins (IHO) at Arizona State University. I thank the following for comments and information: Nuno Bicho, Darren Fa, Emily Hallett-Desguez, Erella Hovers, Panagiotis Karkanas, Telmo Pereira, Miguel Cortés Sánchez, Tom Vollman, Sara Wurz, and João Zilhão. Erich Fisher and Ben Schoville assisted with the figures. Panagiotis Karkanas provided the block and thin section photography in Figure 6. Two referees provided very helpful comments. 


\section{References}

Aldeias, V. 2013. Contexte Géologique et Remplissage Sédimentaire. In: El Hajraoui, M. A.,

Debénath, A., Nespoulet, R., Dibble, H. (Eds.), Préhistoire de la région de Rabat-Témara. Villes

et Sites Archéologiques du Maroc (VESAM) Volume III. pp. 205-210.

Ames, K.M. 1994. The Northwest Coast: Complex Hunter-Gatherers, Ecology, and Social

Evolution. A. Rev. Anthropol. 23, 209-229.

Ames, K.M. 2001. Slaves, chiefs and labour on the northern Northwest Coast. World Archaeol.

$33,1-17$.

Antunes, M.T. 2000. The Pleistocene fauna from Gruta da Figueira Brava: a synthesis. Memorias da Academia das Ciencias de Lisboa. Classe de Ciencias 28, 259-282.

Arnold, J.E. 1992. Complex Hunter-Gatherer-Fishers of Prehistoric California: Chiefs,

Specialists, and Maritime Adaptations of the Channel Islands. Am. Antiq. 57, 60-84.

Arnold, J.E. 1993. Labor and the rise of complex hunter-gatherers. J. Anthropol. Archaeol. 12,

$75-119$.

Arnold, J.E. 1996. The Archaeology of Complex Hunter-Gatherers. J. Archaeol. Meth. Theory 3, $77-126$.

Arnold, J.E., Walsh, M.R. 2010. California's Ancient Past: From the Pacific to the Range of Light. The SAA Press, Washington D.C..

Avery, G. 1986. Sacred cows or jackel kitchens, hyaena middens and bird nests: some implications of multi-agent contributions to archaeological accumulations. In: Hall, M.J., Avery, 
${ }_{5}^{4} 1213$ G., Avery, D.M., Wilson, M.L., Humphemp, A.J.B. (Eds.), Frontiers: Southern African 
Berger, L.R., Parkington, J.E. 1995. A new Pleistocene hominid-bearing locality at

Hoedjiespunt, South Africa. Am. J. Phys. Anthropol. 98, 601-609.

Bicho, N., Haws, J. 2008. At the land's end: Marine resources and the importance of fluctuations in the coastline in the prehistoric huntergatherer economy of Portugal. Quatern. Sci. Rev. 27, 2166-2175.

Bicho, N. 2004. The Middle Paleolithic Occupation of southern Portugal. In: Conard, N. J. (Ed.), Settlement Dynamics of the Middle Paleolithic and Middle Stone Age. Kerns Verlag, Tubingen, pp. 513-531.

Binford, L. R. 1990. Mobility, housing, and environment: a comparative study. J. Anthropol. Res $119-152$.

Binford, L. R. 2001. Constructing Frames of Reference: An Analytical Method for

Archaeological Theory Building using Ethnographic and Environmental Data Sets. University of California Press, Berkeley.

Binford, L. R. 2004. Beliefs about Death, Behaviour, and Mortuary Practices among Huntergatherers: a Search for Causal Structure? In: McDonald Institute for Archaeological Research, University of Cambridge (Ed.), Explaining Social Change: Studies In Honour Of Colin Renfrew. Cambridge, UK, pp. 1-15.

Bird, D.W., Bliege-Bird, R., Richardson, J.L. 2004. Merian Ethnoarchaeology: Shellfishing and Shell Middens. Memoirs of the Queensland Museum 31, 183-197. 
Birdsell, J.B. 1953. Some Environmental and Cultural Factors Influencing the Structuring of Australian Aboriginal Populations. The American Naturalist 87, 171-207.

Boudad, L., El Hammouti, K., Nespoulet, R., El Hajraoui, M.A. 2013. Le Remplissage

Sédimentaire. Etude Préliminaire. In: El Hajraoui, M. A., Debénath, A., Nespoulet, R., Dibble, H. (Eds.), Préhistoire de la région de Rabat-Témara. Villes et Sites Archéologiques du Maroc (VESAM) Volume III. pp. 31-34.

Bouzouggar, A., Kozlowski, J.K., Otte, M. 2002. Étude des ensembles lithiques atériens de la grotte d' El Aliya á Tanger (Maroc). L'Anthropologie. 106, 207-248.

Bowles, S. 2009. Did Warfare Among Ancestral Hunter-Gatherers Affect the Evolution of Human Social Behaviors? Science 324, 1293-1298.

Bowles, S., Gintis, H. 2011. A Cooperative Species: Human Reciprocity and its Evolution.

Princeton University Press, Princeton.

Branch, G. 1994. Two Oceans: A Guide to the Marine Life of Southern Africa. D. Philip, Cape Town.

Branch, G. M., Branch, M. 1992. The Living Shores of Southern Africa. Struik Publishers, Cape Town.

Branch, G.M., Menge, B.A. 2001. Rocky Intertidal Communities. In: Bertness, Mark D., Gaines, Steven D., Hay, Mark E. (Eds.), Marine Community Ecology. Sinauer Associates, Inc., Sunderland, pp. 221-251. 
Braun, D.P. 1974. Explanatory Models for the Evolution of Coastal Adaptation in Prehistoric

Eastern New England. Am. Antiq. 39, 582-596.

Brink, J.S., Deacon, H.J. 1982. A study of a last interglacial shell midden and bone accumulation at Herolds Bay, Cape Province, South Africa. Paleoecol. Afr 15, 31-40.

Broadhurst, C.L., Wang,Y., Crawford, M.A., Cunnane, S.C., Parkington, J.E., Schmidt, W.F. 2002. Brain-specific lipids from marine, lacustrine, or terrestrial food resources: potential impact on early African Homo sapiens. Comp. Biochem. Physiol. B Biochem. Mol. Biol. 131, 653-673.

Brown, K.S., Marean, C.W., Herries, A.I.R., Jacobs, Z., Tribolo, C., Braun, D., Roberts, D.L.,

Meyer, M.C., Bernatchez, J. 2009. Fire as an Engineering Tool of Early Modern Humans.

Science $325,859-862$.

Brown, K.S., Marean, C.W., Jacobs, Z., Schoville, B.J., Oestmo, S., Fisher, E.C., Bernatchez, J., Karkanas, P., Matthews, T. 2012. An early and enduring advanced technology originating 71,000 years ago in South Africa. Nature 491, 590-593.

Butzer, K.W. 2004. Coastal eolian sands, paleosols, and Pleistocene geoarchaeology of the

Southwestern Cape, South Africa. J. Archaeol. Sci. 31, 1743-1781.

Carlson, B.A., Kingston, J.D. 2007. Docosahexaenoic acid biosynthesis and dietary contingency: Encephalization without aquatic constraint. Am. J. Hum. Biol. 19, 585-588.

Carpenter, A. 1887. Monkeys opening Oysters. Nature 36, 53.

Cashdan, E.A. 1983. Territorality among human foragers: ecological models and an application to four Bushmen groups. Curr. Anthrop. 24, 47-66. 
Charnov, E.L. 1976. Optimal foraging, the marginal value theorem. Theo. Pop. Bio. 9, 129-136.

Claassen, C. 1998. Shells. Cambridge University Press, Cambridge.

Cleyet-Merle, J.-J., Madelaine, S. 1995. Inland evidence of human sea coast exploitation in

Palaeolithic France. In: Fisher, Anders (Ed.), Man and Sea in the Mesolithic: Coastal Settlement Above and Below Present Sea Level. Oxbow, Exeter, pp. 303-308.

Colonese, A. C., Mannino, M.A., Bar-Yosef Mayer, D.E., Fa, D.A., Finlayson, J.C., Lubell, D., Stiner, M.C. 2011. Marine mollusc exploitation in Mediterranean prehistory: An overview.

Quatern. Int. 239, 86-103.

Cortés-Sánchez, M., Bao, J.F.G., Vallejo, M.D.S. 2011a. Level 14 of Bajondillo Cave and the end of the Middle Paleolithic in the south of the Iberian Peninsula. In: Conard, Nicholas J., Richter, Jürgen (Eds.), Springer, London, pp. 241-247.

Cortés-Sánchez, M., Morales-Muñiz, A., Simón-Vallejo, M. D., Lozano-Francisco, M. C., VeraPeláez, J. L., Finlayson, C., Rodríguez-Vidal, J., Delgado-Huertas, A., Jiménez-Espejo, F. J., Martínez-Ruiz, F., Aranzazu Martínez-Aguirre, M., Pascual-Granged, A. J., Mercé BergadáZapata, M., Gibaja-Bao, J. F., Sakai, S., Sugisaki, S., Finlayson, G., Fa, D. A., Bicho, N. F. 2011b. Earliest Known Use of Marine Resources by Neanderthals. PLoS ONE 6, e24026.

Cunnane, S.C., Plourde, M., Stewart, K., Crawford, M.A. 2007. Docosahexaenoic acid and shorebased diets in hominin encephalization: A rebuttal. Am. J. Hum. Biol. 19, 578-581.

Davidson, I., Noble,W. 1992. Why the First Colonisation of the Australian Region Is the Earliest Evidence of Modern Human Behaviour. Archaeology in Oceania 27, 135-142. 
${ }_{5}^{4} 1311$ de Lumley, H. 1969. A Paleolithic camp at Nice. Scientific American 220, 42-50.

81312 Deacon, H.J., Geleijnse,V.B. 1988. The stratigraphy and sedimentology of the Main site

sequence, Klasies River, South Africa. S. Afr. Archaeol. Bulln. 43, 5-14.

Deacon, J. 1984. Later Stone Age people and their descendants in southern Africa. In: Klein, R. G. (Ed.), Southern African Prehistory and Paleoenvironments. Balkema, Rotterdam, pp. 221328.

Dibble, H.L., Aldeias,V., Alvarez-Fernández, E., Blackwell, B.A.B., Hallett-Desguez, E., Jacobs, Z., Goldberg, P., Lin, S.C., Morala, A., Meyer, M.C., Olszewski, D.I., Reed, K., Reed, D.,

Rezek,Z., Richter, D., Roberts, R.G., Sandgathe, D., Schurmans, U., Skinner, A.R., Steele, T.E., el-Hajraoui, M. 2012. New Excavations at the Site of Contrebandiers Cave, Morocco.

PaleoAnthropology 2012, 145-201.

Dyson-Hudson, R., Smith, E.A. 1978. Human territoriality: an ecological reassessment. Amer. Anthropol. 80, 21-41.

El Hajraoui, M.A., Debénath, A. 2013. Contexte Géologique et Remplissage Sédimentaire. In: El Hajraoui, M.A., Debénath, A., Nespoulet, R., Dibble, H. (Eds.), Préhistoire de la région de Rabat-Témara. Villes et Sites Archéologiques du Maroc (VESAM) Volume III. pp. 108-109.

Erlandson, J.M. 1988. The role of shellfish in prehistoric economies: a protein perspective. Am. Antiq. 53, 102-109.

Erlandson, J.M. 2001. The Archaeology of Aquatic Adaptations: Paradigms for a New Millennium. J. Arch. Res. 9, 287-350. 
Erlandson, J. M., Moss, M.L. 2001. Shellfish feeders, carrion eaters, and the archaeology of aquatic adaptations. Am. Antiq. 66, 413-432.

Erlandson, J.M., Graham, M.H., Bourque, B.J., Corbett, D., Estes, J.A., Steneck, R.S. 2007. The Kelp Highway Hypothesis: Marine Ecology, the Coastal Migration Theory, and the Peopling of the Americas. The Journal of Island and Coastal Archaeology 2, 161-174.

Fa, D.A. 2008. Effects of tidal amplitude on intertidal resource availability and dispersal pressure in prehistoric human coastal populations: the Mediterranean-Atlantic transition. Quatern. Sci. Rev. 27, 2194-2209.

Fa, D.A. 2013. A report on the marine mollusca from the Gorham's Cave excavations 19982005: Preliminary results and interpretation. In: Finlayson, Clive, Pacheco, Francison Giles, Vidal, Joaquin Rodriquez (Eds.), Where the Last Neanderthals Lived: A Study of Neanderthal and Modern Human Behavioural Ecology in a Glacial Refugium. Oxbow Books, Oakville, CA.

Feathers, J.K., Bush, D.A. 2000. Luminescence dating of Middle Stone Age deposits at Die

Kelders. J. Hum. Evol. 38, 91-120.

Fernandes, M. 1991. Tool use and predation of oysters (\&lt;i\&gt;Crassostrea

rhizophorae\&lt;/i\&gt;) by the tufted capuchin,\&lt;i\&gt;Cebus apella appella\&lt;/i\&gt;, in brackish water mangrove swamp. Primates 32, 529-531.

Finlayson, C. 2008. On the importance of coastal areas in the survival of Neanderthal populations during the Late Pleistocene. Quatern. Sci. Rev. 27, 2246-2252. 
Finlayson, C., Giles Pacheco, F., Rodriguez-Vidal, J., Fa, D.A., Maria Gutierrez Lopez, J.,

Santiago Perez, A., Finlayson, G., Allue, E., Baena Preysler, J., Caceres, I., Carrion, J.S.,

Fernandez Jalvo, Y., Gleed-Owen, C.P., Jimenez Espejo, F.J., Lopez, P., Antonio Lopez Saez, J., Antonio Riquelme Cantal, J., Sanchez Marco, A., Giles Guzman, F., Brown, K., Fuentes, N., Valarino, C.A., Villalpando, A., Stringer, C.B., Martinez Ruiz, F., Sakamoto, T. 2006. Late survival of Neanderthals at the southernmost extreme of Europe. Nature 443, 850-853.

Fisher, E.C., Bar-Matthews, M., Jerardino, A., Marean, C.W. 2010. Middle and Late Pleistocene Paleoscape Modeling along the Southern Coast of South Africa. Quatern. Sci. Rev. 29, 13821398.

Fitzhugh, W. W. 1972. Environmental archaeology and cultural systems in Hamilton Inlet, Labrador . Smithsonian Institution Press, Washington D.C..

Foley, R., Lahr, M. 1997. Mode 3 technologies and the evolution of modern humans. Cambridge Archaeological Journal 1, 3-36.

Garrod, D.A.E., Buxton, L.H.D., Smith, G.E., Bate, D.M.A., Spiller, R.C., Hinton, M.A.C., Fischer, P. 1928. Excavation of a Mousterian rock-shelter at Devil's Tower, Gibraltar. Journal of the Royal Anthropological Institute of Great Britain and Ireland 33-113.

Gat, A. 1999. The pattern of fighting in simple, small-scale, prestate societies. J. Anthropol. Res $563-583$.

Gat, A. 2000a. The human motivational complex: Evolutionary theory and the causes of huntergatherer fighting, part II. Proximate, subordinate, and derivative causes. Anthropological Quarterly 74-88. 
${ }_{5}^{4} 1371$ Gat, A. 2000b. The human motivational complex: evolutionary theory and the causes of huntergatherer fighting. Part I. Primary somatic and reproductive causes. Anthropological Quarterly 20-34.

Goldberg, P. 2000. Micromorphology and site formation at Die Kelders Cave 1, South Africa. J. Hum. Evol. 38, 43-90.

Goldberg, P., Sherwood, S. 2006. Deciphering Human Prehistory Through the Geoarcheological Study of Cave Sediments. Evol. Anthropol. 15, 20-36.

Gonder, M.K., Mortensen, H.M., Reed, F.A., de Sousa, A., Tishkoff, S.A. 2007. Whole-mtDNA Genome Sequence Analysis of Ancient African Lineages. Molec. Bio. Evol. 24, 757-768.

Gumert, M.D., Hoong,L.K., Malaivijitnond,S. 2011. Sex differences in the stone tool-use behavior of a wild population of burmese long-tailed macaques (Macaca fascicularis aurea). Am. J. Primatol. 73, 1239-1249.

Gumert, M.D., Kluck, M., Malaivijitnond, S. 2009. The physical characteristics and usage patterns of stone axe and pounding hammers used by long-tailed macaques in the Andaman Sea region of Thailand. Am. J. Primatol. 71, 594-608.

Halkett, D., Hart, T., Yates, R., Volman, T.P., Parkington, J.E., Orton, J., Klein, R.G., CruzUribe, K., Avery, G. 2003. First excavation of intact Middle Stone Age layers at Ysterfontein, Western Cape Province, South Africa: implications for Middle Stone Age ecology. J. Archaeol. 1389 Sci. 30, 955-971. 
Hall, K.R.L. 1962. Numerical data, maintenance activities and locomotion of the wild Chacma baboon, Papio ursinus. Proc. Zool. Soc. Lond. 139, 181-220.

Hallam, S.J. 1987. Coastal Does Not Equal Littoral. Australian Archaeology 10-29.

Hallmann, N., Burchell, M., Schöne, B.R., Irvine, G.V., Maxwell, D. 2009. High-resolution sclerochronological analysis of the bivalve mollusk Saxidomus gigantea from Alaska and British

Columbia: techniques for revealing environmental archives and archaeological seasonality. J. Archaeol. Sci. 36, 2353-2364.

Hawes, J.A., Funk, C.L., Benedetti, M.M., Bicho, N.F., Daniels, J.M., Minckley, T.A., Denniston, R.F., Jeraj, M., Gibaja, J.F., Hocket, B.S., Forman, S.L. 2011. Paleolithic landscape and seascapes of the west coast of Portugal. In: Bicho, Nuno, Haws, Jonathan A., Davis, Loren G. (Eds.), Trekking the Shore: Changing Coastlines and the Antiquity of Coastal Settlement. Springer, New York, pp. 203-246.

Hearty, P.J., Hollin,J.T., Neumann, A.C., O’Leary, M.J., McCulloch, M. 2007. Global sea-level fluctuations during the Last Interglaciation (MIS 5e). Quatern. Sci. Rev. 26, 2090-2112.

Heinz, H.J. 1972. Territoriality among the Bushmen in general and the !ko in particular. Anthropos 67, 405-416.

Henrich, J. 2004. Demography and cultural evolution: How adaptive cultural processes can produce maladaptive losses: the Tasmanian case. Am. Antiq. 69, 197-214.

Henshilwood, C.S., Sealy, J.C., Yates, R.J., Cruz-Uribe, K., Goldberg, P., Grine, F.E., Klein, R.G., Poggenpoel, C., van Niekerk, K., Watts, I. 2001. Blombos Cave, southern Cape, South 
Africa: Preliminary report on the 1992-1999 excavations of the Middle Stone Age levels. J. 
Karkanas, P., Goldberg, P. 2010. Site formation processes at Pinnacle Point Cave 13B (Mossel

Bay, Western Cape Province, South Africa): resolving stratigraphic and depositional

complexities with micromorphology. J. Hum. Evol. 59, 256-273.

Keeley, L.H. 1988. Hunter-gatherer economic complexity and 'population pressure": a crosscultural analysis. J. anthrop. Arch. 7, 373-411.

Keeley, L.H. 1996. War before Civilization. Oxford University Press, New York.

Kelly, R. 1992. Mobility/sedentism: concepts, archaeological measures, and effects. A. Rev. Anthropol. 21, 43-66.

Kelly, R.L. 1983. Hunter-gatherer mobility strategies. J. Anthropol. Res 39, 277-306.

Kelly, R.L. 1995. The Foraging Spectrum. Smithsonian Institution Press, Washington D.C..

Kelly, R.C. 2000. Warless Societies and the Origin of War. University of Michigan Press, Ann Arbor.

Kennett, D.J. 2005. The Island Chumash: Behavioral Ecology of a Maritime Society. University of California Press, Berkeley.

King, A.R. 1950. Cattle Point: A Stratified Site in the Southern Northwest Coast Region.

Memoirs of the Society for American Archaeology 7, 1-94.

Klein, R.G. 1983. Palaeoenvironmental implications of Quaternary large mammals in the Fynbos Region. In: Deacon, H. J., Hendey, Q. B., Lambrechts, J. J. N. (Eds.), Fynbos Palaeoecology: A preliminary synthesis. Cooperative Scientific Programmes, Pretoria, pp. 116-138. 
Klein, R.G., Cruz-Uribe, K. 1996. Exploitation of large bovids and seals at Middle and Later

Stone Age sites in South Africa. J. Hum. Evol. 31, 315-334.

Klein, R.G., Cruz-Uribe, K. 2000. Middle and Later Stone Age large mammal and tortoise remains from Die Kelders Cave 1, Western Cape Province, South Africa. J. Hum. Evol. 38, 169196.

Klein, R.G., Avery, G., Cruz-Uribe, K., Halkett, D., Parkington, J.E., Steele, T., Volman, T.P., Yates, R. 2004. The Ysterfontein 1 Middle Stone Age site, South Africa, and early human exploitation of coastal resources. PNAS 101, 5708-5715.

Kroeber, A.L. 1939. Cultural and natural areas of native North America. University of California Publications in American Archaeology and Ethnology 1-242.

Kyle, R., Pearson, B., Fielding, P.J., Robertson, W.D., Birnie, S.L. 1997a. Subsistence shellfish harvesting in the Maputaland Marine Reserve in northern KwaZulu-Natal, South Africa: Rocky shore organisms. Biological Conservation 82, 183-192.

Kyle, R., Robertson, W.D., Birnie, S.L. 1997b. Subsistence shellfish harvesting in the Maputaland Marine Reserve in northern KwaZulu-Natal, South Africa: Sandy beach organisms. Biological Conservation 82, 173-182.

Lahr, M., Foley, R. 2001. Mode 3, Homo helmei, and the pattern of human evolution in the Middle Pleistocene. In: Barham, L. S., Robson-Brown, K. (Eds.), Human Roots: Africa and Asia in the Middle Pleistocene. Western Academic and Specialist Press Limited, Bristol, pp. 2340. 
Lahr, M.M., Foley, R.A. 1998. Towards a Theory of Modern Human Origins: Geography,

Demography, and Diversity in Recent Human Evolution. Yearbook of Physical Anthroplogy 41, $137-176$.

Lambert, P. M. 1997. Patterns of violence in prehistoric hunter-gatherer societies of coastal southern California. In: Martin, Debra L., Frayer, David W. (Eds.), Troubled Times: Violence and Warfare in the Past, Amsteldijk, Amsterdam, pp. 77-110.

Lambert, P.M. 2002. The archaeology of war: A North American perspective. J. Arch. Res. 10, 207-241.

Langdon, J.H. 2006. Has an aquatic diet been necessary for hominin brain evolution and functional development? British Journal of Nutrition 96, 7-17.

Langejans, G.H.J., van Niekerk,K.L., Dusseldorp, G.L., Thackeray, J.F. 2012. Middle Stone Age shellfish exploitation: Potential indications for mass collecting and resource intensification at Blombos Cave and Klasies River, South Africa. Quatern. Int. 270, 80-94.

Lasiak, T.A. 1992. Contemporary shellfish-gathering practices of indigenous coastal people in Transkei: some implications for interpretation of the archaeological record. S. Afr. J. Sci. 88, 1928.

Lasiak, T.A. 1993. Temporal and spatial variations in exploited and non-exploited populations of the intertidal limpet Cellana capensis. Journal of Molluscan Studies 59, 295-307.

Macphail, R. I., Goldberg, P. 2000. Geoarchaeological Investigation of Sediments from Gorham's and Vanguard Caves, Gibraltar: Microstratigraphical (Soil Micromorphological and 
Chemical) Signatures. In: Stringer, C. B., Barton, R. N. E., Finlayson, J. C. (Eds.), Neanderthals on the Edge. Oxbow Books, Oakville, pp. 183-200.

Malaivijitnond, S., Lekprayoon, C., Tandavanittj, N., Panha, S., Cheewatham, C., Hamada, Y. 2007. Stone-tool usage by Thai long-tailed macaques (Macaca fascicularis). Am. J. Primatol. 69, 227-233.

Marean, C.W., Abe, Y., Frey, C.J., Randall, R.C. 2000a. Zooarchaeological and taphonomic analysis of the Die Kelders Cave 1 Layers 10 and 11 Middle Stone Age larger mammal fauna. J. Hum. Evol. 38, 197-233.

Marean, C.W., Goldberg, P., Avery, G., Grine, F.E., Klein, R.G. 2000b. Middle Stone Age stratigraphy and excavations at Die Kelders Cave 1 (Western Cape Province, South Africa): the 1992, 1993, and 1995 field seasons. J. Hum. Evol. 38, 7-42.

Marean, C.W. 2010a. Introduction to the Special Issue--The Middle Stone Age at Pinnacle Point Site 13B, a Coastal Cave near Mossel Bay (Western Cape Province, South Africa). J. Hum. Evol. $59,231-233$.

Marean, C.W. 2010b. Pinnacle Point Cave 13B (Western Cape Province, South Africa) in context: The Cape Floral kingdom, shellfish, and modern human origins. J. Hum. Evol. 59, 425443.

Marean, C. W. 2011. Coastal South Africa and the co-evolution of the modern human lineage and coastal adaptations. In: Bicho, Nuno, Haws, Jonathan A., Davis, Loren G. (Eds.), Trekking the Shore: Changing Coastlines and the Antiquity of Coastal Settlement. Springer, New York, pp. 421-440. 
Marean, C.W., Bar-Matthews, M., Bernatchez, J., Fisher, E., Goldberg, P., Herries, A.I.R.,

Jacobs, Z., Jerardino, A., Karkanas, P., Minichillo, T., Nilssen, P.J., Thompson, E., Watts, I., Williams, H.M. 2007. Early human use of marine resources and pigment in South Africa during the Middle Pleistocene. Nature 449, 905-908.

Marean, C.W., Bar-Matthews, M., Fisher, E., Goldberg, P., Herries, A., Karkanas, P., Nilssen, P.J., Thompson, E. 2010. The stratigraphy of the Middle Stone Age sediments at Pinnacle Point Cave 13B (Mossel Bay, Western Cape Province, South Africa). J. Hum. Evol. 59, 234-255.

Marlowe, F.M., Berbesque, J.C. 2009. Tubers as fallback foods and their impact on Hadza hunter-gatherers. Am. J. Phys. Anthropol. 140, 751-758.

Marlowe, F.W. 2005. Hunter-gatherers and human evolution. Evol. Anthropol. 14, 54-67.

Marquet, P.A., Santoro, C.M., Latorre, C., Standen,V.G., Abades, S.R., Rivadeneira, M.M., Arriaza, B., Hochberg, M.E. 2012. Emergence of social complexity among coastal huntergatherers in the Atacama Desert of northern Chile. PNAS 109, 14754-14760.

Maschner, H.D.G., Reedy-Maschner,K.L. 1998. Raid, retreat, defend (repeat): the archaeology and ethnohistory of warfare on the North Pacific Rim. J. Anthropol. Archaeol. 17, 19-51.

1541 Mather, A.A., Garland,G.G., Stretch,D.D. 2009. Southern African sea levels: corrections, influences and trends. African Journal of Marine Science 31, 145-156.

McArthur, R.H., Pianka, E.R. 1966. On the optimal use of a patchy environment. Am. Nat. 100, 603-609. 

71546 Highlands. Cambridge. 631-652. D.C..

Meehan, B. 1982. Shell Bed To Shell Midden. Australian Institute of Aborginal Studies, Atlantic

Mitchell, P. 2002. The Archaeology of Southern Africa. Cambridge University Press,

Montes, R. 1991. La Cueva de los Aviones. Un yacimiento del Paleolítico Medio (Cartagena, Spain). Memorias de Arqueología de la Región de Murcia 2, 35-58.

Moss, M.L. 1993. Shellfish, Gender, and Status on the Northwest Coast: Reconciling Archeological, Ethnographic, and Ethnohistorical Records of the Tlingit. Amer. Anthropol. 95,

Moss, M. L. 2011. Northwest Coast: Archaeology as Deep History. The SAA Press, Washington,

Moss, M.L., Jon,M.E. 1992. Forts, Refuge Rocks, and Defensive Sites: The Antiquity of Warfare along the North Pacific Coast of North America. Arctic Anthropology 29, 73-90.

Nespoulet, R., El Hajraoui, M. A. 2013. Présentation Du Site Et Archéostratigraphie. In: El Hajraoui, M. A., Debénath, A., Nespoulet, R., Dibble, H. (Eds.), Préhistoire de la région de Rabat-Témara. Villes et Sites Archéologiques du Maroc (VESAM) Volume III. pp. 27-30.

O'Connell, J. F., Allen, J., Hawkes, K. 2010. Pleistocene Sahul and the Origins of Seafaring. In: Anderson, A., Barrett, J., Boyle, K. (Eds.), The Global Origins and Development of Seafaring. McDonald Institute for Archaeological Research, Cambridge, pp. 57-68. 
Oswalt, W. H. 1973. Habitat and Technology: The Evolution of Hunting. Holt, Reinhart and

Winston, Inc., New York.

Oswalt, W. H. 1976. An Anthropological Analysis of Food-Getting Technology. John Wiley and Sons, New York.

Otterbein, K. F. 2004. How War Began. Texas A \& M University, College Station, TX.

Parkington, J. 1976. Coastal settlement between the mouths of the Berg and Olifants Rivers, Cape Province. S. Afr. Archaeol. Bulln. 31, 127-140.

Parkington, J.E. 1972. Seasonal mobility in the late stone age. African Studies 31, 223-244.

Parkington, J. 2003. Middens and moderns: shellfishing and the Middle Stone Age of the

Western Cape, South Africa. S. Afr. J. Sci. 99, 243.

Parkington, J. 2006. Shorelines, Strandlopers and Shell Middens. Krakadouw Trust, Cape Town.

Parkington, J. E. 2001. Milestones: the Impact of the Systematic Exploitation of Marine Foods on Human Evolution. In: Tobias, P. V., Raath, M. A., Moggi-Cecci, J., Doyle, G. A. (Eds.), Humanity from African Naissance to Coming Millennia. Firenze University Press, Firenze, pp. 327-336.

Perlman, S.M. 1980. An optimum diet model, coastal variability, and hunter-gatherer behavior. Advances in archaeological method and theory 3, 257-310. 
Petersen, N. 1975. Hunter-gatherer territoriality: the perspective from Australia. American

Petersen, N. 1979. Territorial adaptations among desert hunter-gatherers: the !Kung and Australians compared. In: Burnham, P., Ellen, R. (Eds.), Social and Ecological Systems.

Academic Press, New York, pp. 112-129.

Powell, A., Shennan,S., Thomas,M.G. 2009. Late Pleistocene Demography and the Appearance of Modern Human Behavior. Science 324, 1298-1301.

Reese, D. 1998. Middle Paleolithic shells from Ras El-Kelb. In: Copeland, Lorraine, Moloney, Norah (Eds.), The Mousterian Site of Ra El-Kelb. British Archaeological Reports, Oxford, pp. 67.

Richerson, P. J., Boyd, R. 2005. Not by Genes Alone. University of Chicago Press, Chicago.

Rick,T.C., andJ.M.Erlandson. 2009. Coastal Exploitation. Science 325:952-953.

Roche, J., Texier,J.-P. 1976. Découverte de restes humains dans un niveau atérien supérieur de la grotte des Contrebandiers, à Temara (Maroc). Comptes Rendues Académie des Sciences Paris $282,45-47$.

Ruhlmann, A. 1951. La Grotte Préhistorique de Dar es-Soltan. Larose, Paris.

Schapera, I., Farrington, E. 1933. The early Cape Hottentots. Van Riebeeck Society, Cape Town.

Schwarcz, H.P., Rink,W.J. 2000. ESR dating of the Die Kelders Cave 1 Site, South Africa. J. Hum. Evol. 38, 121-128. 
Sealy, J.C., Sillen,A. 1988. Sr and Sr/Ca in marine and terrestrial foodwebs in the Southwestern

Cape, South Africa. J. Archaeol. Sci. 15, 425-438.

Sealy, J. C., Van der Merwe, N. J. 1987. Stable carbon isotopes, Later Stone Age diets and seasonal mobility in the South-western Cape. In: Parkington, J., Hall, M. (Eds.), Papers in the Prehistory of the Western Cape, South Africa. BAR International, Oxford, pp. 262-268.

Shennan, S. 2001. Demography and cultural innovation: a model and its implications for the emergence of modern human culture. Cambridge Archaeological Journal 11, 5-16.

Shott, M. 1986. Technological Organization and Settlement Mobility: An Ethnographic

Examination. J. Anthropol. Res 42, 15-51.

Singer, R., Wymer, J. 1982. The Middle Stone Age at Klasies River Mouth in South Africa.

University of Chicago Press.

Smith, M.W. 1956. The cultural development of the Northwest Coast. Southwestern Journal of Anthropology 272-294.

Snow, D.R. 1972. Rising sea level and prehistoric cultural ecology in northern New England. Am. Antiq. 211-221.

Speck, F.G., Eiseley,L.C. 1939. Significance of Hunting Territory Systems of the Algonkian in Social Theory. Amer. Anthropol. 41, 269-280.

Steele, T. E. 2013. Late Pleistocene Human Subsistence in Northern Africa: The State of our Knowledge and Placement in a Continental Context. In: Hublin, Jean-Jacques, McPherron, 

71622 107-125.

Shannon P. (Eds.), Modern Origins: A North African Perspective. Springer, New York, pp.

Steele, T. E., Álvarez-Fernádez, E. 2011. Initial investigations into the exploitation of coastal resources in North Africa during the late Pleistocene at Grotte Des Contrebandiers, Morocco. In:

Bicho, Nuno, Haws, Jonathan A., Davis, Loren G. (Eds.), Trekking the Shore: Changing

Coastlines and the Antiquity of Coastal Settlement. Springer, New York, pp. 383-403.

Stephens, D., Krebs, J. 1986. Foraging Theory. Princeton University Press, Princeton.

Stiner, M.C., Munro,N.D., Surovell,T.A. 2000. The tortoise and the hare: small-game use, the broad-spectrum revolution, and Paleolithic demography. Curr. Anthrop. 41, 39-73.

Stiner, M.C., Munro,N.D., Surovell,T.A., Tchernov,E., Bar-Yosef,O. 1999. Paleolithic

population growth pulses evidenced by small animal exploitation. Science 283, 190-194.

Stiner, M. C. 1994. Honor Among Thieves: A Zooarchaeological Study of Neandertal Ecology. Princeton University Press, Princeton.

Stiner, M.C. 2001. Thirty years on the "Broad Spectrum Revolution" and paleolithic demography. PNAS 98, 6993-6996.

Stoetzel,E., E.Campmas, P.Michel, B.Bougariane, B.Ouchaou, F.Amani, M.A.El Hajraoui, and R.Nespoulet. 2013. Context of modern human occupations in North Africa: Contribution of the Témara caves data. Quatern. Int. in press.

Straus, L. G. 1992. Iberia before the Iberians: The Stone Age Prehistory of Cantabria Spain. University of New Mexico Press, Albuquerque. 
Stringer, C.B., Finlayson, J.C., Barton, R.N.E., Fernández-Jalvo,Y., Cáceres, I., Sabin, R.C., Rhodes, E.J., Currant, A.P., Rodríguez-Vidal, J., Giles-Pacheco,F., Riquelme-Cantal,J.A. 2008.

Neanderthal exploitation of marine mammals in Gibraltar. PNAS 105, 14319-14324.

Stynder, D.D., Moggi-Cecchi, J., Berger, L.R., Parkington, J.E. 2001. Human mandibular incisors from the late Middle Pleistocene locality of Hoedjiespunt 1, South Africa. J. Hum. Evol. 41, 369-383.

Tankard, A.J., Schweitzer, F.R. 1974. The geology of Die Kelders cave and environs: a

palaeoenvironmental study. S. Afr. J. Sci. 70, 365-369.

Thackeray, J.F. 1988. Molluscan Fauna from Klasies River, South Africa. The South African Archaeological Bulletin 43, 27-32.

Thompson, J.C. 2010. Taphonomic analysis of the Middle Stone Age faunal assemblage from

Pinnacle Point Cave 13B, Western Cape, South Africa. J. Hum. Evol. 59, 321-339.

Tindale, N. B. 1974. Aboriginal tribes of Australia, their terrain, environmental controls, distribution, limits, and proper names. University of California Press.

Tomalin, B.J., Kyle, R.. 1998. Subsistence and recreational mussel (Perna perna) collecting in KwaZulu-Natal, South Africa: fishing mortality and precautionary management. South African Journal of Zoology 33.

Tribolo, C., Mercier,N., Selo, M., Valladas, H., Joron, J.L., Reyss, J.L., Henshilwood, C., Sealy, J., Yates, R. 2006. TL dating of burnt lithics from Blombos Cave (South Africa): further evidence for the antiquity of modern human behaviour. Archaeometry 48, 341-357. 
Van Andel, T.H. 1989. Late Pleistocene Sea Levels and the Human Exploitation of the Shore and Shelf of Southern South Africa. J. Field. Arch. 16, 133-155.

Van Erkom Schurink, C., Griffiths, C.L. 1991. A comparison of reproductive cycles and reproductive output in four southern African mussel species. Marine ecology progress series. Oldendorf 76, 123-134.

Villa, P. 1983. Terra Amata and the Middle Pleistocene Archaeological Record of Southern France. University of California Press, Berkeley.

Voigt, E. 1973a. Klasies River Mouth Cave: An exercise in shell analysis. Bulletin of the Transvaal Museum 14, 14-15.

Voigt, E. 1973b. Stone age molluscan utilization at Klasies River Mouth Caves. S. Afr. J. Sci. 69, 306-309.

Voigt, E. A. 1982. The Molluscan Fauna. In: Singer, Ronald, Wymer, John (Eds.), The Middle Stone Age at Klasies River Mouth in South Africa. University of Chicago Press, Chicago, pp. 155-186.

Volman, T.P. 1978. Early archeological evidence for shellfish collecting. Science 201, 911-913.

Will, M., Parkington, J.E., Kandel, A.W., Conard, N.J. 2013. Coastal adaptations and the Middle Stone Age lithic assemblages from Hoedjiespunt 1 in the Western Cape, South Africa. J. Hum. Evol. 64, 518-537.

Wilson, E. O. 1975. Sociobiology: The New Synthesis. Harvard University Press, Cambridge, MA. 
${ }_{5}^{4} 1681$ Yesner, D.R., Ayres, W.S., Carlson, D.L., Davis, R.S., Dewar,R., Morales, M.R.G., Hassan, 6

71682 F.A., Hayden, B., Lischka, J.J., Sheets, P.D. 1980. Maritime hunter-gatherers: ecology and 8 91683 prehistory [and comments and reply]. Curr. Anthrop. 727-750. 


\section{Figure 1}

Click here to download high resolution image

A
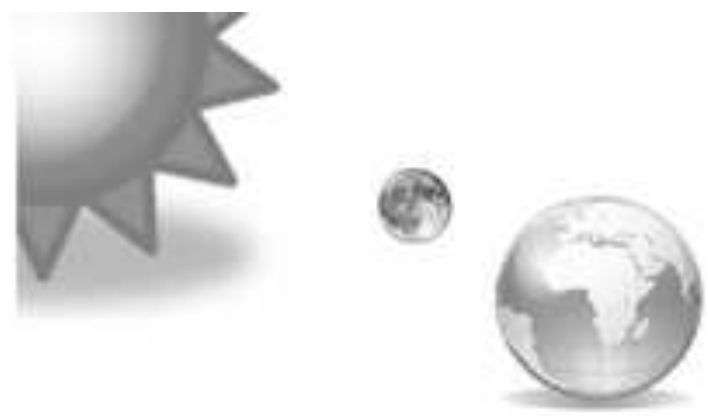

\section{Low Spring Tide Availability}
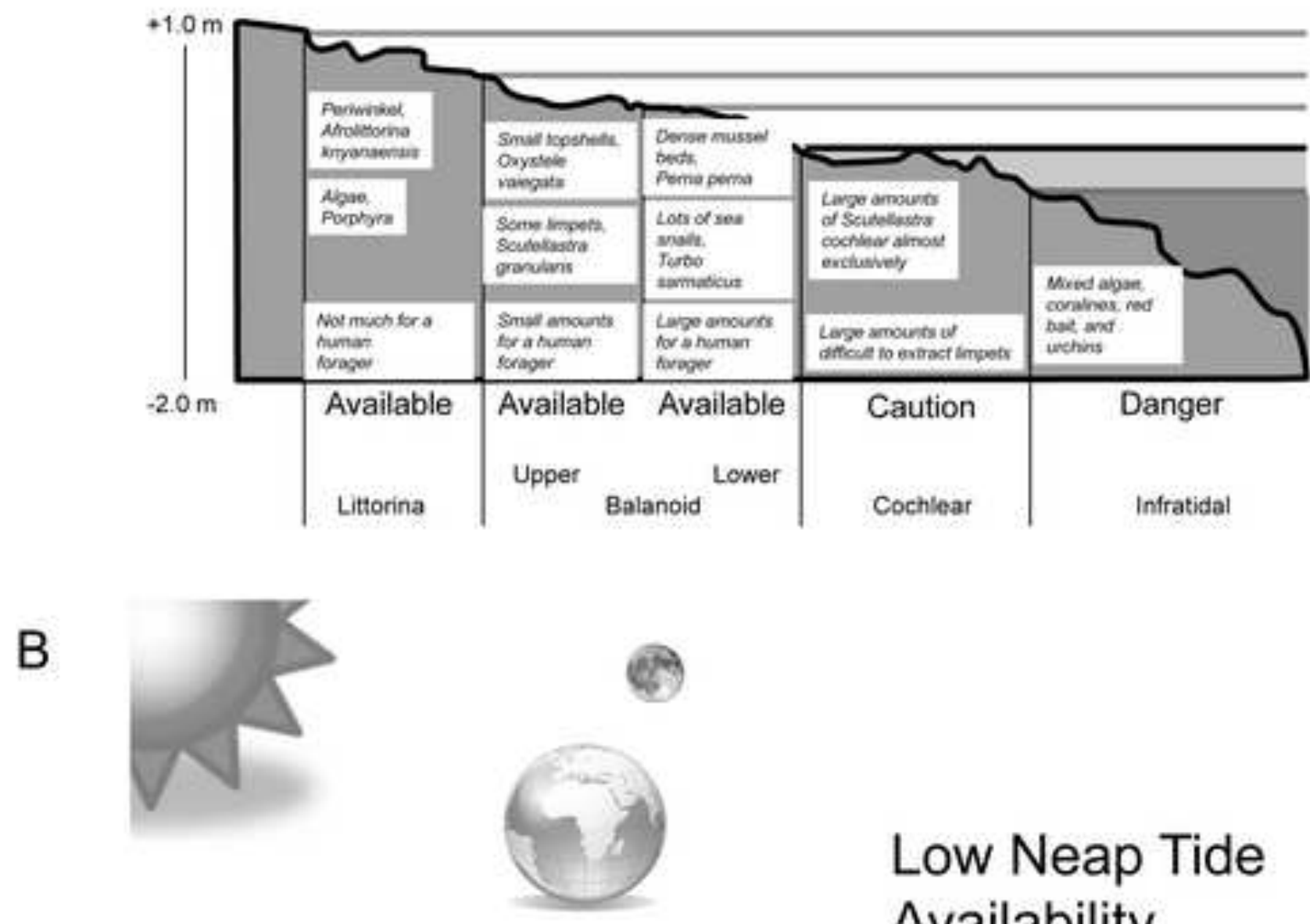

\section{Low Neap Tide Availability}

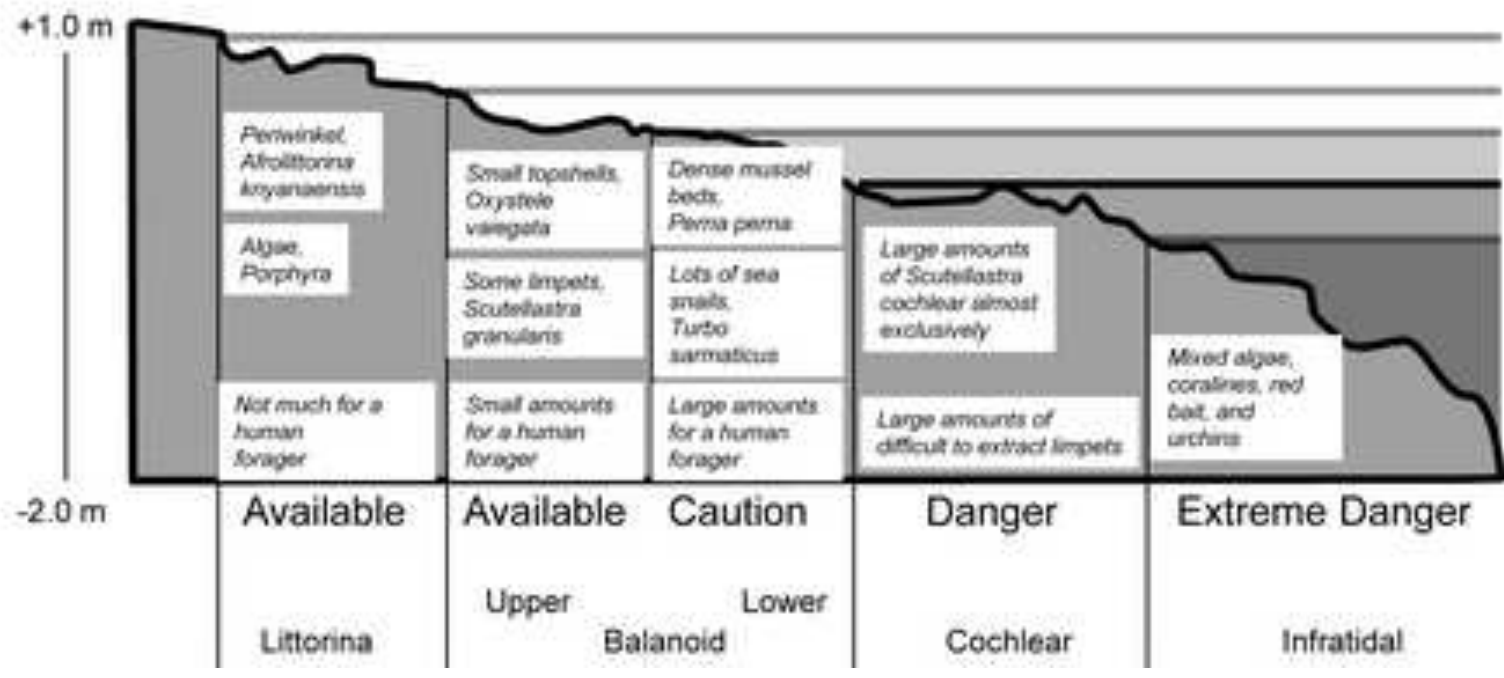




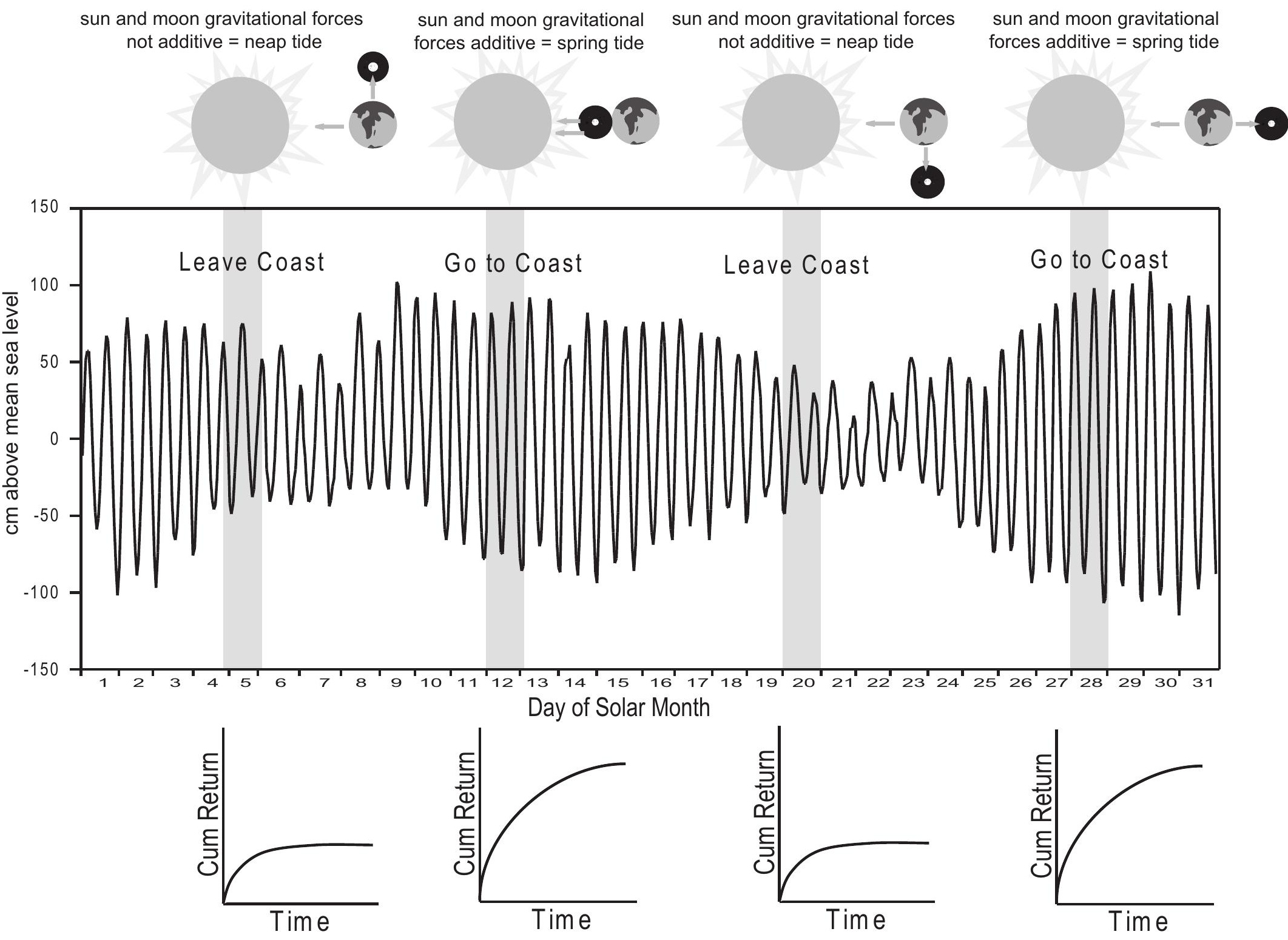




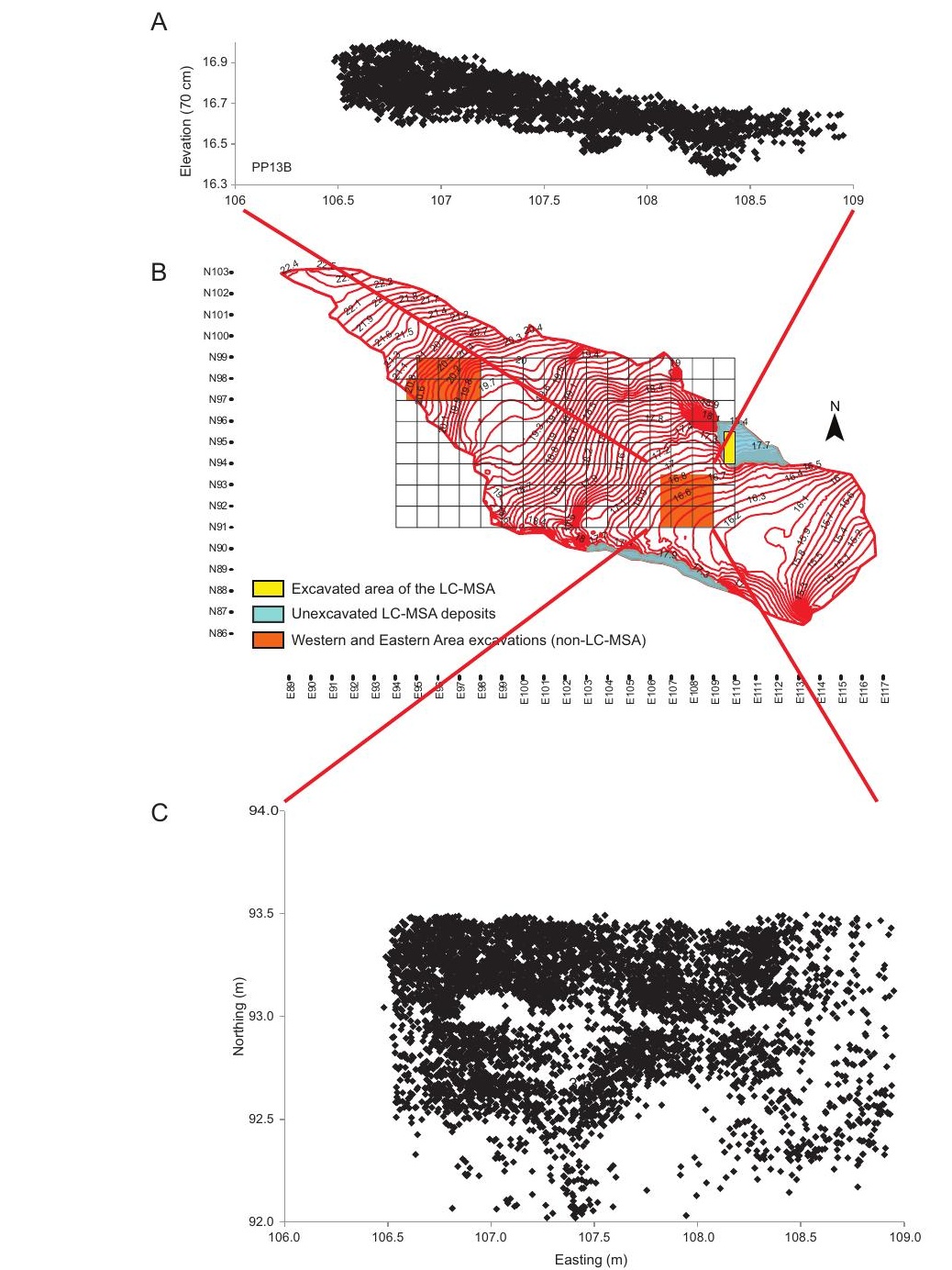

Figure 3 Color

Figure 3 Color 
Figure 3 BW

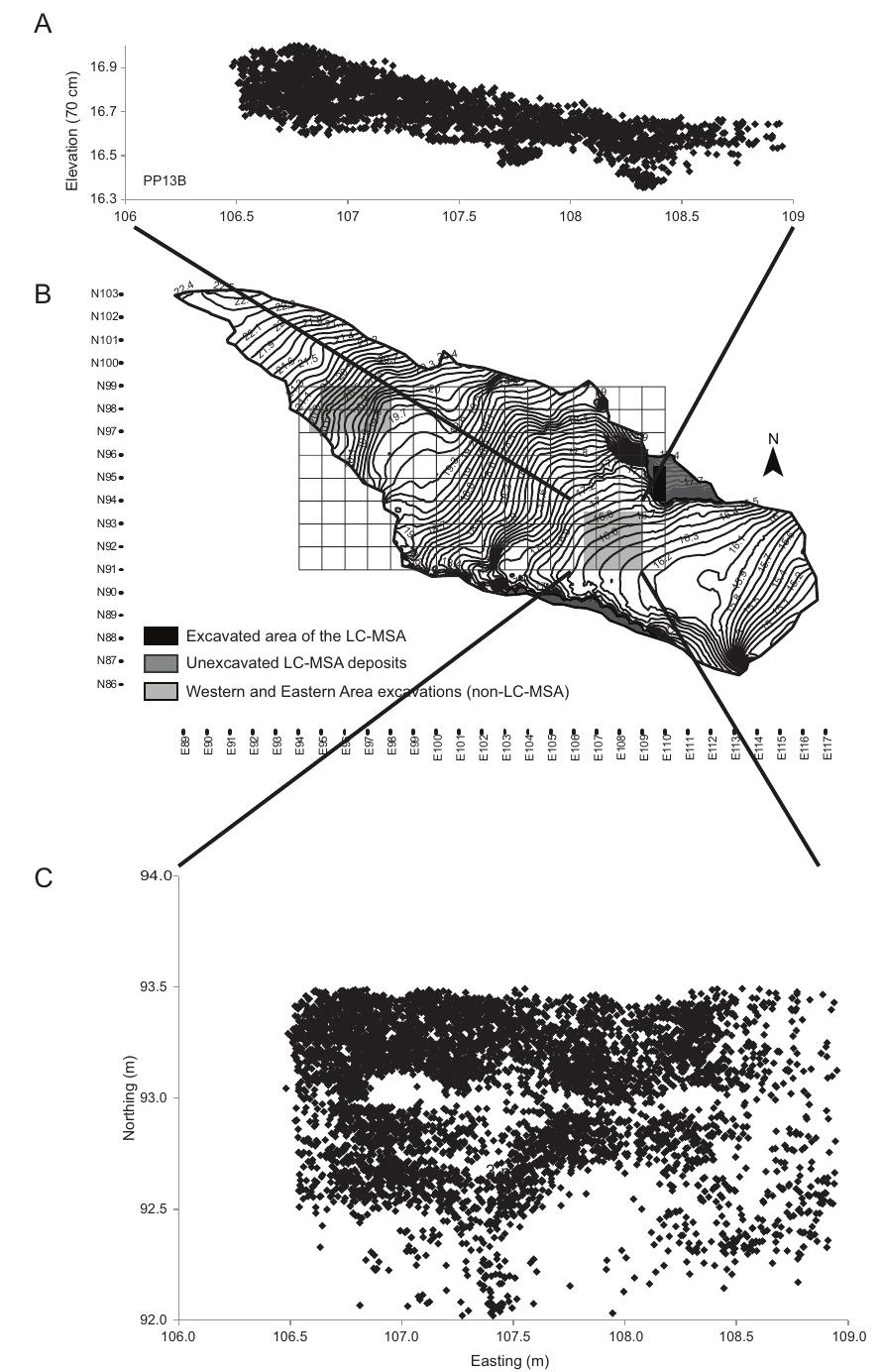

Figure 3 BW

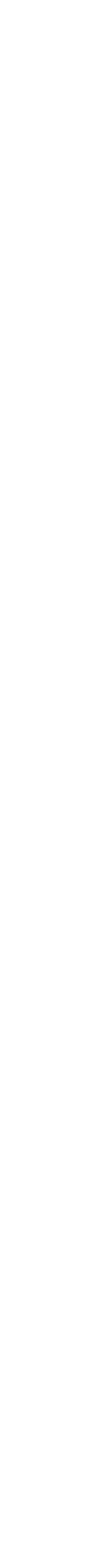


Click here to download high resolution image

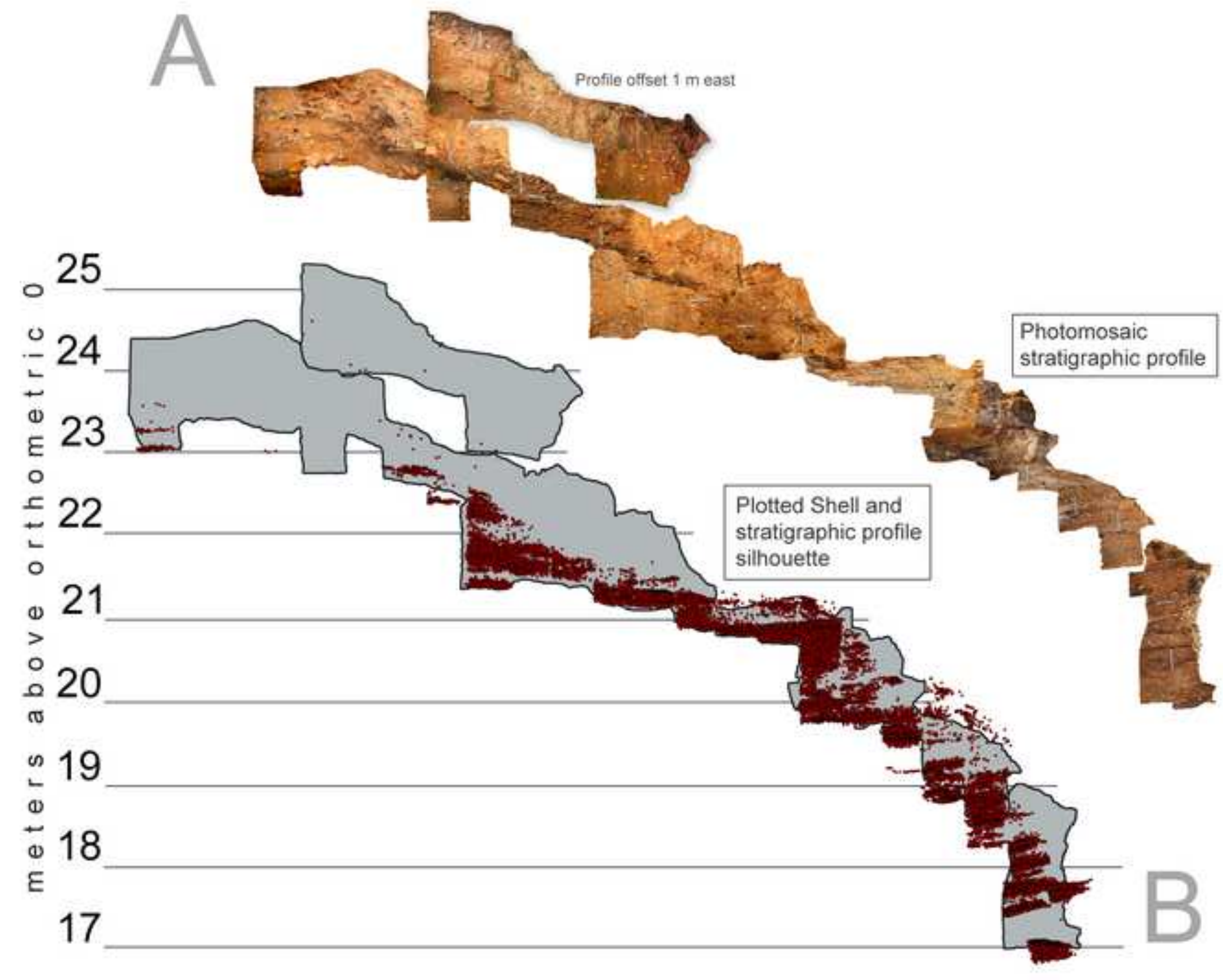


Click here to download high resolution image

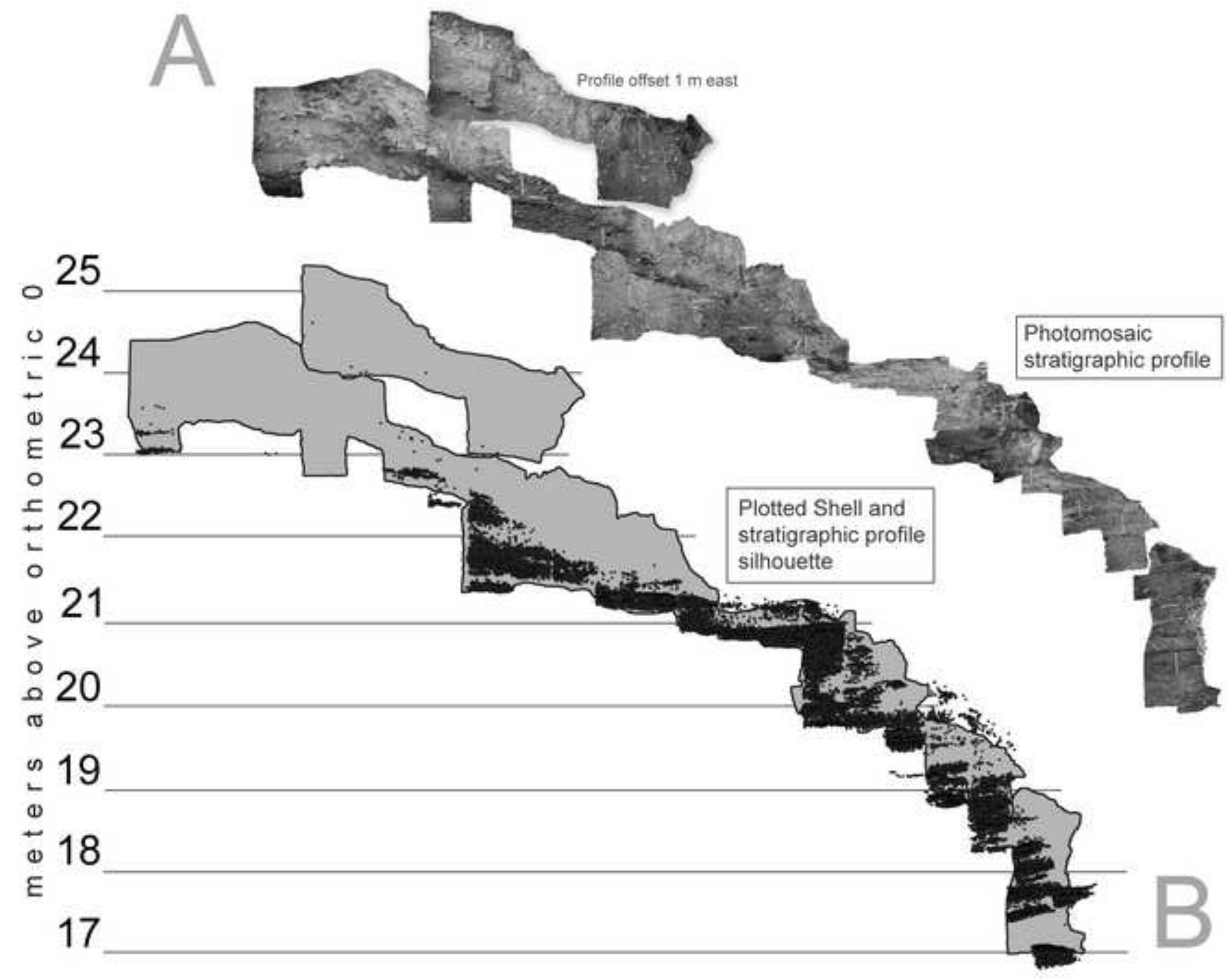



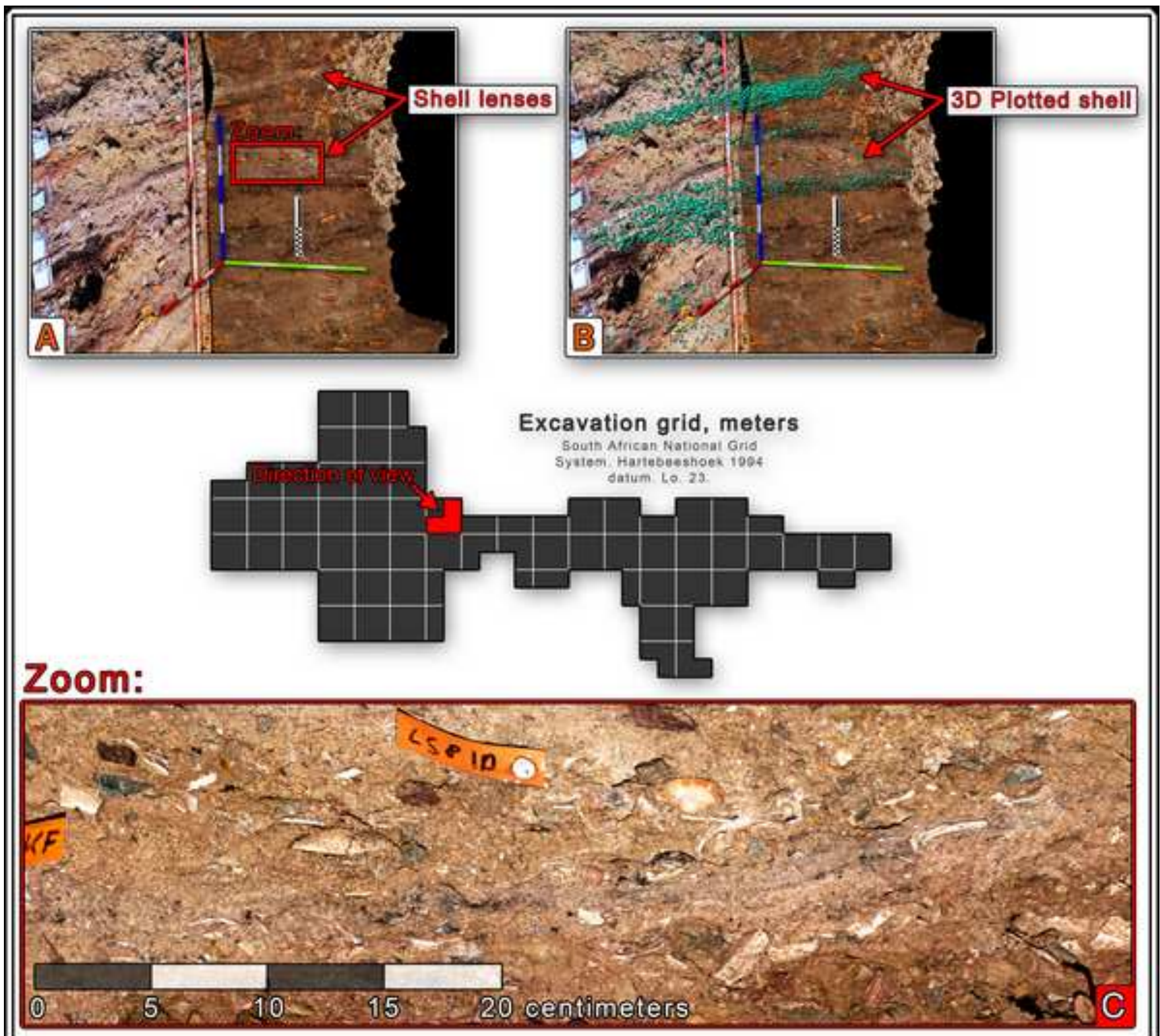
Click here to download high resolution image
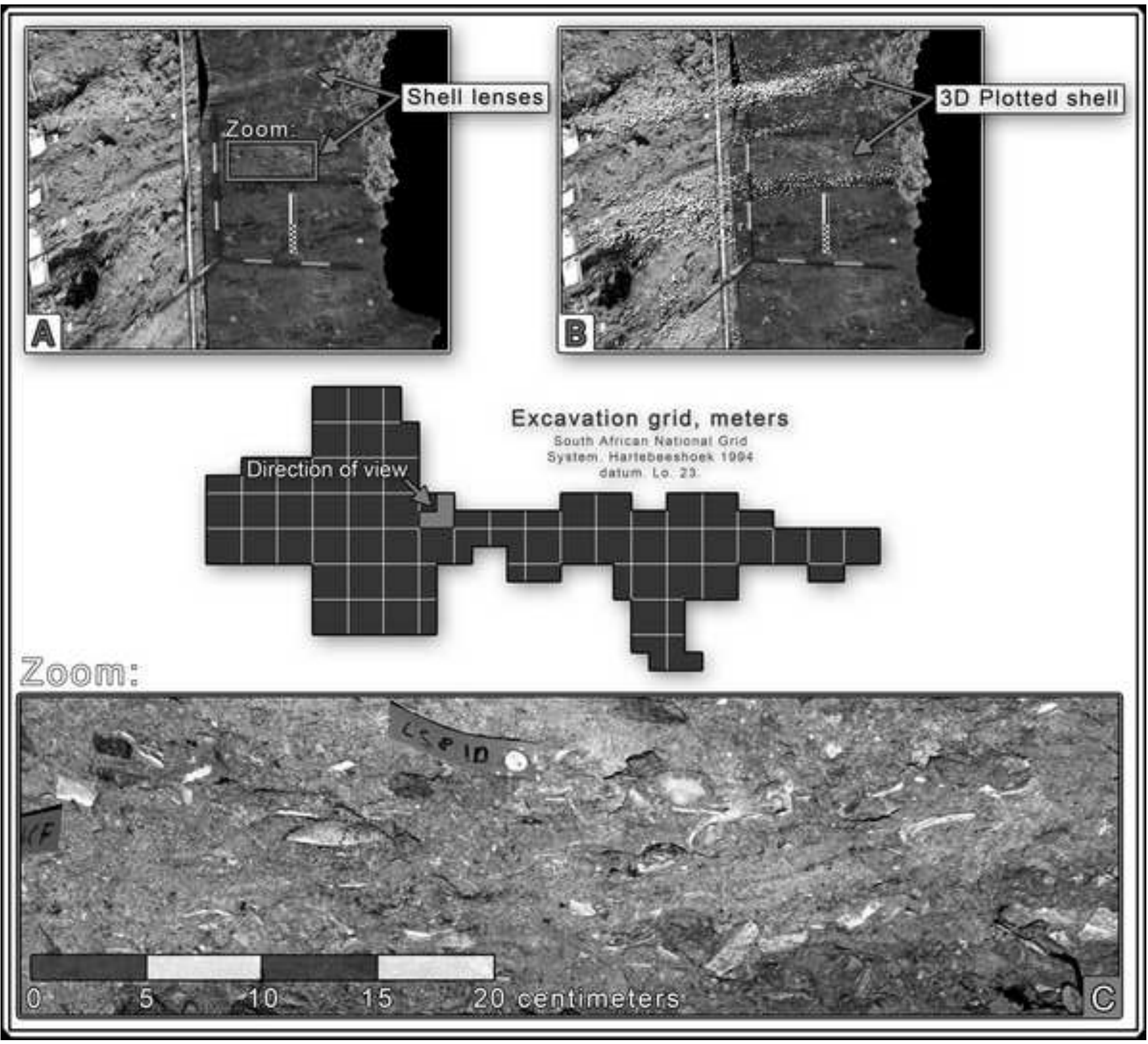


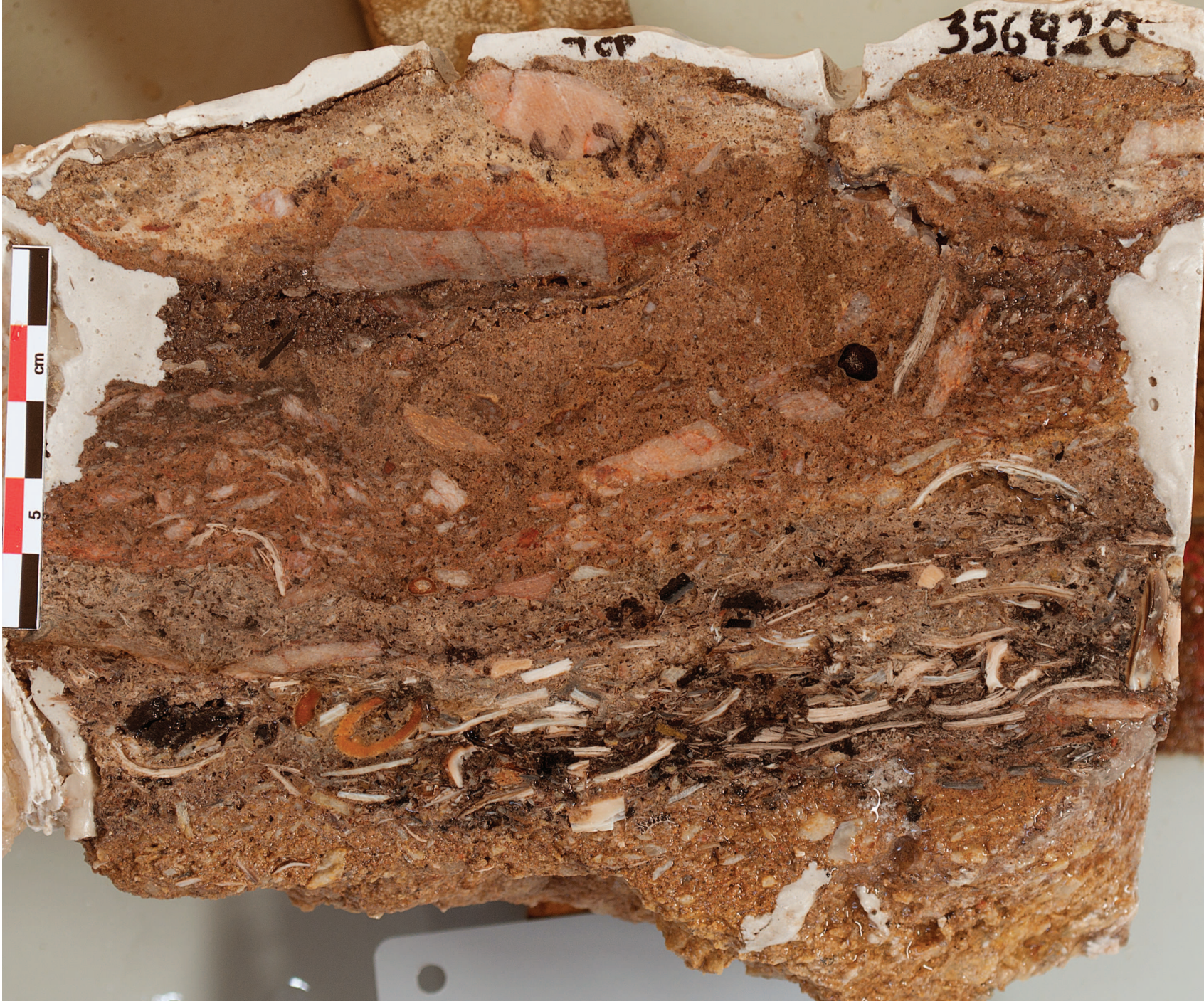

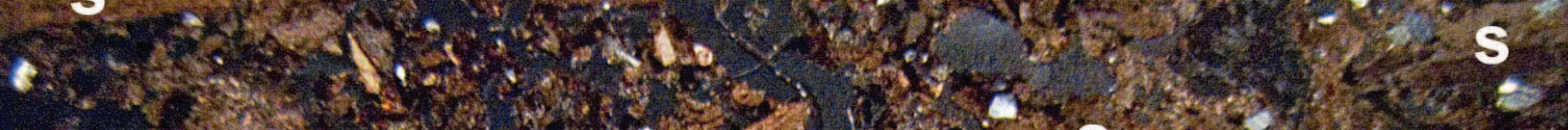

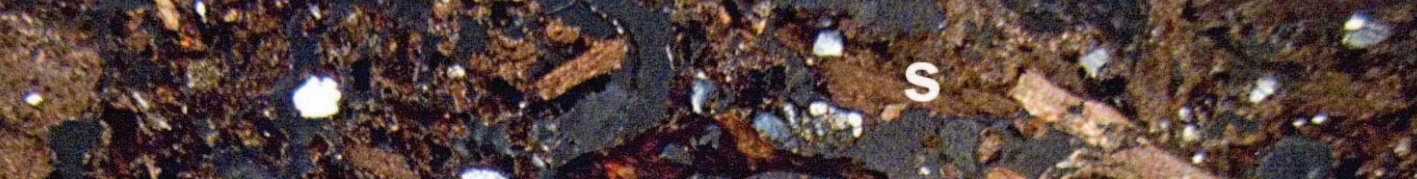

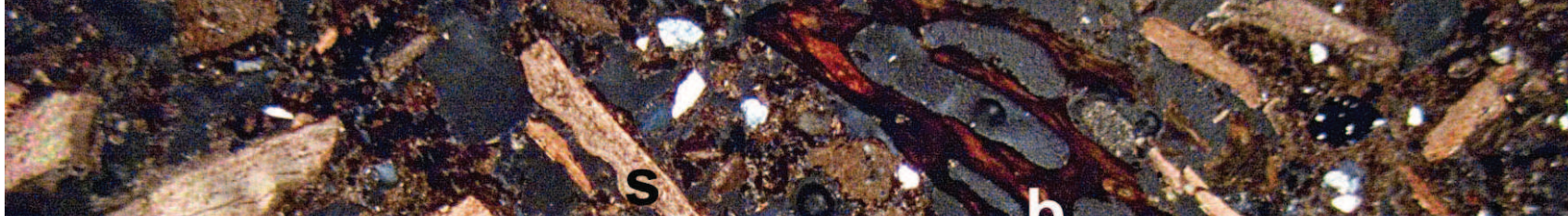

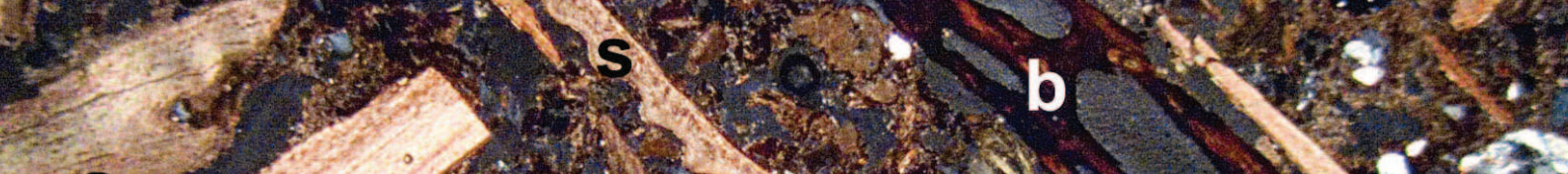

s

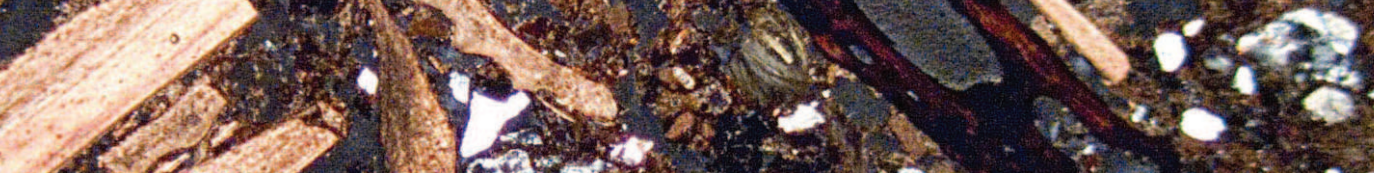

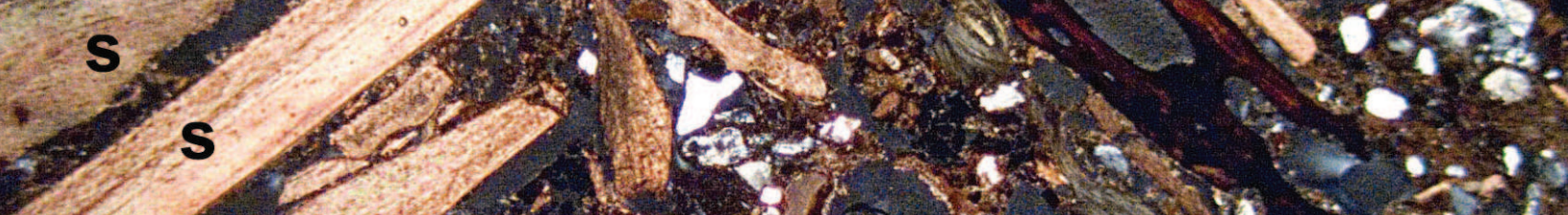

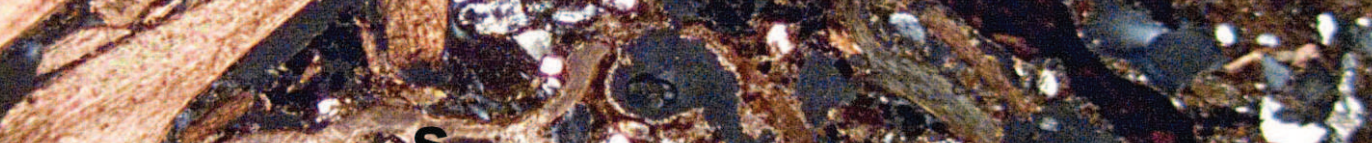

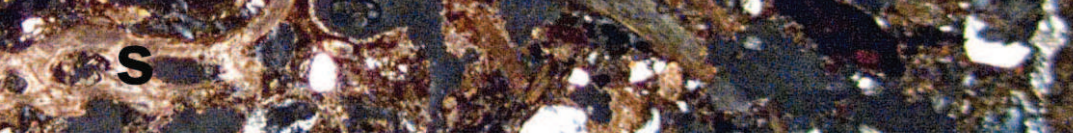

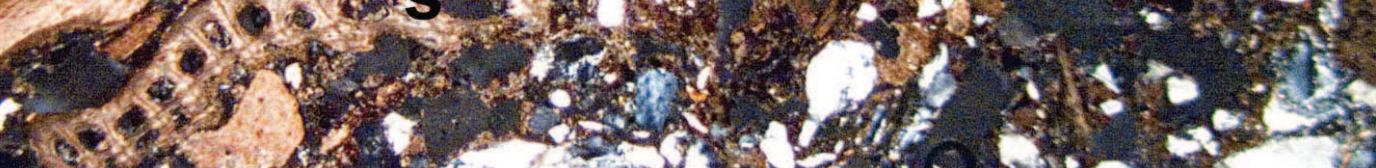
6.

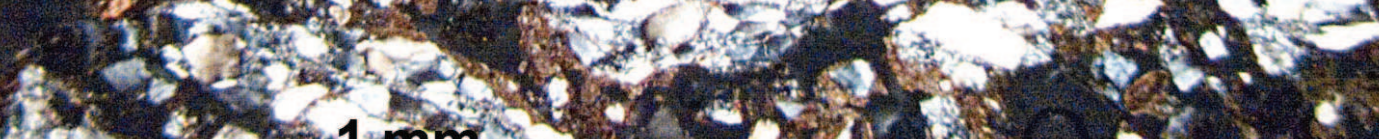
9. 

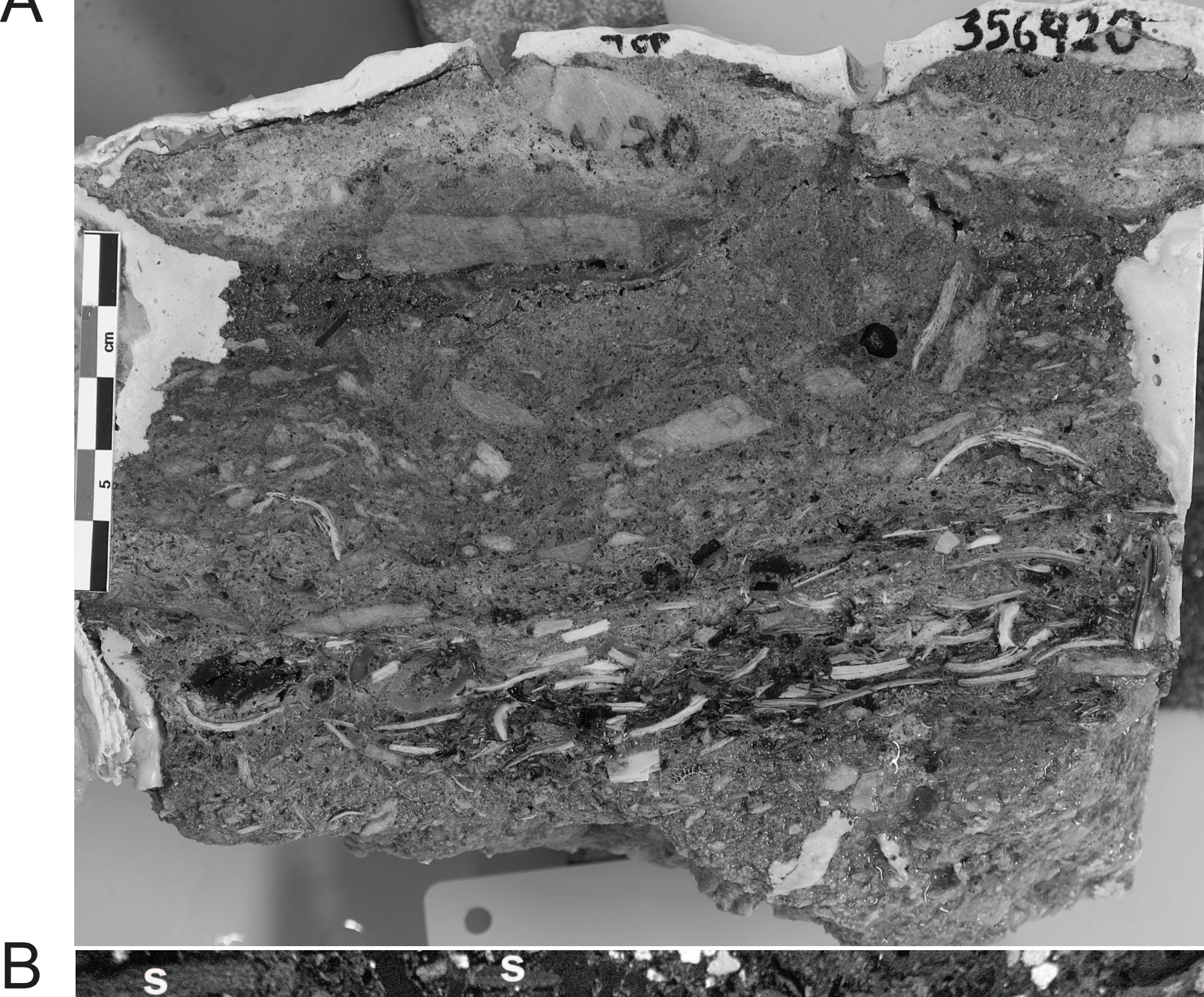

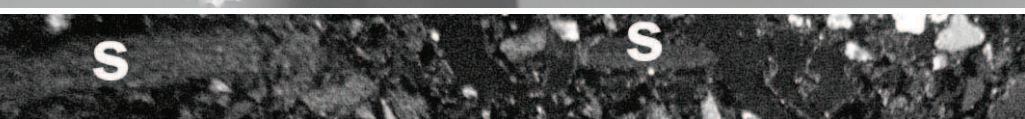

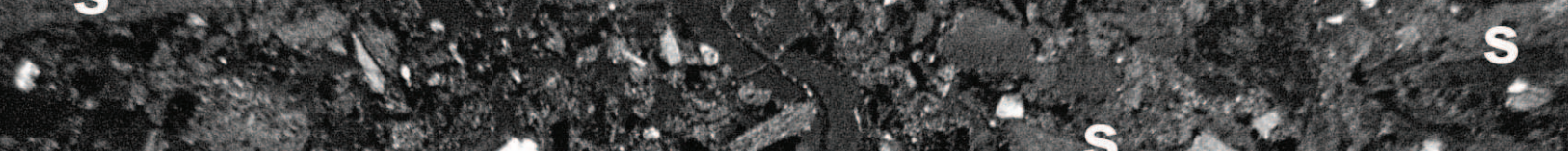

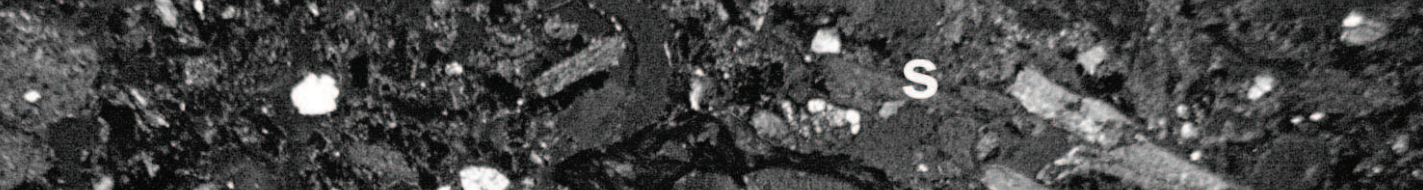

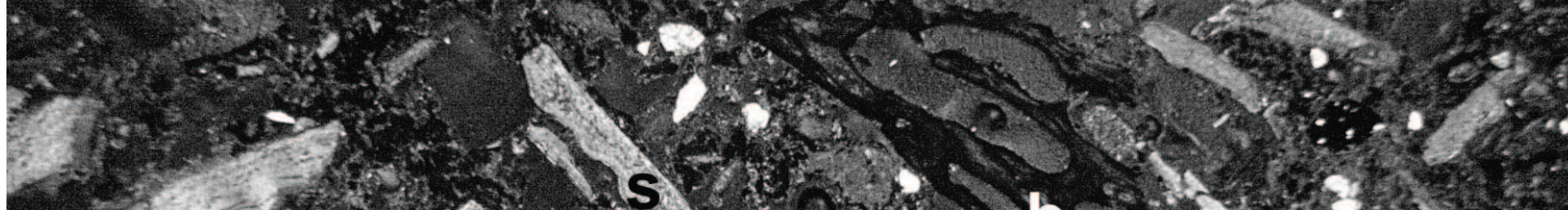

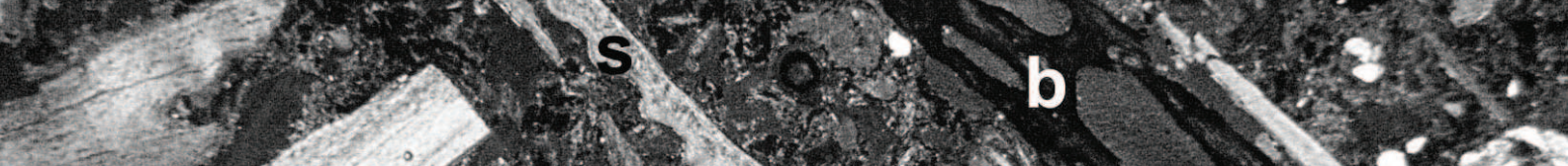
$\mathrm{S}$

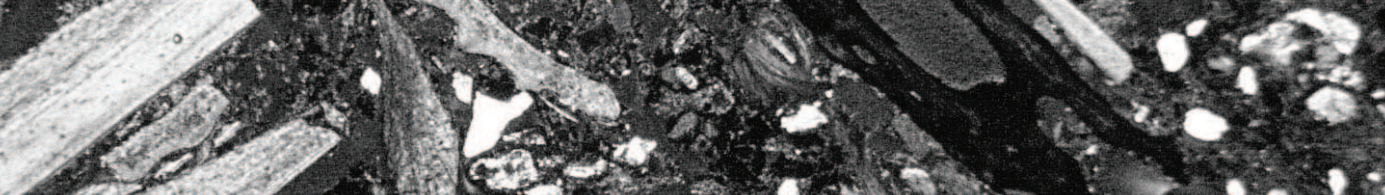

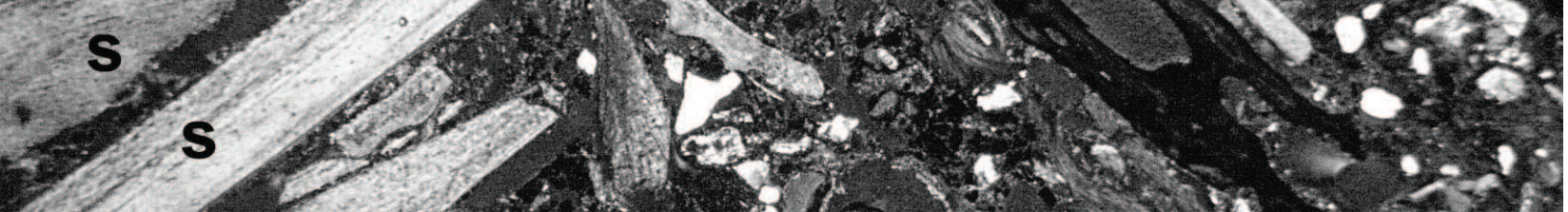

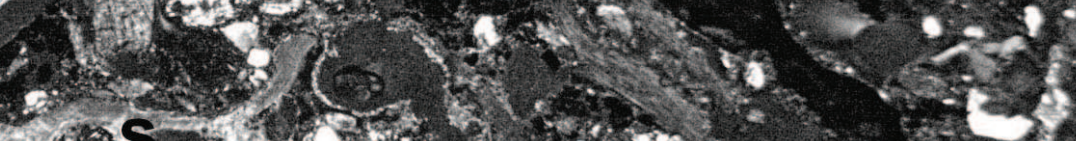

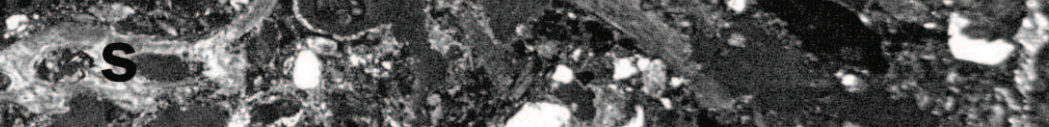

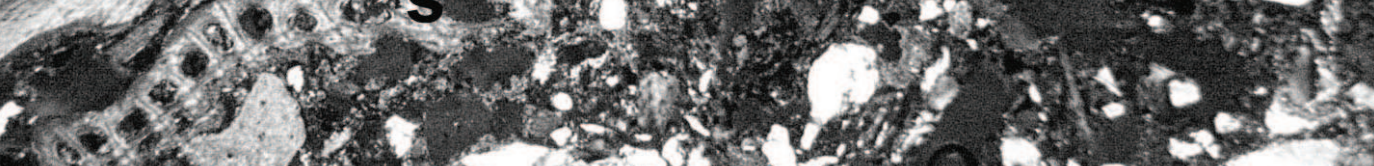

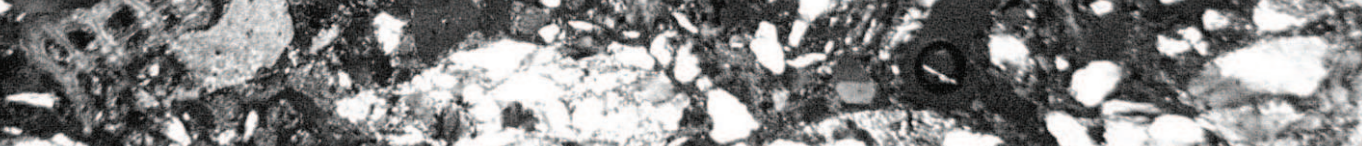

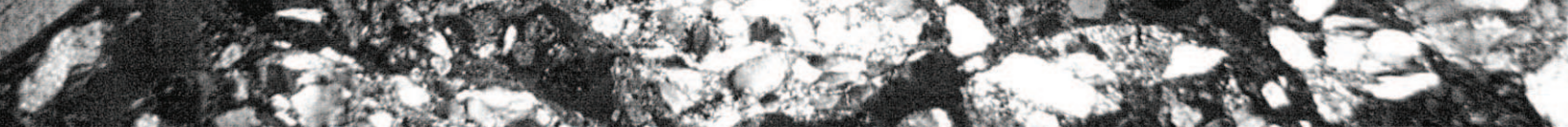
3 a 5. 


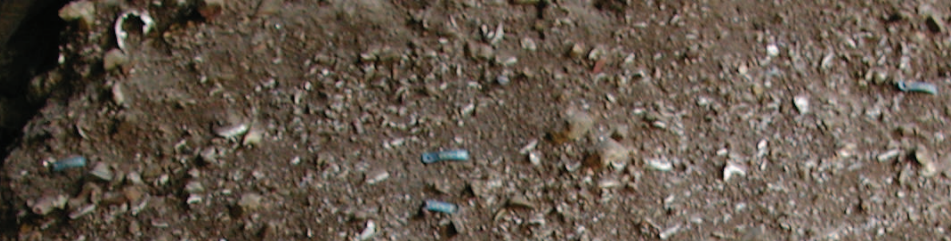

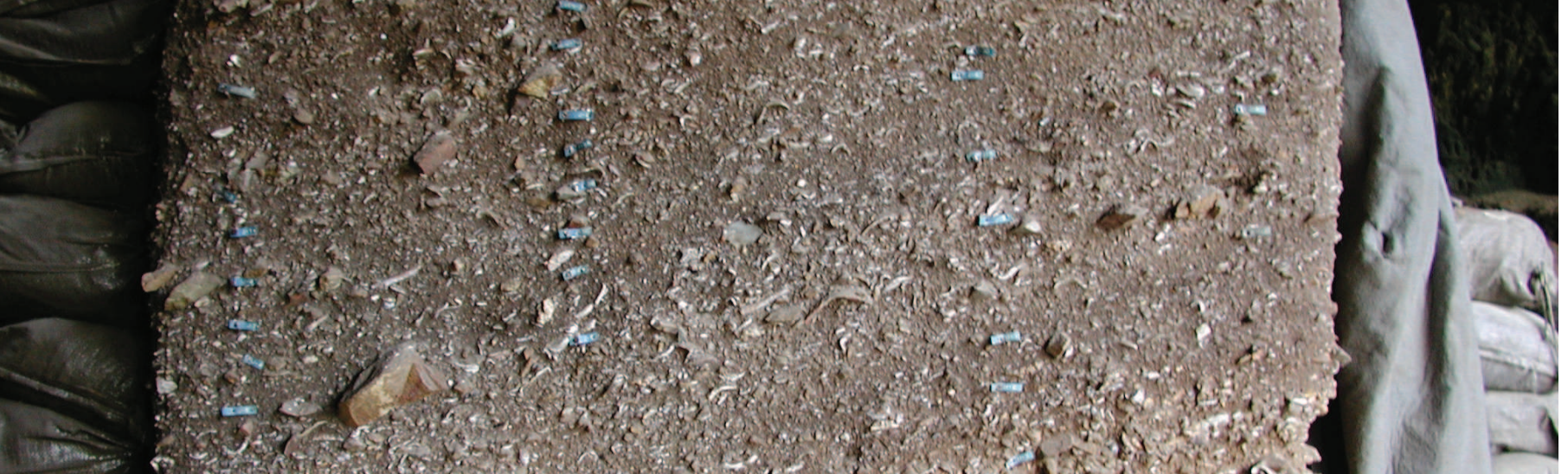

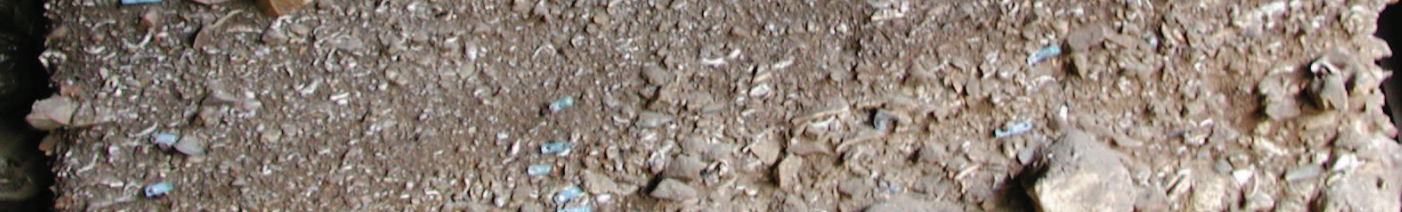

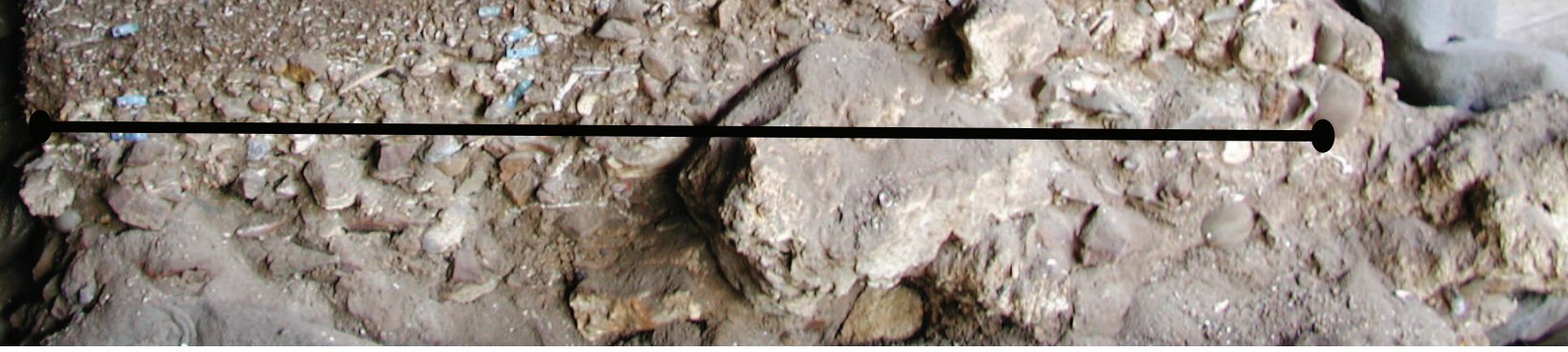

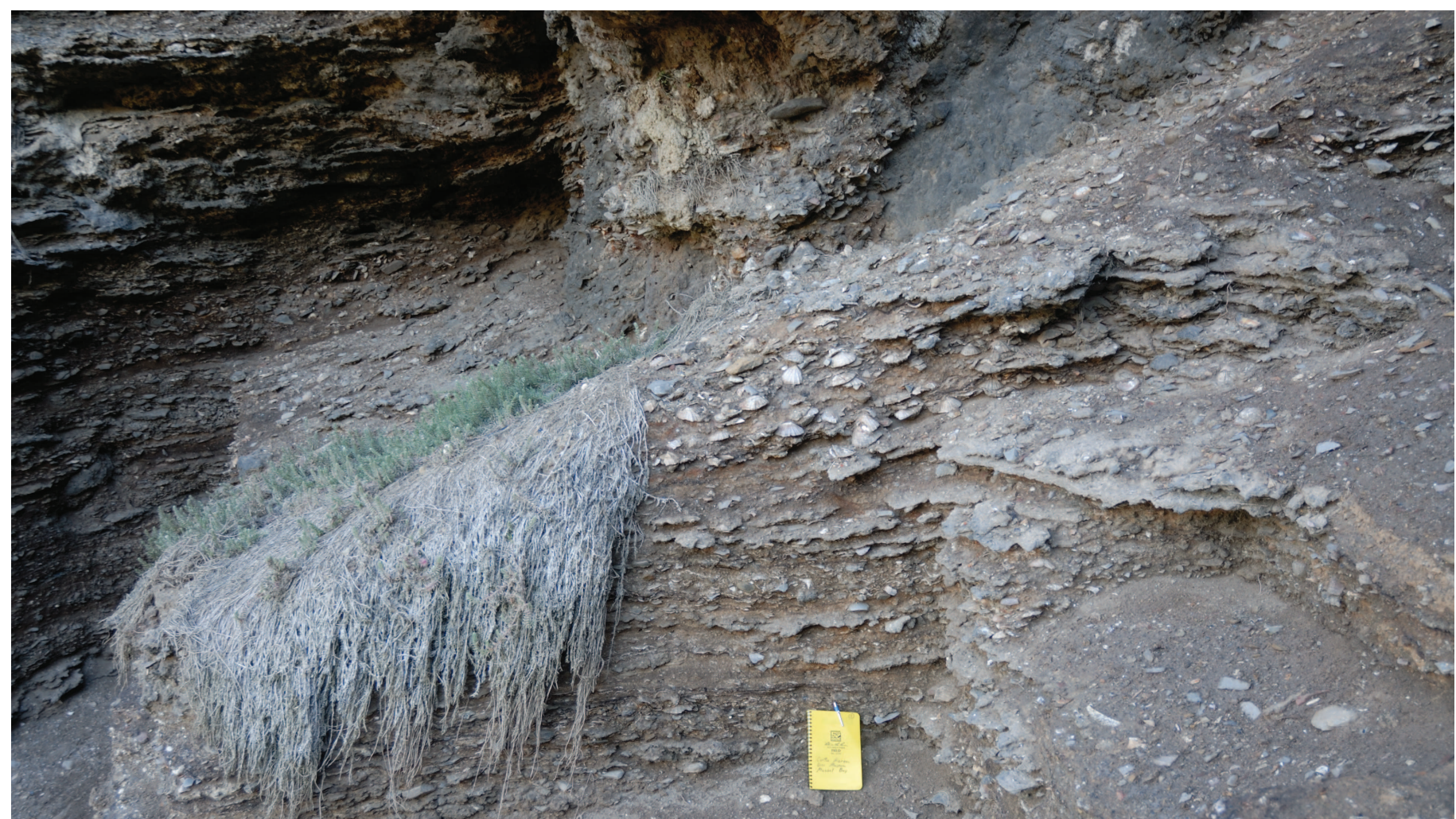


4.

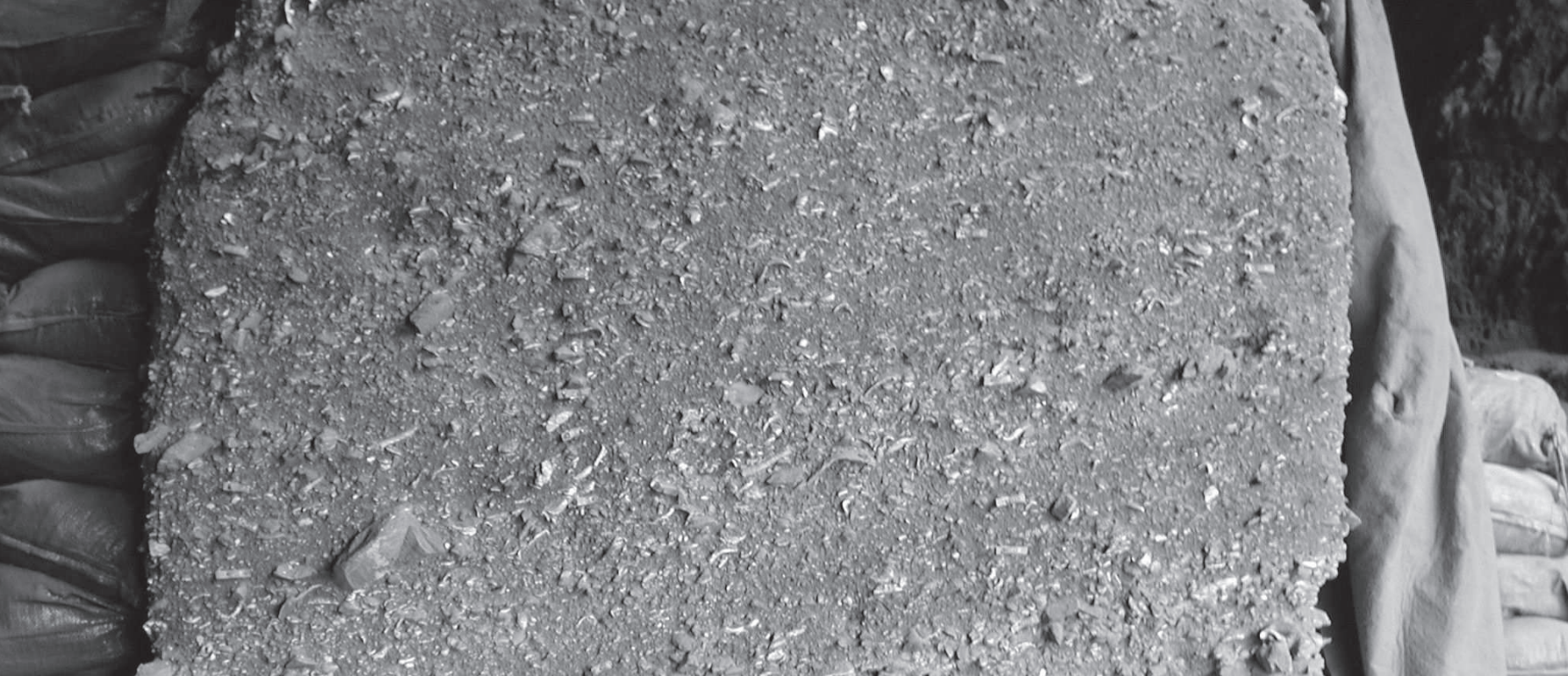

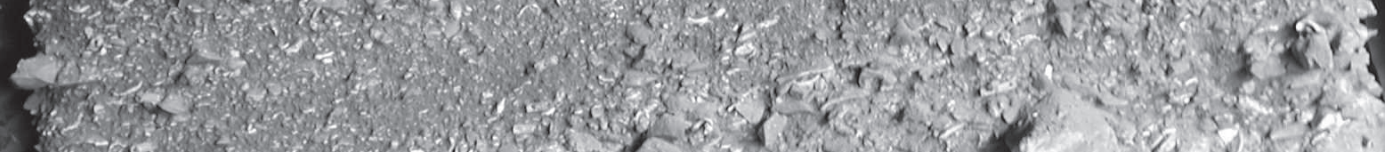

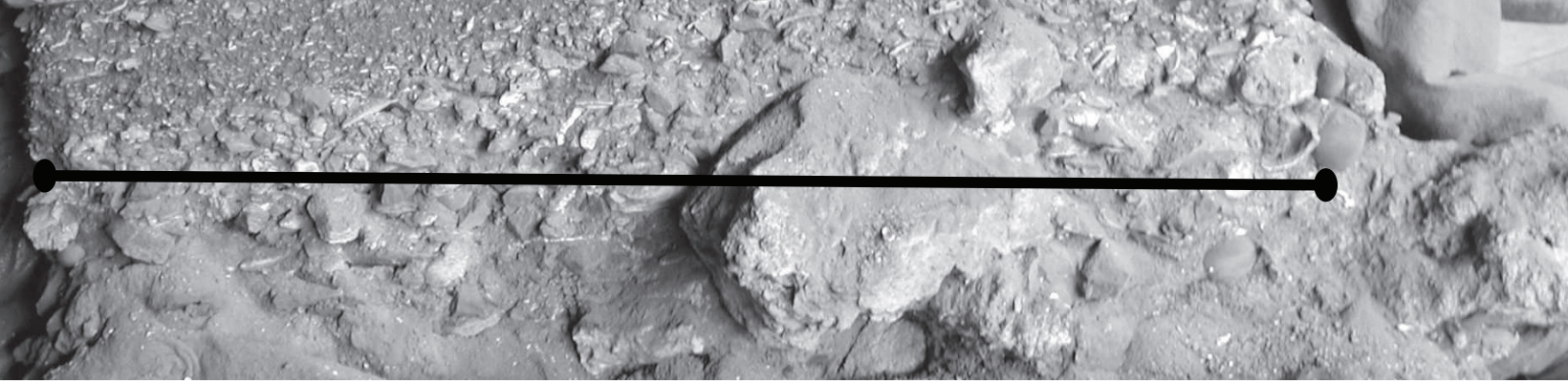

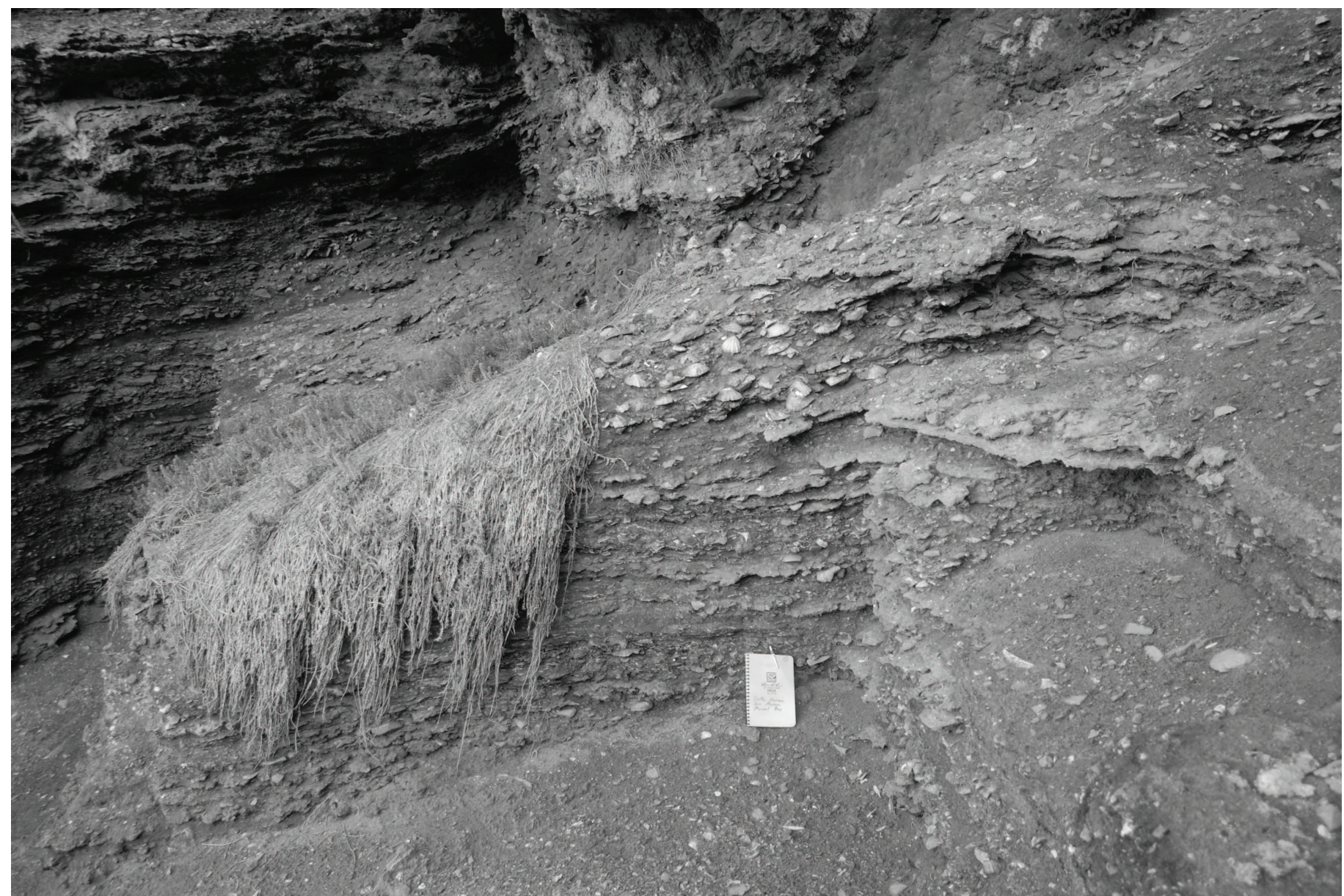


Figutq19 filea

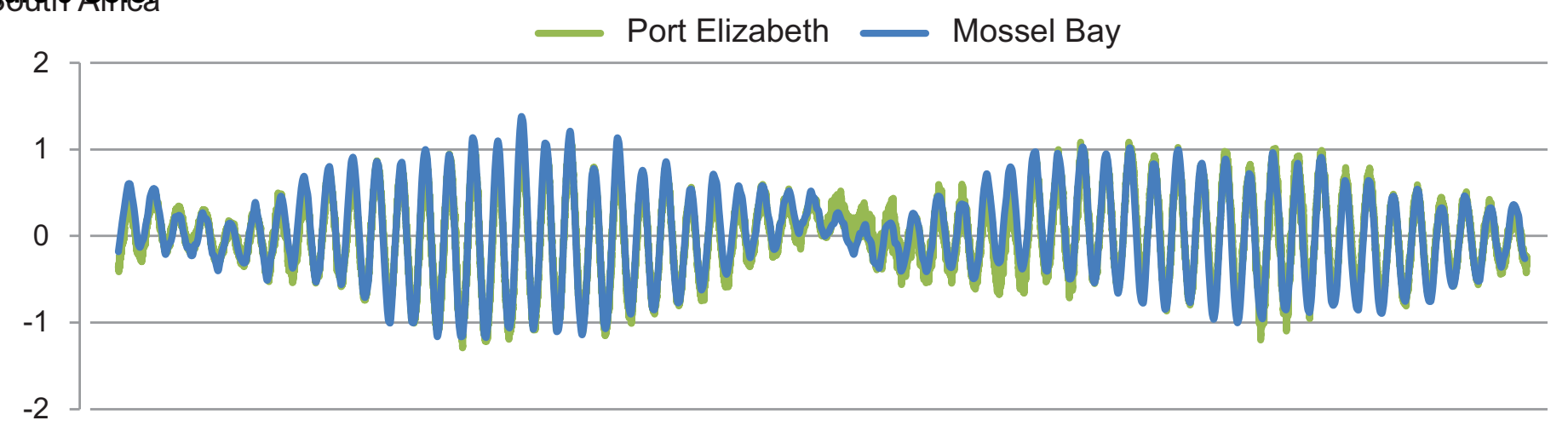

Cascais, Portugal and Arrecife, Spain (Canary Islands)

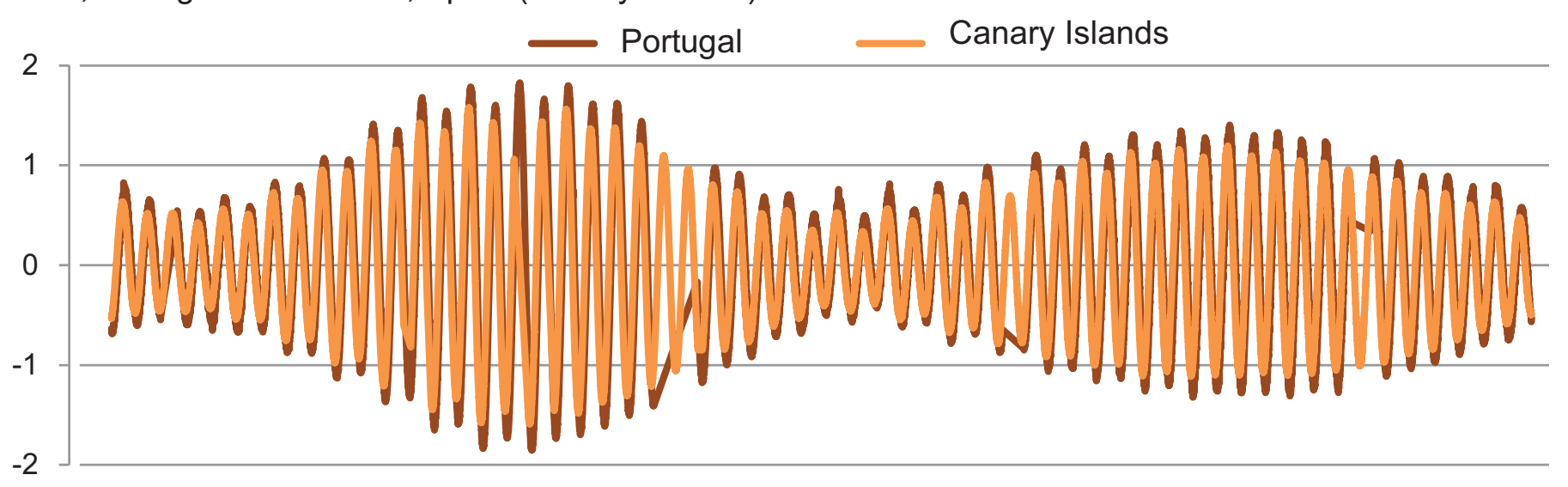

Gibraltar

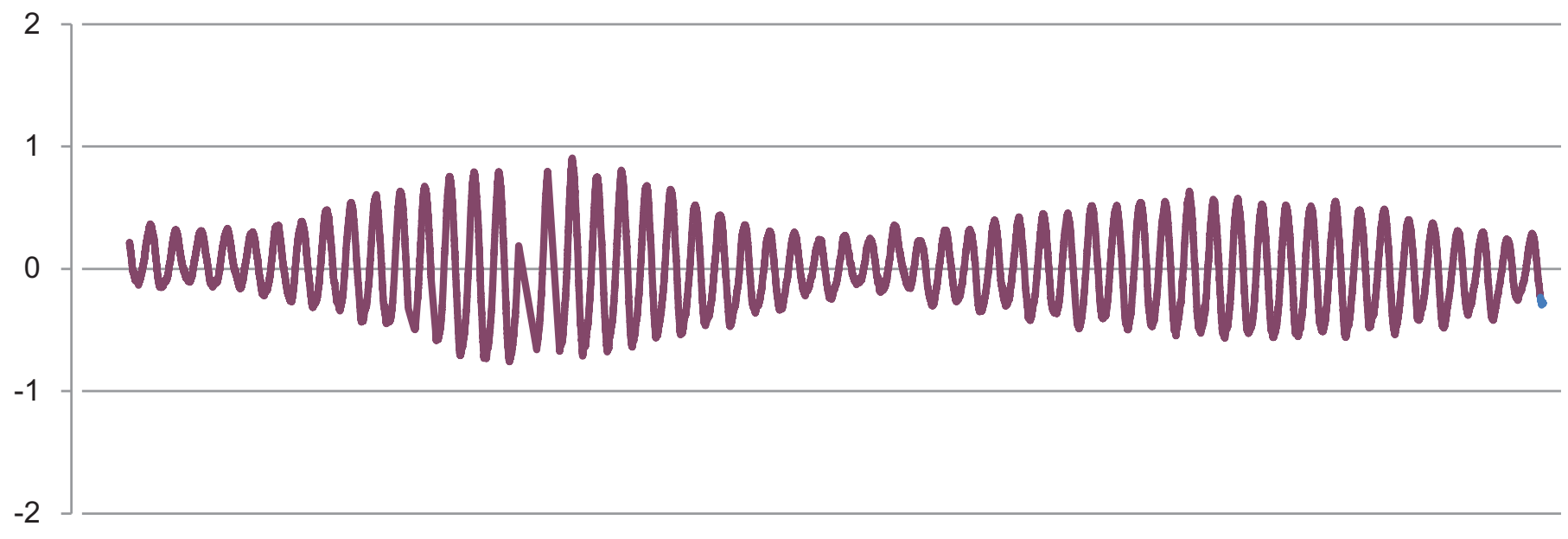

Barcelona, Spain and Napoli, Italy

_ Spain _ Italy

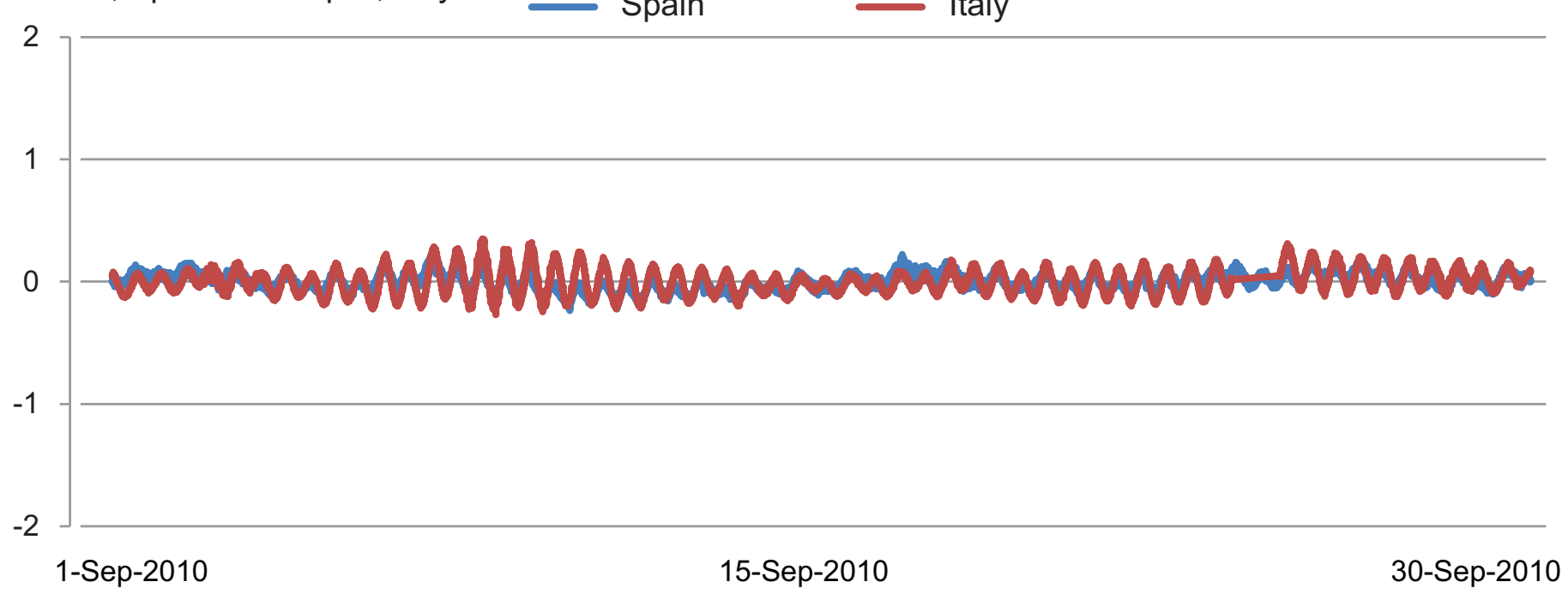




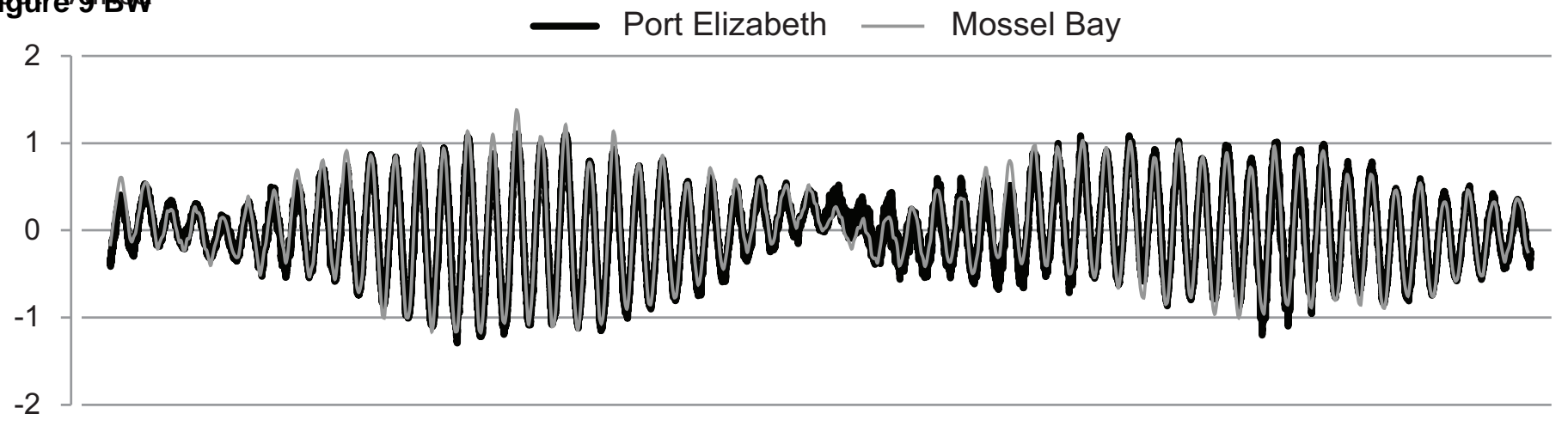

Cascais, Portugal and Arrecife, Spain (Canary Islands)

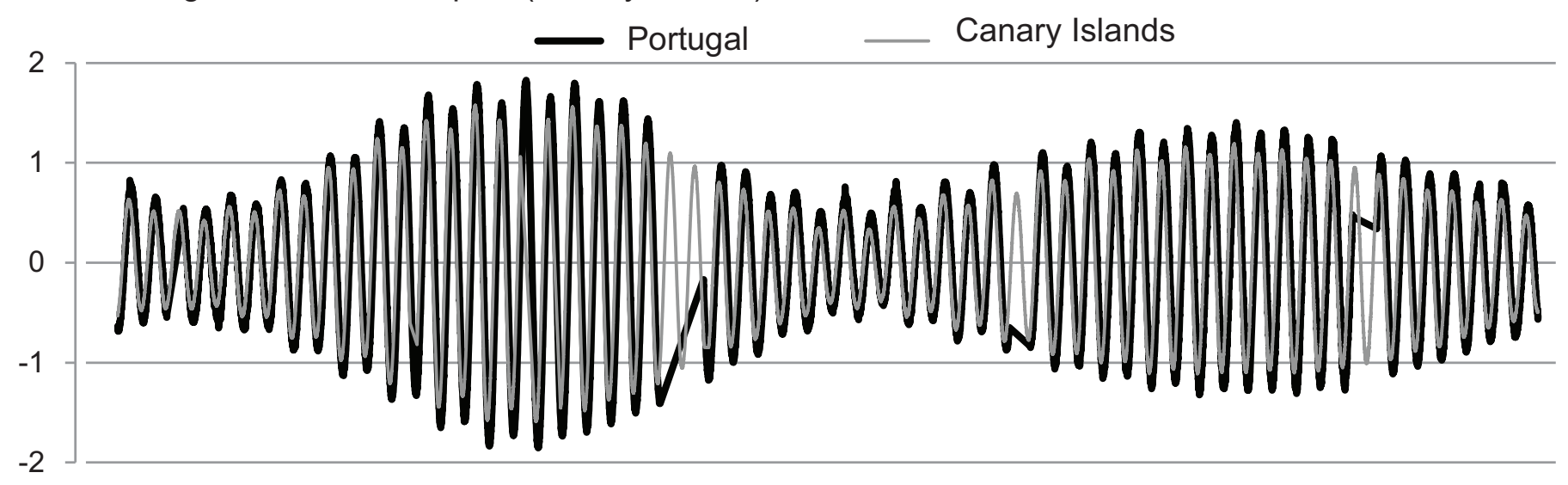

Gibraltar

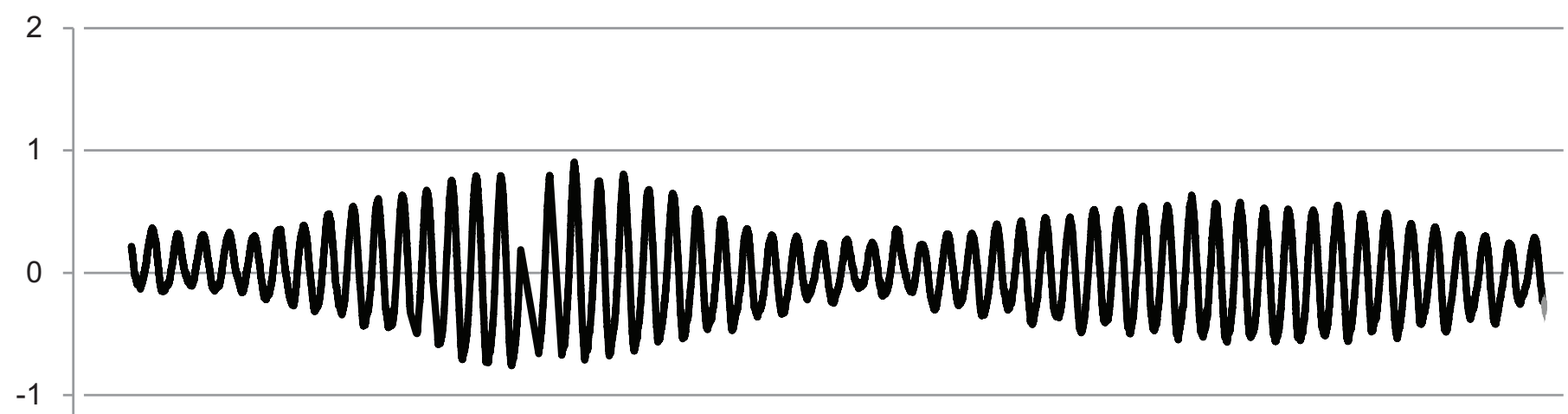

Barcelona, Spain and Napoli, Italy

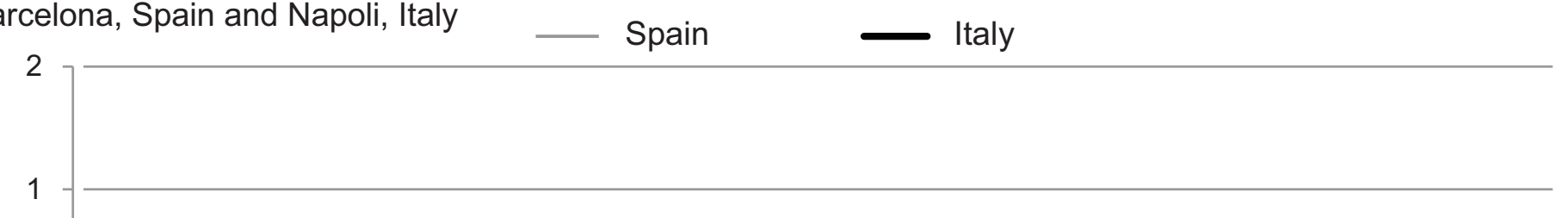

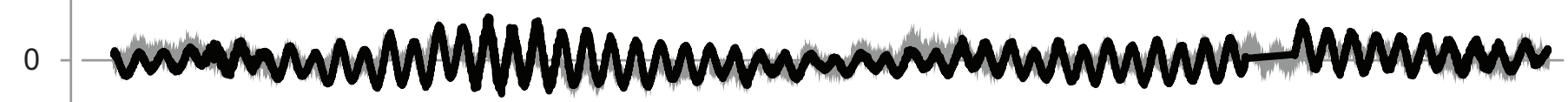

$-1$

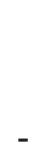

